Editor's Note

Joe W. Kotrlik

A Study of Supervisor and Employee Perceptions of Work

Attitudes in Information Age Manufacturing Industries

Md. Shafiqul Azam and Paul E. Brauchle...

Entrepreneurial Careers of Women in Zimbabwe

Lisa B. Ncube and James P. Greenan

Developing Authentic, Integrated, Standards-Based Mathematics

Curriculum: [More Than Just] An Interdisciplinary Collaborative Approach

Victor M. Hernández and Jonathan L. Brendefur.

Perceptions of Traditionally and Alternatively Certified Career and Technical Education Teachers

Sheila K. Ruhland and Christine D. Bremer.

Journal of Vocational Education Research Field Reviewers for Volume 28 .

The Journal of Vocational Education Research (JVER) is published three times a year and is an official publication of the American Vocational Education Research Association (AVERA). AVERA was organized in 1966 and strives to: (a) stimulate research and development activities related to vocational education, (b) stimulate the development of training programs designed to prepare persons for responsibilities in vocational education research, (c) foster a cooperative effort in research and development activities with the total program of vocational education, career and technical education, and other areas of education and other disciplines, and (d) facilitate the dissemination of research findings and diffusion of knowledge. 


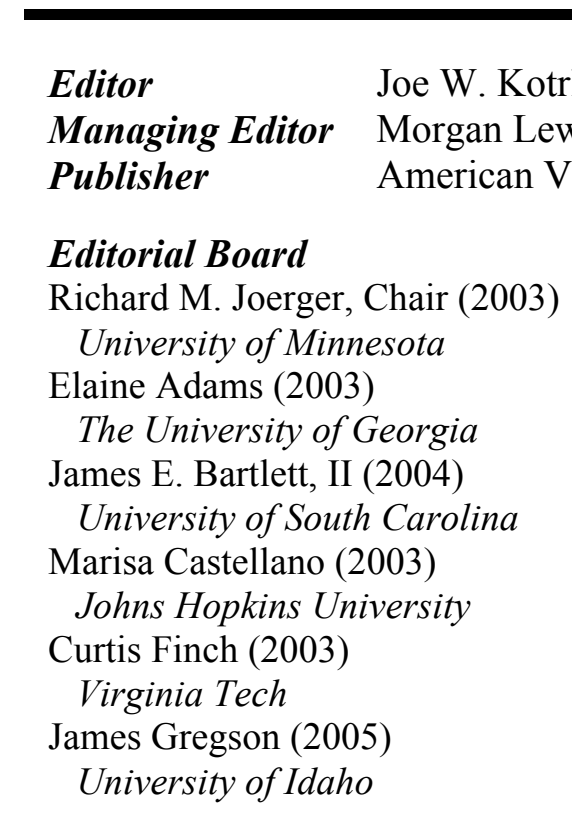

\section{Past Editors}

$\begin{array}{lr}\text { Jay W. Rojewski } & 2002 \\ \text { James R. Stone, III } & 2000-2001 \\ \text { Jay W. Rojewski } & 1998-1999 \\ \text { Theodore Lewis } & 1995-1997 \\ \text { R. Brian Cobb } & 1993-1994 \\ \text { Wendy L. Way } & 1991-1992 \\ \text { Leonard Albright } & 1988-1990 \\ \text { Jerelyn B. Schultz } & 1986-1987\end{array}$

Jane Plihal

University of Minnesota

Sheila Ruhland (2005)

University of Minnesota

John W. Schell (2005)

University of Georgia

Kirk Swortzel (2005)

Mississippi State University

Allen Truell (2004)

Ball State University

Janet Zaleski-Burns (2004)

Georgia State University

EDITORIAL POLICY: The Journal of Vocational Education Research (JVER) publishes refereed articles that examine research and research-related topics in vocational education, career and technical education, preparation for work, and the workplace. The JVER Editorial Board is committed to publishing scholarly work that represents a variety of conceptual and methodological bases. Submission of manuscripts representing one of the following styles is encouraged: (a) empirically-based manuscripts that report results of original research, either quantitative or qualitative, (b) reviews or synthesis of empirical or theoretical literature, (c) essays derived from original historical or philosophical research, (d) reviews of recently published books, and (e) rejoinders to articles recently published in the JVER. Page costs are not typically assessed. However, if a manuscript is accepted, authors will be asked either to supply camera-ready tables and figures, or pay for the costs incurred in preparing complex tables and figures for publication.

Printed by The Ohio State University, Columbus, $\mathrm{OH}$. 
MANUSCRIPT PREPARATION. One (1) electronic copy (on floppy disk, CD, or email) of the manuscript should be submitted to the Editor. The electronic version must be in MS Word version 6 or higher. All lines should be numbered. Manuscripts typically range in length from 20 to 30 double-spaced pages including references, tables, and figures. Text, references, and tables must be prepared according to the guidelines detailed in the Publication Manual of the American Psychological Association (5th edition). The title page should include the title of the article, and the name, affiliation, mailing address, e-mail address, and telephone number for each author. Each manuscript must be accompanied by an abstract of no more than 150 words and all lines in the manuscript must be consecutively numbered. The receipt of all manuscripts will be acknowledged within one week of receipt. Manuscripts are subjected to a double-blind refereed review process. Typically, three individuals, plus the Editor, review each manuscript. Reviewers' comments and a letter indicating the publication decision will be sent to the primary author approximately 3-4 months following receipt. Manuscripts accepted for publication are usually published within one year of formal acceptance. To defray rising publication costs, authors who are not members of $A V E R A$ will be required to pay a $\$ 50.00$ fee if their manuscript is accepted for publication. Published authors will receive two complimentary copies of the JVER.

Send manuscripts to:

Dr. Joe W. Kotrlik, Editor

School of Human Resource Educ. \& Workforce Dev. Louisiana State University, 129 Old Forestry Bldg. Baton Rouge, LA 70803-5477
Phone: 225.578 .5753

FAX: 225.578.5755

E-mail: kotrlik@1su.edu

READER COMMENTS The Journal welcomes comments from readers on articles that have appeared in recent issues. Submitted comments must speak directly to content of the article of reference, not exceed four manuscripts pages, and conform to $A P A$ reporting format. These manuscripts may be sent out for peer review at the Editor's discretion. Author(s) of the original article will have an option of responding to published comments of their work.

SUBSCRIPTIONS The JVER is included in regular and student membership dues to the American Vocational Education Research Association (AVERA). Journal subscriptions are $\$ 57$ per calendar year to nonmembers. Subscribers outside the United States should add an additional $\$ 10$ to cover mailing costs. Subscription orders should be addressed to Dr. Morgan Lewis, JVER Managing Editor, Center for Education and Training for Employment, 1900 Kenny Road, Columbus, OH 43210

REPRODUCTION RIGHTS AVERA retains literary property rights on copyrighted articles. However, articles published in the JVER can be reproduced for academic and not-forprofit activities with the stipulation that credit is given to the JVER. All other forms of use require written permission from the publisher.

This publication is available in microform. Call toll-free 800.521 .3044 or mail inquiry to University Microfilms International, 300 North Zeeb Road, Ann Arbor, MI 48106. 


\section{American Vocational Education Research Association (AVERA) Membership Form}

Join AVERA today! Support for research in vocational, career and technical education has never been more important and affiliation with AVERA is an important facet of that support. Your membership in AVERA brings to you the most up-to-date and highest quality research in the field.

\begin{tabular}{|c|c|c|c|c|}
\hline $\begin{array}{l}\text { Membership } \\
\text { Entitles You } \\
\text { To Receive }\end{array}$ & \multirow{3}{*}{\multicolumn{4}{|c|}{$\begin{array}{l}\text { The Beacon-quarterly newsletter of the Association. } \\
\text { - The Journal of Vocational Education Research,. } \\
\text { - Who's Who in Vocational Education Research membership directory. } \\
\text { - Accessacts of papers presented at national conventions. } \\
\text { - Attend annual meetings held n conjunction with the Association for Career } \\
\text { and Technical Education (ACTE) Convention in December. } \\
\text { - Serve your profession as an officer, on committees, or with the board or staff } \\
\text { of this journal. } \\
\text { - Share research at AVERA-sponsored presentations and symposia at the annual } \\
\text { ACTE Convention and the American Educational Research Assoc. meeting. } \\
\text { - Recognize outstanding contributions in vocational, career, and technical } \\
\text { education. }\end{array}$}} \\
\hline $\begin{array}{c}\text { You Can } \\
\text { Also }\end{array}$ & & & & \\
\hline $\begin{array}{l}\text { AVERA } \\
\text { Members }\end{array}$ & & & & \\
\hline \multicolumn{5}{|c|}{ AVERA Membership Application Form } \\
\hline \multicolumn{3}{|c|}{$\begin{array}{l}\text { Send form/check to: Div of Teaching \& } \\
\text { Learning, } 529 \text { Education, Bowling Green } \\
\text { State Un, Bowling Green, OH } 43441 .\end{array}$} & \multicolumn{2}{|c|}{$\begin{array}{l}\text { - Make checks payable to AVERA. } \\
\text { - Dues outside USA should be paid in US dollars. } \\
\text { - Membership is good for } 12 \text { months. }\end{array}$} \\
\hline \multicolumn{2}{|c|}{ Membership Category } & & $\begin{array}{l}\text { Regular }(\$ 40.00) \\
\text { Emeritus }(\$ 10.00) \\
\text { Student }(\$ 10.00) \\
\end{array}$ & $\begin{array}{l}\square \text { New } \\
\square \text { Renewal }\end{array}$ \\
\hline \\
\hline \multicolumn{5}{|c|}{ Institution or Organization: } \\
\hline \multicolumn{5}{|c|}{ Mailing Address: } \\
\hline \multicolumn{5}{|c|}{$\begin{array}{l}\text { Phone \#: } \\
\text { E-mail Address: }\end{array}$} \\
\hline \multicolumn{5}{|c|}{ E-mail Address: } \\
\hline \multicolumn{5}{|c|}{$\begin{array}{l}\text { Please indicate whether you would like to have your e-mail address on the AVERA } \\
\text { Web page: } \square \text { Yes } \square \text { No }\end{array}$} \\
\hline \multicolumn{5}{|c|}{ ACTE Divisions (Check one or more): } \\
\hline \multicolumn{2}{|c|}{ 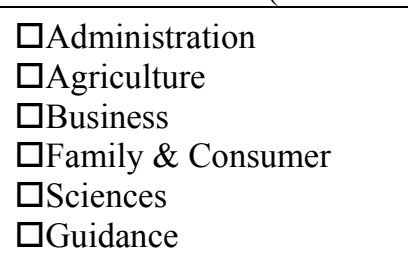 } & \multicolumn{2}{|c|}{$\begin{array}{l}\text { Health } \\
\square \text { International } \\
\square \text { Marketing } \\
\square \text { New \& Related } \\
\square \text { Special Needs }\end{array}$} & $\begin{array}{l}\square \text { Technical } \\
\square \text { Technology Education } \\
\square \text { Trade \& Industrial } \\
\square \text { Other }\end{array}$ \\
\hline
\end{tabular}

Please list two areas of research expertise/interest for the membership directory. 


\section{Editor's Note}

\section{Joe W. Kotrlik \\ Louisiana State University}

As I prepare this issue for publication, I am also preparing for the Journal of Vocational Education Research (JVER) Editorial Board meeting and the American Vocational Education Research Association (AVERA) meetings in Orlando, Florida. This year will be different because two of AVERA's research paper sessions will be held jointly with Omicron Tau Theta (OTT). This collaboration between AVERA and OTT is a positive development in our field.

I want to thank the many reviewers who served JVER this year by providing high quality and prompt manuscript reviews. A list of these reviewers is included in this issue. Their professionalism and support has enabled me to handle manuscript reviews in a timely manner. In most cases, authors have been notified of the publication decision on their manuscripts in two months or less.

In this issue, Brauchle and Azam report their investigation of supervisor and employee perceptions of work attitudes in information age manufacturing industries. Significant differences existed between self-perceived work attitudes of information and non-information employees and their supervisors, and indicated that the selfperceived work attitudes of information and non-information employees were different. The analyses also revealed that female information employees possessed better work attitudes than their male counterparts.

Ncube and Greenan studied the pathways of entrepreneurial career development and the processes involved for women to become entrepreneurs in Zimbabwe. They found that women's agency or the ability to carry out initiatives was critical to overcoming social and economic subjugation in the colonial and postcolonial states. Entrepreneurial outcomes included gain in capital and power as well as construction and acquisition of skills. In addition, women entrepreneurs became increasingly visible as they developed more power within society, and technology played an important role in the development of enterprises.

Hernández and Brendefur analyzed the collaborative process of mathematics and vocational-technical education instructors as they developed an authentic, integrated mathematics curriculum unit. They found it is possible for interdisciplinary teams of teachers to create high quality integrated mathematics curriculum units if certain conditions are met. Having support from the school's community, meeting regularly with all the team members, focusing conversations toward student understanding, writing tasks that promote conceptual and integrated 
understanding of the concepts, and writing the unit together with reflective thought, all seemed to be critical elements in successful integrated unit writing.

Ruhland and Bremer describe traditionally and alternatively certified secondary career and technical education teachers' perceptions of their first year teaching experience. On a national level, there is an increase in the number of states providing alternative certification as an option to enter the teaching profession. Critics have argued that alternatively certified teachers are inferior to traditionally certified teachers. Results from this study reported secondary CTE teachers who completed a traditional certification program had better pre-service preparation in pedagogy while alternatively certified teachers felt more prepared in knowledge of subject matter. Considering the many changes taking place in teacher education and the staffing of secondary schools, this study has addressed one of the current major issues in the preparation of career and technical education teachers.

These articles make a significant contribution to our research mission in vocational, career and technical education. These studies make a substantial contribution to our body of knowledge in vocational, career and technical education, and provide a solid foundation for further research.

jwk 


\title{
A Study of Supervisor and Employee Perceptions of Work Attitudes in Information Age Manufacturing Industries
}

\author{
Md. Shafiqul Azam \\ Pro-Tech Search, Inc. \\ Paul E. Brauchle \\ Illinois State University
}

\begin{abstract}
The self-perceived work ethic of industrial employees in information jobs $(N=304)$ and non-information jobs $(N=277)$, and employees' work ethic as assessed by their supervisors, were examined using the Occupational Work Ethic Inventory (OWEI). A Principle Components Analysis yielded four factors (Teamwork, Dependability, Ambition and Self-Control) based on factor loadings equal to or greater than 0.45. A MANOVA analysis revealed significant differences between self-perceived work attitudes of information and non-information employees and their supervisors, and indicated that the self-perceived work attitudes of information and non-information employees were different. Hierarchical Multiple Regression Analysis revealed that female information employees possessed better work attitudes than their male counterparts. No relationships were found to exist between the demographic variables of gender, age, education and length of service for non-information employees.
\end{abstract}

\section{Introduction}

While the life cycle of most animals tends to focus on the three dimensions of foraging food, sleeping, and reproducing, typical activities in humans contain one more dimension: work. Work is composed of tasks performed to add values to the products in exchange for monetary remuneration and psychological compensation (Wang, 1996).

Throughout history, work has been viewed and interpreted in various ways, sometimes with a very negative attitude - especially toward physical labor (Anthony, 1977; Hill, 1996a, Maywood, 1982; Tilgher, 1930). The Protestant Work Ethic evolved in the sixteenth century, based on the teachings of Luther and Calvin. This view, based on attitudes and beliefs that supported hard work, gradually became secularized and woven into the norms of western culture (Lipset, 1990; Rodgers, 1978; Rose, 1985).

During the industrial revolution in the eighteenth century, machines gradually replaced manual labor and individual control over the quantity and methods of personal production was diminished (Gilbert, 1977). In the early twentieth century, 
various management models were developed to motivate workers in industries with the aim of increasing productivity and generating more profits for the owners. Most of these models were early authoritarian styles of management such as Taylor's scientific management and McGregor's Theory X. Later, other more humane approaches, such as the behaviorist approach and McGregor's Theory Y, were developed (Gaither, 1996).

Regardless of their style of management, employers have always placed great importance on employee attitudes (Natriello, 1989). The social competencies (sociability, responsibility, self-management, integrity, and self-esteem) are the ones most in need of improvement (Smith, Jones, \& Lane, 1997). For example, Beach (1982) cited research indicating that fully $87 \%$ of persons losing their jobs or failing to be promoted were found to have ". . improper work habits and attitudes rather than insufficient job skills or knowledge" (p. 69).

The challenging nature of work itself also affects the relationships between workers and their jobs. According to Toffler (1981), a transition from the Industrial Age to the Information Age occurred in the mid 1950s when white-collar and service workers for the first time outnumbered blue collar workers. Today, the information and services sectors jointly control more than $80 \%$ of the U.S. economy (Huitt, 1997). Information age jobs, in contrast to industrial age jobs, are high-discretion positions which require considerable thinking and decision making on the part of workers (Miller, 1986). People who work with information often must set their own schedules, work with little or no supervision, and deal with frequent changes in work procedures. With jobs such as these requiring more self-direction and selfmotivation, good work attitudes and a positive work ethic seem more important than ever before.

Good work attitudes are often mentioned as attributes that employers want their employees to have, but these attributes are often hard to find. Even though various programs such as technical preparation, apprenticeships, Partners in Education projects, curriculum review, mentoring programs, and employability certification have attempted to address the problem, employers still complain that they are unable to find a dependable work force (Hill \& Petty, 1995). Studies conducted by Custer and Claiborne (1992 \&1995) found that both vocational educators and employers gave more emphasis to employability skills than technical skills and basic skills. Their employability skills cluster includes all the ingredients of a good work ethic (i.e., good work habits, attitudes, and interpersonal skills).

The concept of work ethic relates to the desirable work attitudes expected from potential employees. Employability skills or positive affective work attitudes are not job-specific, but are skills which cut horizontally across all industrial and vertically across all jobs from entry level to chief executive officer (Sherer \& Eadie, 1987).

Researchers have long sought to identify affective characteristics considered desirable for working people. Early attempts include those of Beech, Kazanas, 
Sapko, Sisson, and List (1978). They identified 63 affective work competencies that were considered important by industry leaders and educators and clustered them into 15 categories. Other studies that have attempted to identify personal-social work competencies include those of Petty, Kazanas, and Eastman (1981) and Brauchle, Petty, \& Morgan (1983). The basis of their research was the Affective Work Competencies Inventory (AWCI) developed by Kazanas (1978). From the original AWCI, Brauchle, Petty, \& Morgan (1983) developed the Work Attitudes Inventory (WAI). Building on this line of research, Petty (as cited in Hill \& Petty, 1995), identified 50 work ethic descriptors which became the Occupational Work Ethic Inventory (OWEI).

The work attitudes of an employee can be measured by administering an appropriate instrument to the employee. However, in a work place, the supervisor often is the rater and may use work attitudes as a major component of that rating. Employee self-ratings may be unreliable and invalid for a number of reasons. On the other hand, the supervisor's rating of an employee's work attitudes seems to have value because employee attitudes that affect working environment may be more visible to the supervisor than technical skills. Even with a supervisor making the assessment, a faulty rating may result if the employee is not on good terms with the supervisor.

Brauchle (1979) studied the relationship between trainee and supervisor perceptions of trainee work attitudes. The results of this study suggested that self-perceptions of trainees' work attitudes did not match the perceptions of their supervisors. However, this study, as well as many other investigations about work attitudes and values, investigated these constructs in industrial workers and supervisors and did not differentiate between information employees and noninformation employees.

Several studies have reported differences in work ethic between males and females (Furnham \& Muhiudeen, 1984; Hall, 1990, 1991; Hill, 1996b, 1997; Hill \& Rojewski, 1999; Petty \& Hill, 1994; Wollack, Goodale, Witjing \& Smith, 1971). However, Tang (1989) found no relationship between gender and work ethic. Using the OWEI, Minton (1997) found a significant difference between employers' expectations of work ethic and the self-perceived work ethic of secondary school students. In terms of the relationships between education and work attitudes, some researchers (Goodale, 1973; Wollack et al., 1971) found positive relationships, while others (Aldag \& Brief, 1975; Buchholz, 1978; MacDonald, 1972) found no relationship or negative relationships (Tang \& Tzeng, 1992). Petty (1995) found significant positive differences in OWEI measured work ethic for the age group 3655 over the other four age groups studied. Hatcher (1995) conducted a study to identify differences in perceived work ethic between apprentices and instructors categorized by job titles, job specialization, years of full-time work experience, and the year of participation in the apprenticeship program. He found significant differences in levels of work ethic between instructors and apprentices. Hill (1996b) 
found differences in work ethic perception between vocational students and workers in two OWEI dimensions. In a recent study, Boatwright and Slate (2000) obtained stronger work ethic values for females, persons aged 20-24, and college students than for others. However, there appears to be little or no research that focuses specifically on the relationship between work attitudes as perceived by employees and as perceived by their supervisors where the individuals studied are information employees and non-information employees.

Information employees are employees who perform information jobs. An information job is one which is characterized by: a) Comprehensive, open-ended tasks requiring high responsibility and critical thinking; b) Tasks which need little supervision and require active individual initiative; c) Tasks that require creative solutions to non-routine situations, deviations are handled by the lowest level of specialist; d) Continued improvement of performance is as important as completing tasks; and e) Integrated work processes; increased ownership of product and process by the individual (Law, Knuth, \& Bergman, 1992).

Non-information employees are those who perform non-information jobs. A non-information job is characterized by: a) Narrowly defined tasks that require minor responsibility; b) Heavy supervision and passive order taking; c) Specific response to a limited number of possible problems with deviations from the norm handled by specialists; d) Task completion is more important than continued improvement of performance; and e) Specific tasks are independent of the purpose in the organization's overall operation (Law et al., 1992).

\section{Research Design and Method}

The purpose of this study was, therefore, to investigate (a) whether the type of job (i.e., information job versus non-information job) was related to employee work attitudes, (b) if there existed any difference between work attitudes as perceived by employees and as perceived by their supervisors, and (c) if there existed any relationship between employee work attitudes and demographic variables such as age, gender, level of education, and length of service. The following five null hypotheses were used:

$\mathrm{H}_{01}$ : At the $p \leq 0.05$ level of confidence, there is no significant difference between the self-perceptions of work attitudes of industrial employees with information jobs and their work attitudes as rated by their supervisors.

$\mathrm{H}_{02}$ : At the $p \leq 0.05$ level of confidence, there is no significant difference between the self-perceptions of work attitudes of industrial employees with non-information jobs and their work attitudes as rated by their supervisors. 
$\mathrm{H}_{03}$ : At the $p \leq 0.05$ level of confidence, there is no significant difference between the perceptions of work attitudes of industrial employees with non-information jobs and industrial employees with information jobs.

$\mathrm{H}_{04}$ : At the $p \leq 0.05$ level of confidence, there is no significant relationship between the work attitudes of information employees and the variables of gender, age, level of education, and length of service.

$\mathrm{H}_{05}$ : At the $p \leq 0.05$ level of confidence, there is no significant relationship between the work attitudes of non-information employees and the variables of gender, age, level of education, and length of service.

\section{Population and Sample}

The population for this study consisted of employees of manufacturing organizations in the central Illinois area. These employees are often at the lowest level in the organization (except for part time hourly employees), or at most one or two levels up in the organizational hierarchy. This study used the procedure of cluster sampling without replacement (Parker, 1998) where each industry was treated as a cluster.

A list of all central Illinois' midsized manufacturing organizations employing 100 to 500 employees was prepared on the basis of the 2000 Illinois Manufacturers Directory (Manufacturers' News, Inc., 1999). Ninety-five midsized manufacturing organizations were listed from the central Illinois area. The total number employed in these organizations was 18,900 .

The required sample size was calculated from the total employee population of 18,900 by using the formula by (Borg \& Gall, 1979): $n=N /\left(N(d)^{\wedge} 2+1\right)$, where $n=$ sample size; $N=$ Total population $(18,990)$; and $d=$ level of significance $(0.05)$. Application of the formula resulted in a required sample size of 392 participants. The average response rate for this type of study was assumed to be about $33 \%$. To achieve 392 respondents, a sample size of 1,176 participants (3 X 392) was targeted for this study. The average number of population members per cluster was: $18,990 / 95=199.89$. The number of clusters (organizations) needed to represent the population was $1,176 / 199.89=5.88$. Therefore, six organizations (clusters) were needed for this study.

Of the 95 manufacturing organizations in the list, six industries were selected randomly. The total number of employees in these six industries was 1,209, a number which exceeded the 1,176 participants needed for the study. We believed that this number was sufficient to represent the population and realized that the results can only be generalized to these respondents. 


\section{Power Analysis}

Statistical power analysis is quite common in recent research studies. According to Wilkinson and the Taskforce on Statistical Inference (1999), "Because power computations are most meaningful when done before data are collected and examined, it is important to show how effect-size estimates have been derived from previous research and theory in order to dispel suspicions that they might have been taken from data used in the study or even worse, constructed to justify a particular sample size" (p. 596). Therefore, a prior power analysis was conducted in this study.

The sample size calculated earlier was verified by methods specified by Cohen (1988). Alpha was set to 0.05 and power to 0.8. Assuming the proportion of the multivariances of set $Y$ (independent variables) accounted for by set $X$ (dependent variables) to be 0.1 and with the two-group MANOVA design, the sample size was calculated as 302 participants. Therefore, the estimated respondent size of 392 seemed adequate to conduct the study.

In a similar way, the adequacy of sample size was checked for hypotheses $4 \& 5$. Using the formulas set forth by Cohen (1988) for use in multiple regression analysis, the required sample size was found to be 111 for an alpha of 0.5 , a power level set at 0.8 , assuming that four variables (age, gender, level of education, and length of employment) accounted for 0.1 of the criterion variance in the population. The results implied that the estimated respondent size of 392 was more than adequate.

\section{Instrumentation}

The Occupational Work Ethic Inventory [OWEI] (Petty, 1995) was used to collect data from both employees and their supervisors. This is a 50-item selfreporting type instrument that uses Likert-type scaling to measure work attitudes. It has been used in industrial and vocational education settings and has been found to be highly reliable with various populations. Reported reliability coefficients (Cronbach's alpha) were: 0.95 (Hill, 1992), 0.95 (Petty, 1995), 0.90 (Hatcher, 1995), and in the present study 0.94 (employee responses) and 0.97 (supervisor responses). No predictive or concurrent validity studies have been reported; however, there appears to be evidence (Hill, 1992, Petty, 1995, Hatcher, 1995, Azam, 2002) for factorial validity. These studies used OWEI responses for educators, students, and workers in various industries. For this study the OWEI was used without modification to collect responses from the employees. However, a slightly modified OWEI was used to collect responses from the supervisors. In the modified OWEI for supervisors, items 3 (Years of full time work experience), 4 (Sex), 5 (Level of Education), 6 (Age), and 7 (Country of citizenship) were excluded because supervisors are not thought to provide accurate information on these items with respect to the employees they supervise. 


\section{Description of Research Procedure}

A list of names and contact telephone numbers of the CEOs or highest-ranking officials of each of the 95 organizations was prepared based on the 2000 Illinois Manufacturers Directory (Manufacturers' News, Inc., 1999). Materials were sent to each of these individuals with a request to participate in the study. Because the sample was to be selected from this population of 95 organizations, materials included a request letter, information sheet, and a reply slip. Each industry was requested to select a contact person with whom the researcher could communicate to administer the instruments and to collect the completed instruments.

As noted earlier, a slightly modified version of OWEI was used to collect supervisor responses. A set of two questionnaires with the same serial number, (a) green - to be completed by the employees and (b) blue - to be completed by the supervisors, was printed and used for each employee-supervisor pair. Two kinds of instruction sheets, (a) "How to fill out the Survey Forms (FOR EMPLOYEES)" and (b) "How to fill in the Survey Form (FOR SUPERVISORS)," were also printed and given to supervisors. Supervisors were asked to identify employees as information or non-information employees according to the definitions printed on the instruction sheets, to indicate type of employee on both blue and green sheets, and to give the green questionnaires to the employees. On the instruction sheet used for employees, instructions were given on how to respond if they thought they had been wrongfully categorized as information or non-information employees by their supervisors. In only three cases were there differences of opinions between employees and supervisors about the information or non-information status of the employees. In these cases the researcher used the employees' self-designations. Of the 95 industrial organizations, 26 agreed to participate in the study (a response rate of 26.32\%).

\section{Data Analysis}

A total of 1,575 green-colored (employee) and 1,575 blue-colored (supervisor) instruments were used to collect employee and supervisor responses on work attitudes of 1,209 employees. A total of 492 (40.70\% response-rate) completed instruments were returned by the employees and 633 were returned by the supervisors. Of the 492 employee responses, 454 were used in the analysis and of the 633 (52.36\% response-rate) supervisor responses, 581 were used in the analysis. The rest were discarded because they contained missing values.

Of the total 581 responses received from supervisors, 304 responses were for information employees and 277 were for non-information employees. These responses were further sorted to match each employee's response with that of his or her supervisor. This procedure yielded 245 matched responses from supervisors and information employees. In a similar manner 169 matched responses from supervisors and non-information employees were obtained. Responses for the 11 negatively 
worded items - stubborn, tardy, irresponsible, depressed, devious, selfish, negligent, apathetic, rude, hostile, and careless - were reversed for consistency in the analysis.

\section{Factor Analysis}

In regression analysis, it is very important to maintain a large number of degrees of freedom, and degrees of freedom are lost as the number of variables increase (Korth, 1975). Because the number of dependent variables was very large (50), the available degrees of freedom were small, making the result of a multiple regression analysis to test hypotheses 4 and 5 difficult to interpret. Moreover, the instrument items (based on employee responses) were found to be highly correlated. In such a situation the interpretation of results is very difficult and likely to be spurious. In view of this, and because the type and the location of the population of the present study was different from previous factor analytic studies on the OWEI, an exploratory factor analysis was conducted to identify the factors represented by the 50 items of the OWEI for the respondents in this study. The analysis was conducted by using responses from information and non-information employees but not supervisors.

Using the SPSS 10 data reduction technique, a Principal Component Analysis (PCA) was used to analyze the dimensionality of the 50-item OWEI. Semantic analysis enabled the factors to be identified as follows: Teamwork, Dependability, Ambition, and Self Control. Because of the complexity of obtaining regression-based factor scores for supervisor responses, factor scores were computed by a simple but effective method recommended by Kerlinger (1973). For this study, a loading of 0.45 , which represents $20 \%$ of the variance, was used to include a variable in a factor. Table 1 lists the factors and loadings.

The factor "Teamwork" represents those items of the OWEI where a higher score may indicate that a person is more comfortable in a team environment than those with lower scores. The factor "Dependability" represents those items of the OWEI where a higher score may indicate that a person is more dependable in the workplace than a person with a lower score. The factor "Ambition" represents those OWEI items where a higher score may indicate a more ambitious person than one who has a lower score. The factor "Self Control" represents those OWEI items where a higher score may indicate a person's greater self-control capability than a person having a lower score. These variables and their values were used in the multiple regression analysis.

Distributions of factor scores (Teamwork, Ambition, Dependability, and SelfControl) were found to have unacceptable negative skewness. This negative skewness was converted to positive skewness by subtracting each value from the largest score in that distribution +1 . For example, if the value of a particular score is 50 and if the largest score in the distribution is 60 , then the modified score will be 
$(60+1)-50=11$. These positively skewed distributions were then subjected to square root transformations as suggested by Tabachnick and Fidell (1983).

Table 1

Factor Loadings of Four Factors in Descending Order of Loading Size

\begin{tabular}{|c|c|c|c|c|c|c|c|}
\hline \multicolumn{8}{|c|}{ Factors } \\
\hline \multicolumn{2}{|c|}{ Teamwork } & \multicolumn{2}{|c|}{ Dependability } & \multicolumn{2}{|c|}{ Ambition } & \multicolumn{2}{|c|}{ Self Control } \\
\hline Item & Loading & Item & Loading & Item & Loading & Item & Loading \\
\hline Friendly & .77 & Reliable & .67 & Persistent & .61 & Devious $^{\mathrm{a}}$ & .70 \\
\hline Pleasant & .74 & Dependable & .67 & Resourceful & .60 & Hostile $^{\mathrm{a}}$ & .69 \\
\hline Courteous & .72 & Effective & .64 & Dedicated & .59 & Rude $^{\mathrm{a}}$ & .61 \\
\hline Loyal & .66 & Careful & .62 & Enthusiastic & .56 & Selfish $^{a}$ & .59 \\
\hline Considerate & .65 & Following & & Initiating & .53 & Depressed $^{\mathrm{a}}$ & .56 \\
\hline Helpful & .64 & directions & .62 & Devoted & .52 & Negligent $^{\mathrm{a}}$ & .50 \\
\hline Likeable & .64 & Following & & Perceptive & .50 & Emotionally & \\
\hline Cooperative & .63 & regulations & .61 & Productive & .49 & stable & .47 \\
\hline Cheerful & .63 & Honest & .59 & Ambitious & .47 & Careless $^{\mathrm{a}}$ & .45 \\
\hline Devoted & .56 & Accurate & .51 & Efficient & .46 & & \\
\hline Dedicated & .50 & Independent & .50 & Persevering & .45 & & \\
\hline Enthusiastic & .46 & Efficient & .50 & & & & \\
\hline Patient & .46 & Adaptable & .50 & & & & \\
\hline & & Ambitious & .46 & & & & \\
\hline & & Perceptive & .45 & & & & \\
\hline
\end{tabular}

${ }^{a}$ Negative items were reversed for scoring.

A MANOVA was used to test hypotheses 1,2 , and 3. Multiple regression analysis was used to test hypotheses 4 and 5. For the MANOVA tests, Pillai's criterion was used over the other three commonly used MANOVA test statistics because, according to Olson (1976) and Tabachnick and Fidell (1983), it may improve the robustness of the test. As effect sizes given by SPSS output on MANOVA do not represent multivariate effect sizes, multivariate effect sizes were calculated by the method given by Stevens (2002), which suggested 0.25 as small, 0.5 as medium, and greater than 1 as large effect sizes. Seven test plans were devised for testing hypotheses $1 \& 2$, and four test plans were devised for testing hypothesis 3 . These test plans were devised to compare the results of MANOVA with various combinations of test variables. The test variables were: a) number of dependent variables (50 OWEI items / 4 factors), sample size (unequal / equal and matched sample size), treatment to scores (untransformed / transformed / transformed and with outliers removed). The authors believed that this endeavor may present an opportunity to test MANOVA robustness indirectly. 


\section{Hypothesis 1}

\section{Findings}

To test null hypothesis 1 "At the $p \leq 0.05$ level of confidence, there is no significant difference between the self-perceptions of work attitudes of industrial employees with information jobs and their work attitudes as rated by their supervisors," seven MANOVA tests were conducted with seven different combinations of test variables (Tables 2 through 5). The test plans were designed with different combinations of dependent variables, matched/unmatched samples,

Table 2

Test Plans 1 and 2 for Hypothesis 1 Including Summary of MANOVA results, Using All Untransformed 50 Items in the OWEI

\begin{tabular}{|c|c|c|}
\hline Test Details & Test Plan 1 & Test Plan 2 \\
\hline \multicolumn{3}{|l|}{ Independent Variable } \\
\hline Quantity & 1 & 1 \\
\hline Name (s) & Perception & Perception \\
\hline Levels & $\begin{array}{l}2 \text { ( Information employee } \\
\text { Self-perception and } \\
\text { Supervisor Perception) }\end{array}$ & $\begin{array}{l}2 \text { ( Information employee } \\
\text { Self-perception and } \\
\text { Supervisor Perception) }\end{array}$ \\
\hline Dependent Variables & Untransformed & Untransformed \\
\hline Quantity & 50 & 50 \\
\hline Names (s) & As appeared in the OWEI & As appeared in the OWEI \\
\hline \multicolumn{3}{|l|}{ Number of Cases } \\
\hline Employee & 265 & 244 \\
\hline Supervisor & 304 & 244 \\
\hline Matched? & No & Yes \\
\hline \multicolumn{3}{|l|}{$\begin{array}{l}\text { Summary of Results } \\
\text { Pillai's Trace }\end{array}$} \\
\hline Value & 0.480 & 0.477 \\
\hline$F$ & 9.548 & 7.969 \\
\hline Sig. & $<0.001$ & $<0.001$ \\
\hline Effect Size & 3.69 & 3.63 \\
\hline
\end{tabular}


Table 3

Test Plans 3 and 4 for Hypothesis 1 Including Summary of MANOVA Results, Using the 4 Untransformed Factors in the OWEI

\begin{tabular}{|c|c|c|}
\hline Test Details & Test Plan 3 & Test Plan 4 \\
\hline \multicolumn{3}{|l|}{ Independent Variable } \\
\hline Quantity & 1 & 1 \\
\hline Name (s) & Perception & Perception \\
\hline Levels & $\begin{array}{l}2 \text { ( Information employee } \\
\text { Self-perception and } \\
\text { Supervisor Perception) }\end{array}$ & $\begin{array}{l}2 \text { ( Information employee } \\
\text { Self-perception and } \\
\text { Supervisor Perception) }\end{array}$ \\
\hline Dependent Variables & Untransformed & Untransformed \\
\hline Quantity & 4 & 4 \\
\hline Names (s) & $\begin{array}{l}\text { Teamwork, Dependability } \\
\text { Ambition, Self Control }\end{array}$ & $\begin{array}{l}\text { Teamwork, Dependability } \\
\text { Ambition, Self Control }\end{array}$ \\
\hline \multicolumn{3}{|l|}{ Number of Cases } \\
\hline Employee & 265 & 244 \\
\hline Supervisor & 304 & 244 \\
\hline Matched? & No & Yes \\
\hline \multicolumn{3}{|l|}{$\begin{array}{l}\text { Summary of Results } \\
\text { Pillai's Trace }\end{array}$} \\
\hline Value & 0.321 & 0.312 \\
\hline$F$ & 66.669 & 54.763 \\
\hline Sig. & $<0.001$ & $<0.001$ \\
\hline Effect Size & 1.89 & 1.81 \\
\hline
\end{tabular}

presence or absence of univariate outliers, and transformed or untransformed scores. Each of the seven tests revealed statistically significant differences between the selfperceived work attitudes of industrial employees with information jobs and their work attitudes as rated by their supervisors (Tables 2, 3, 4, and 5 ), leading to rejection of the first null hypothesis. Effect sizes were medium to large.

The ANOVA yields most reliable results when dependent variables are uncorrelated and sample (group) sizes are equal (Tabachnick \& Fidell, 1983). Of the seven Test Plans, only Test Plan 4 (Table 3) satisfies these conditions. The data in 
Table 6 reveals significant follow-up ANOVAs for Test Plan 4 along with $F$-values in descending order. The Bonferroni method (Barker \& Barker, 1984) was used to control Type I error.

The data in Table 6 indicates that three of the four follow-up ANOVAs were significant, with the exception of the factor Self Control. Null hypothesis 1 was rejected for the factors Dependability, Ambition, and Teamwork. Self-perceived work attitudes of Information employees were different from their supervisors' perceptions of their work attitudes on those three factors.

Table 4

Test Plans 5 and 6 for Hypothesis 1 Including Summary of MANOVA Results, Using the 4 Factors with Transformed Scores in the OWEI

\begin{tabular}{cll}
\hline Test Details & Test Plan 5 & Test Plan 6 \\
\hline Independent Variable & & \\
Quantity & 1 & 1 \\
Name (s) & Perception & Perception \\
Levels & 2 ( Information employee & 2 ( Information employee \\
& Self-perception and & Self-perception and \\
& Supervisor Perception) & Supervisor Perception) \\
Dependent Variables & Transformed & Transformed \\
Quantity & 4 & 4 \\
Names (s) & Teamwork, Dependability & Teamwork, Dependability \\
& Ambition, Self Control & Ambition, Self Control \\
Number of Cases & & \\
Employee & 265 & 244 \\
Supervisor & 304 & 244 \\
Matched? & No & Yes \\
Summary of Results & & \\
Pillai's Trace & & 0.179 \\
Value & 0.178 & 26.279 \\
$F$ & 30.56 & $<0.001$ \\
Sig. & $<0.001$ & 0.87 \\
Effect Size & 0.87 & \\
& &
\end{tabular}


Table 5

Test Plan 7 for Hypothesis 1 Including Summary of MANOVA results, Using the 4 Transformed Factor Distributions Without Outliers in the OWEI

\begin{tabular}{cl}
\hline Test Details & Test Plan 7 \\
Quantity & 1 \\
Name (s) & $\begin{array}{l}\text { Perception } \\
\text { Levels }\end{array}$ \\
$\begin{array}{c}\text { Supervisor Perception) } \\
\text { Transformed and outliers removed }\end{array}$ \\
Dependent Variables & 4 \\
Quantity & Teamwork, Dependability, Ambition, Self Control \\
Names (s) & \\
Number of Cases & 265 \\
Employee & 301 \\
Supervisor & No \\
Matched? & \\
Summary of Results & \\
Pillai's Trace & \\
Value & 0.186 \\
$F$ & 32.054 \\
Sig. & $<0.001$ \\
Effect Size & 0.92
\end{tabular}

Table 6

Summary of Test Results of Follow-up ANOVAs (Hypothesis 1)

\begin{tabular}{lcc}
\hline Test Plan & Variable (Factors) scores & $\begin{array}{c}F \text {-value } \\
\text { (in descending order) }\end{array}$ \\
\hline Test Plan & Sig. at $p<0.0125$ & 70.34 \\
4 & Dependability & 55.40 \\
& Ambition & 43.31 \\
\hline
\end{tabular}




\section{Hypothesis 2}

To test null hypothesis 2, "At the $p \leq 0.05$ level of confidence, there is no significant difference between the self-perceptions of work attitudes of industrial employees with non-information jobs and their work attitudes as rated by their supervisors", seven MANOVA tests were conducted with seven different combinations of test variables (Table 7 through Table 10). These test plans were also

Table 7

Test Plans 8 and 9 for Hypothesis 2 Including Summary of MANOVA Results for All the Untransformed 50 Items in the OWEI

\begin{tabular}{|c|c|c|}
\hline Test Details & Test Plan 8 & Test Plan 9 \\
\hline \multicolumn{3}{|l|}{ Independent Variable } \\
\hline Quantity & 1 & 1 \\
\hline Name (s) & Perception & Perception \\
\hline Levels & $\begin{array}{l}2 \text { ( Non-information } \\
\text { employee Self-perception } \\
\text { and Supervisor } \\
\text { Perception) }\end{array}$ & $\begin{array}{l}2 \text { ( Non-information } \\
\text { employee Self-perception } \\
\text { and Supervisor } \\
\text { Perception) }\end{array}$ \\
\hline Dependent Variables & Untransformed & Untransformed \\
\hline Quantity & 50 & 50 \\
\hline Names (s) & As appeared in the OWEI & As appeared in the OWEI \\
\hline \multicolumn{3}{|l|}{ Number of Cases } \\
\hline Employee & 189 & 169 \\
\hline Supervisor & 277 & 169 \\
\hline Matched? & No & Yes \\
\hline \multicolumn{3}{|l|}{$\begin{array}{l}\text { Summary of Results } \\
\text { Pillai's Trace }\end{array}$} \\
\hline Value & 0.532 & 0.523 \\
\hline$F$ & 9.425 & 6.288 \\
\hline Sig. & $<0.001$ & $<0.001$ \\
\hline Effect Size & 4.69 & 4.36 \\
\hline
\end{tabular}


Table 8

Test Plans 10 and 11 for Hypothesis 2 Including Summary of MANOVA Results for the Four Factors in the OWEI, Using Untransformed Factor Scores

\begin{tabular}{|c|c|c|}
\hline Test Details & Test Plan 10 & Test Plan 11 \\
\hline \multicolumn{3}{|l|}{ Independent Variable } \\
\hline Quantity & 1 & 1 \\
\hline Name (s) & Perception & Perception \\
\hline Levels & $\begin{array}{l}2 \text { ( Non-information } \\
\text { employee Self-perception } \\
\text { and Supervisor } \\
\text { Perception) }\end{array}$ & $\begin{array}{l}2 \text { ( Non-information } \\
\text { employee Self-perception } \\
\text { and Supervisor } \\
\text { Perception) }\end{array}$ \\
\hline Dependent Variables & Untransformed & Untransformed \\
\hline Quantity & 4 & 4 \\
\hline Names (s) & As appeared in the OWEI & As appeared in the OWEI \\
\hline \multicolumn{3}{|l|}{ Number of Cases } \\
\hline Employee & 189 & 169 \\
\hline Supervisor & 277 & 169 \\
\hline Matched? & No & Yes \\
\hline \multicolumn{3}{|l|}{$\begin{array}{l}\text { Summary of Results } \\
\text { Pillai's Trace }\end{array}$} \\
\hline Value & 0.356 & 0.326 \\
\hline$F$ & 63.759 & 40.236 \\
\hline Sig. & $<0.001$ & $<0.001$ \\
\hline Effect Size & 2.29 & 1.92 \\
\hline
\end{tabular}

designed with different combinations of dependent variables, matched/unmatched samples, presence or absence of univariate outliers, and transformed or untransformed scores.

As can be seen, each of the seven tests (Tables 7, 8, 9 and 10), revealed statistically significant differences between group means. All of the effect sizes were large. Thus, null hypothesis 2 was rejected. There were significant differences between the self-perception of work attitudes of industrial employees with noninformation jobs and their work attitudes as rated by their supervisors. The results of 
follow-up ANOVA tests according to Test Plan 11 (uncorrelated variables and equal sample size between groups) are presented in Table 11.

It is evident from Table 11 that all four follow-up ANOVAs were found significant for hypothesis 2. Self-perceived work attitudes of non-information employees were significantly different from their supervisors' perceceptions of their work attitudes on all of the dimensions measured by the OWEI.

Table 9

Test Plans 12 and 13 for Hypothesis 2 Including Summary of MANOVA Results for the Four Factors in the OWEI, Using Transformed Factor Scores

\begin{tabular}{|c|c|c|}
\hline Test Details & Test Plan 12 & Test Plan 13 \\
\hline \multicolumn{3}{|l|}{ Independent Variable } \\
\hline Quantity & 1 & 1 \\
\hline Name (s) & Perception & Perception \\
\hline Levels & $\begin{array}{l}2 \text { ( Information employee } \\
\text { Self-perception and } \\
\text { Supervisor Perception) }\end{array}$ & $\begin{array}{l}2 \text { ( Information employee } \\
\text { Self-perception and } \\
\text { Supervisor Perception) }\end{array}$ \\
\hline Dependent Variables & Transformed & Transformed \\
\hline Quantity & 4 & 4 \\
\hline Names (s) & $\begin{array}{l}\text { Teamwork, Dependability } \\
\text { Ambition, Self Control }\end{array}$ & $\begin{array}{l}\text { Teamwork, Dependability } \\
\text { Ambition, Self Control }\end{array}$ \\
\hline \multicolumn{3}{|l|}{ Number of Cases } \\
\hline Employee & 189 & 169 \\
\hline Supervisor & 277 & 169 \\
\hline Matched? & No & Yes \\
\hline \multicolumn{3}{|l|}{$\begin{array}{c}\text { Summary of Results } \\
\text { Pillai's Trace }\end{array}$} \\
\hline Value & 0.24 & 0.202 \\
\hline$F$ & 36.396 & 21.02 \\
\hline Sig. & $<0.001$ & $<0.001$ \\
\hline Effect Size & 1.3 & 1 \\
\hline
\end{tabular}


Table 10

Test Plan 7 for Hypothesis 2 Including Summary of MANOVA Results for All 4 Factors in the OWEI, Using Transformed Factor Scores with Outliers Removed

\begin{tabular}{cl}
\hline Test Details & Test Plan 14 \\
Quantity & 1 \\
Name (s) & Perception \\
Levels & $\begin{array}{l}\text { 2 ( Non-information employee Self-perception and } \\
\text { Supervisor Perception) }\end{array}$ \\
Tependent Variables & Transformed and outliers removed \\
Quantity & 4 \\
Names (s) & Teamwork, Dependability, Ambition, Self Control \\
Number of Cases & 189 \\
Employee & 266 \\
Supervisor & No \\
Matched? & \\
Summary of Results & \\
Pillai's Trace & \\
Value & 0.276 \\
$F$ & 42.827 \\
Sig. & $<0.001$ \\
Effect Size & 1.56
\end{tabular}

Table 11

Summary of Test Results Follow-up ANOVAs (Hypothesis 2)

\begin{tabular}{lcc}
\hline Test Plan & Variable (Factor) scores & F-value \\
Test Plan & Sig. at $p<0.0125$ & (in descending order) \\
11 & Ambition & 85.10 \\
& Dependability & 67.51 \\
& Teamwork & 55.45 \\
& Self Control & 17.58 \\
\hline
\end{tabular}




\section{Hypothesis 3}

To test hypothesis 3, "At the $p \leq 0.05$ level of confidence, there is no significant difference between the perceptions of work attitudes of industrial employees with non-information jobs and industrial employees with information jobs," four MANOVA tests were conducted according four Test Plans (Table 12-13). The test plans were designed with different combinations of dependent variables, presence or absence of univariate outliers, and transformed or untransformed scores.

As a result of the significant differences for Test Plans 15,16,17, and 18, null hypothesis three was rejected. There was a significant difference between selfperceived work attitudes of Information and Non-information employees. However, the effect sizes were not as large as those in the cases of hypothesis 1 and 2. None of the four Test Plans represented uncorrelated dependent variables and equal sample

sizes between groups. Therefore, results of follow-up ANOVA tests were not appropriate.

\section{Hypothesis 4}

A multiple regression analysis was conducted to test null hypothesis 4 , which states that at the $p \leq 0.05$ level of confidence, there is no significant relationship between the work attitudes of information employees based on gender, age, level of education, and length of service.

Multiple regression analyses are extensions of bivariate regression analyses and are related to partial and semi-partial analyses. Multiple regression analysis can be termed as a specialization of the more general canonical correlation. In the simplest way, multiple regression analysis allows one to assess relationships between one dependent variable and more than one independent variable at one or more levels (Tabachnick \& Fidell, 1983).

For better interpretability of multiple regression results, the number of dependent variables should be reduced. In this study, 4 factors had been identified from the 50 items of the OWEI by conducting an exploratory factor analysis. These factors were named as Teamwork, Dependability, Ambition, and Self Control and they were treated as dependent variables in the multiple regression analyses. Both untransformed and transformed factor scores were used in the analysis. The categorical independent variables of gender, years of full-time work experience, level of education, and age were coded into dummy variables with two, three, five, and five levels respectively. Multiple regression analysis was used to test the relationship between gender, age, level of education and length of service on work attitudes because it was believed that there these four variables might affect the criterion variable in unison and not independently.

The regression model applicable to this study was the fixed-effects model. This model assumes that values of independent variables are "fixed" because these are selected by the researcher rather than sampled from some population (Cohen \& 
Cohen, 1983). The values of independent variables exhaust the set of all possible values of interest. For example, the variable gender has two values: male and female, and these two values exhaust all possible values for gender.

Hierarchical multiple regression analysis was conducted using SPSS 10 based on responses from information employees. The sampling plan was random, i.e., numbers of participants in different levels of an independent variable were not the

Table 12

Test Plans 15 and 16 for Hypothesis 3 Including Summary of MANOVA Results, Using Untransformed Scores for all 50 Variables in the OWEI

\begin{tabular}{|c|c|c|}
\hline Test Details & Test Plan 15 & Test Plan 16 \\
\hline \multicolumn{3}{|l|}{ Independent Variable } \\
\hline Quantity & 1 & 1 \\
\hline Name (s) & Perception & Perception \\
\hline Levels & $\begin{array}{l}2 \text { (Information employee } \\
\text { Self-perception and Non- } \\
\text { information employee } \\
\text { Self-perception) }\end{array}$ & $\begin{array}{l}2 \text { (Information employee } \\
\text { Self-perception and Non- } \\
\text { information employee } \\
\text { Self-perception) }\end{array}$ \\
\hline Dependent Variables & Untransformed & Untransformed \\
\hline Quantity & 50 & 4 \\
\hline Names (s) & As appeared in the OWEI & $\begin{array}{l}\text { Teamwork, Dependability } \\
\text { Ambition, Self Control }\end{array}$ \\
\hline \multicolumn{3}{|l|}{ Number of Cases } \\
\hline Employee & 265 & 265 \\
\hline Supervisor & 189 & 189 \\
\hline Matched? & No & No \\
\hline \multicolumn{3}{|l|}{$\begin{array}{c}\text { Summary of Results } \\
\text { Pillai's Trace }\end{array}$} \\
\hline Value & 0.152 & 0.033 \\
\hline$F$ & 1.447 & 3.78 \\
\hline Sig. & 0.03 & 0.005 \\
\hline Effect Size & 0.74 & 0.14 \\
\hline
\end{tabular}


Table 13

Test Plans 17 and 18 for Hypothesis 3 Including Summary of MANOVA Results Using transformed Scores and Transformed Scores with Outliers Removed for the Four Factors

\begin{tabular}{|c|c|c|}
\hline Test Details & Test Plan 17 & Test Plan 18 \\
\hline \multicolumn{3}{|l|}{ Independent Variable } \\
\hline Quantity & 1 & 1 \\
\hline Name (s) & Perception & Perception \\
\hline Levels & $\begin{array}{l}2 \text { (Information employee } \\
\text { Self-perception and Non- } \\
\text { information employee } \\
\text { Self-perception) }\end{array}$ & $\begin{array}{l}2 \text { (Information employee } \\
\text { Self-perception and Non- } \\
\text { information employee } \\
\text { Self-perception) }\end{array}$ \\
\hline Dependent Variables & Transformed & $\begin{array}{l}\text { Transformed and outliers } \\
\text { removed }\end{array}$ \\
\hline Quantity & 4 & 4 \\
\hline Names (s) & $\begin{array}{l}\text { Teamwork, Dependability } \\
\text { Ambition, Self Control }\end{array}$ & $\begin{array}{l}\text { Teamwork, Dependability } \\
\text { Ambition, Self Control }\end{array}$ \\
\hline \multicolumn{3}{|l|}{ Number of Cases } \\
\hline Employee & 265 & 264 \\
\hline Supervisor & 189 & 189 \\
\hline Matched? & No & Yes \\
\hline \multicolumn{3}{|l|}{$\begin{array}{l}\text { Summary of Results } \\
\text { Pillai's Trace }\end{array}$} \\
\hline Value & 0.03 & 0.03 \\
\hline$F$ & 3.495 & 3.494 \\
\hline Sig. & 0.008 & 0.008 \\
\hline Effect Size & 0.13 & 0.13 \\
\hline
\end{tabular}

same (Cohen \& Cohen, 1983). Sets of independent variables were entered in terms of causal priority, which is required for conducting any hierarchical multiple regression analysis. It is important to note that no variable can be causally affected by one that appears after it. The order of assumed causal priority was gender, level of education, age, and years of full-time work experience. Using this order, level of education can 
not affect gender, age can not affect level of education (e.g., being older is not necessarily associated with having a higher level of education, but having more education does require the expenditure of time, which would make the employee older), and years of full-time work experience can not affect age.

The aim of the regression analysis was to predict the work attitudes as measured by each of the four factors from the variables:

- Gender,

- Level of education over and above gender,

- Age over and above gender and level of education, and

- Years of full-time work experience over and above gender, level of education, and age.

In hierarchical regression, the effect size is a function of $R^{2}$ and $R^{2}$-Change (Cohen $\&$ Cohen, 1983). $R^{2}$ accounts for the variance in the dependent variable that is contributed by the set or sets of independent variables and $R^{2}$-Change accounts for the variance in the dependent variable contributed by the set of independent variables over and above the set or sets of independent variables entered earlier in the regression equation.

Table 14 shows the $R^{2}, R^{2}$-Change, effect size, and significance of the change in $F$-value for the relationship between gender and latent dependent variables. The dependent variables are the factors Teamwork, Dependability, Ambition, and SelfControl.

Inspection of Table 14 lead to the rejection of null hypothesis 4 , "at the $p \leq$ 0.05 level of confidence, there is no significant relationship between the work attitudes of information employees based on gender, age, level of education, and length of service" because of the existence of statistically significant relationships between each of the dependent variables and gender. It was recognized, however, that the presence of a statistically significant relationship may not necessarily indicate significance in a practical sense. Table 15 shows bivariate and partial correlations of being female (a level of gender) with information employee work attitude measures with untransformed and transformed scores.

A review of Table 15 indicates that the bivariate and partial correlations between being female and work attitude measures were positive for untransformed scores but negative for transformed scores. However, the negative bivariate correlation was not an error. This was an effect of transforming the negatively skewed distributions to positively skewed distributions. Therefore, the result suggests that female Information employees possess better work attitudes than their male counterparts. 
Table 14

Summary of Hierarchical Multiple Regression Analysis for Predictor Gender Predicting Work Attitude Measures of Teamwork, Dependability, Ambition, and Self Control with Untransformed and Transformed Scores $(N=223)$

\begin{tabular}{lllll}
\hline Dependent Variables & $R^{2}$ & $R^{2}$-Change & Effect Size & Sig. F-Change \\
\hline Teamwork & & & & \\
$\quad$ Untransformed Scores & 0.047 & 0.047 & 0.0493 & 0.001 \\
$\quad$ Transformed Scores & 0.06 & 0.06 & 0.0638 & 0.001 \\
$\begin{array}{l}\text { Dependability } \\
\quad\end{array}$ & & & & \\
$\quad$ Untransformed Scores & 0.053 & 0.053 & 0.056 & 0.001 \\
$\quad$ Transformed Scores & 0.066 & 0.066 & 0.0707 & 0.001 \\
Ambition & & & & \\
$\quad$ Untransformed Scores & 0.041 & 0.041 & 0.0428 & 0.002 \\
$\quad$ Transformed Scores & 0.048 & 0.048 & 0.0504 & 0.001 \\
Self Control & & & & \\
$\quad$ Untransformed Scores & 0.045 & 0.045 & 0.0471 & 0.002 \\
$\quad$ Transformed Scores & 0.062 & 0.062 & 0.066 & 0.001 \\
\hline
\end{tabular}

\section{Hypothesis 5}

Application of multiple regression analysis to test hypothesis 5, "At the $p \leq$ 0.05 level of confidence, there is no significant relationship between the work attitudes of non-information employees and the variables gender, level of education, age, and length of service" revealed no statistically significant relationship between the work attitudes of non-information employees based on gender, level of education, age, and length of service. Null hypothesis 5 was, therefore, accepted.

\section{Discussion}

The OWEI is a self-reporting type instrument designed to obtain scores on work attitudes. The distributions of data collected from information employees, non-information employees and their supervisors were found to be severely negatively skewed. Even though this negatively skewed distribution made multivariate analysis more difficult, this kind of distribution was anticipated. It is a general human tendency for people to rate themselves in a positive way. The other reason for high self-ratings on OWEI items may be attributed to the fact that these employees were probably hired over their competitors for good reasons and some of these reasons may be good work attitudes. 
Table 15

Bivariate and Partial Correlations of Being Female (Level of Gender) with Information Employee Work Attitude Measures with Untransformed and Transformed Scores

\begin{tabular}{|c|c|c|}
\hline $\begin{array}{c}\text { Work Attitude } \\
\text { Measure }\end{array}$ & $\begin{array}{c}\text { Correlation Between } \\
\text { Being Female And Work } \\
\text { Attitude Measure }\end{array}$ & $\begin{array}{c}\text { Correlation Between } \\
\text { Being Female And The } \\
\text { Work Attitude Measure } \\
\text { Controlling For All } \\
\text { Other Predictors }\end{array}$ \\
\hline \multicolumn{3}{|l|}{ Teamwork } \\
\hline Untransformed & 0.217 & 0.202 \\
\hline Transformed & -0.244 & -0.224 \\
\hline \multicolumn{3}{|l|}{ Dependability } \\
\hline Untransformed & 0.230 & 0.216 \\
\hline Transformed & -0.257 & -0.242 \\
\hline \multicolumn{3}{|l|}{ Ambition } \\
\hline Untransformed & 0.203 & 0.183 \\
\hline Transformed & -0.218 & -0.197 \\
\hline \multicolumn{3}{|l|}{ Self Control } \\
\hline Untransformed & 0.211 & 0.197 \\
\hline Transformed & -0.249 & -0.233 \\
\hline
\end{tabular}

Judging or rating one's own self is always difficult and can be affected by one's state of mind at the time of filling out the self-rating instrument, in addition to other factors. Because the supervisors are the ones who judge the work performance of the employees under them, a supervisor's rating may appear to be more authentic than the employee's self-rating. While the supervisor rates an employee, he/she is more likely to evaluate the employee by making a comparison with another employee. This may not be the case when the employee rates himself/herself. However, this does not imply that the supervisors' perceptions of work attitudes of their employees are always correct. Employees having good relationships with their supervisors may get a higher rating and employees with poor or negative relationships with their supervisors may suffer from poorer ratings. In this study, supervisors' responses were found to be more evenly distributed than those of the employees. This statement is true for both original scores and untransformed scores on latent variables (factors).

Perceptions of work attitudes, as perceived by information employees and their supervisors, is significantly different with all combinations of test variables. Medium to large effect sizes confirm that the difference is indeed strong. Similarly, significant 
differences were found between perceptions of work attitudes by non-information employee and their work attitudes as perceived by their supervisors. In this case, the large effect sizes indicate a very strong difference. Moreover, statistically significant differences were found in self-perceived work attitudes of information and non-information employees at an alpha level of 0.05 (hypothesis three). Given the very small $F$-value and small to medium effect sizes, these differences may or may not have much practical significance.

For hypothesis 1, Test Plan 4 (Table 6) three significant follow-up ANOVAs on three latent variables (factors or dimensions) were presented in descending order of $F$-values. The differences in perceptions of information employee work attitudes as measured by these three latent variables, between information employees and their supervisors, contributed directly to the rejection of hypothesis 1 (significant MANOVA test). With an $F$-value of 70.34, the latent variable Dependability topped the list while with an $F$-value of 55.40 Ambition ranked second, and with an $F$-value of 43.31 Teamwork ranked third. These results mean that supervisors and information employees differed significantly in their perceptions of information employee work attitudes measured by these three latent variables (factors or dimensions). Mean scores obtained for the factor Dependability for employees and supervisors were 81.18 and 74.18 respectively. Similarly, mean scores obtained for the factor Ambition for employees and supervisors were 69.39 and 63.62 respectively. For the factor Teamwork, mean scores obtained for employees and supervisors were 89.73 and 82.79 respectively. It can, therefore, be said that supervisors rate information employee work attitudes measured by the above mentioned three latent variables (factors or dimensions) lower than the information employees rate themselves on work attitudes measured by the same three latent variables.

A gap between employers' expectations of employee work attitudes and the employees' assertion of their own work attitudes is possible for at least two reasons: (a) No set standard for ideal information employee work attitudes is available which could be taken as a benchmark and (b) selection of the levels (1 through 7) of work attitude measures (original OWEI items) were subjective.

The greatest concern for employers should, therefore, be of the scarcity of dependable information employees followed by the scarcity of ambitious information employees. The least serious concern is the scarcity of team-player information employees. There appears to be no scarcity of information employees who are emotionally stable, and not devious, hostile, rude, selfish, depressed, negligent, or careless.

Test Plan 11 (Table 11) listed four significant follow-up ANOVAs on four-latent variables (factors or dimensions) in descending order of $F$-values. The differences in perceptions of non-information employee work attitudes as measured by these four latent variables, between non-information employees and their supervisors, contributed directly to the rejection of hypothesis 2 via a significant 
MANOVA test. The results of the ANOVAs were similar to that for hypothesis 1 with the exception that a statistically significant difference was also obtained for the latent variable Self Control. However, the relatively small F-value for ANOVAs testing Self Control, though statistically significant, may be of little practical importance. In this case too, supervisors' ratings on non-information employees' work attitudes were lower than the non-information employees' self-perceived work attitudes. Mean scores obtained for factors Dependability, Ambition, Teamwork, and Self-control were 81.17, 68.77, 90.21, and 61.82 for employees and 70.87, 60.25, 80.09 , and 58.09 for supervisors.

The results of this study also revealed that information employee work attitudes, as measured by the OWEI, relate significantly with gender (Tables 12 and 13) and female information employees are more likely to endorse a positive work ethic than their male counterparts. This finding was consistent with other studies (Boatwright \& Slate, 2000; Hall, 1990, 1991; Hill, 1997; Wayne, 1989; Petty \& Hill, 1994; Wollack, Goodale, Witjing, \& Smith, 1971). However, the same was not true when the employees are non-information employees. In this case, gender could not predict good or poor work attitudes.

Cohen \& Cohen (1983) mentioned 0.02 as small effect, 0.15 as medium effect, and 0.35 as large effect for behavioral studies. For this study (hypothesis 4), effect sizes varied from 0.0471 to 0.0707 . These fall into the category of small effect size. This finding generally agrees with the small to medium effect sizes reported by Hill (1997).

This study demonstrated that age (age groups), levels of education, and years of fulltime work experience are of little practical significance in predicting work attitudes of Information and non-information employees. It also showed that noninformation employee work attitudes can not be predicted by gender.

\section{Conclusions}

To the extent that the data and findings of this research study were valid and reliable, the following conclusions were drawn:

Supervisors perceive and rate Information employee work attitudes differently than the Information employees perceive and rate their work attitudes by themselves. The information employees rated themselves higher on 45 of the OWEI items than their supervisors rated them and the supervisors rated the information employees higher on 5 OWEI items than the employees rated themselves. Information employees rated themselves higher on all four OWEI factors than their supervisors rated them on those same factors.

Non-information employees perceive their work attitudes differently than their supervisors $d o$. Non-information employees rated themselves higher on 45 of the OWEI items than their supervisors rated them. The supervisors rated the non-information employees higher on 5 OWEI items than the employees rated 
themselves. The Non-information employees also rated themselves higher on all four factors of the OWEI than their supervisors rated them on those same factors.

Information and Non-information employees do not perceive their work attitudes similarly. The information employees rated themselves higher on 45 of the OWEI items and the non-information employees rated themselves higher on 23 items. One item was a tie. Each group had higher means in two OWEI factors. Information employees had higher means for Dependability and Ambition and noninformation employees had higher means for Teamwork and Self-Control.

In terms of the factors measured by the OWEI, there were differences in the strength of disagreement of responses across the groups. The strongest disagreement between employees (both information and non-information) and supervisors on the perceptions of employee (both information and non-information) work attitudes was obtained for the work attitudes dimension Dependability. The second strongest disagreement between employees (both information and non-information) and supervisors on the perceptions of employee (both information and non-information) work attitudes was obtained for the work attitudes dimension Ambition. The third strongest disagreement between employees (both information and non-information) and supervisors on the perceptions of employee (both information and non-information) work attitudes was obtained for the work attitudes dimension Teamwork.

\section{Recommendations}

We suggest that employers explore the following areas to minimize the gap between employers' expectation of employee work attitudes and employees' assertion of their own work attitudes:

Both information and non-information employees perceived their own work attitudes differently than their supervisors perceived those work attitudes. This situation may lead to miscommunication between the supervisor and worker if the worker does not clearly understand the supervisor's expectations. To minimize the likelihood of misunderstandings, we recommend that supervisors discuss with workers their expectations of worker job performance, both technical and nontechnical, and provide frequent feedback on worker performance in both technical and non-technical areas.

The process of seeking and obtaining ISO 9000 certification may help bring work expectations into better alignment between workers and supervisors. In a manufacturing concern, the ISO requirement that job duties and tasks be clearly, precisely, and completely described can provide a foundation for a clearer understanding of supervisor's work expectations and can ensure that those expectations are reasonable and are related to the effective conduct of the job. We think that future research may show the merits of the ISO 9000 process for clarifying job expectations for both supervisors and workers. 
Because information and non-information employees perceive their work ethic in very different ways, we recommend additional research to ascertain whether this is a function of the type of job duties each must perform or a function of the type of persons who are attracted to information versus non-information jobs. If the differences in work ethic perception prove to be a function of the nature of job duties workers can be recruited according to the work ethic they possess insofar as it is consistent with the demands of the types of jobs that are open.

This study did not consider the contribution that appropriate training interventions may have upon employee work attitudes. The contribution of training interventions to important employee work attitudes, values and habits should be explored in subsequent research.

The reasons for the differences between the employers' and workers' perceptions of the workers' work ethic is not clear. We suggest additional research to ascertain the causes of differences between employers' expectations of employee work ethic and the employees' perceptions of their own work ethic.

For an information job position, when there is a tie between a male and a female applicant, the female applicant may be given preference for hiring because she may be more likely to have desirable work attitudes.

\section{References}

Aldag, R. \& Brief, A. (1975). Some correlates of work values. Journal of Applied Psychology, 60, 757-760.

Anthony, P. D. (1977). The ideology of work. Great Britain: Tavistock.

Azam, M. S. (2002). A study of supervisor and employee perceptions of work attitudes in information age manufacturing industries. Unpublished master's thesis, Illinois State University, Normal.

Barker, H. R., \& Barker, B. M. (1984). Multivariate analysis of variance (MANOVA). University, AL: The University of Alabama Press.

Beach, D. P. (1982). A training program to improve work habits, attitudes, and values. Journal of Epsilon Pi Tau, 8 (2), 69-74.

Beech, J. P., Kazanas, H.C., Sapko, J. Jr., Sisson, K. A., \& List, R. (1978). Necessary work values, habits, and attitudes: A final report. (Report No. 1368). Jefferson City, MO: Missouri State Department of Education.

Boatwright, J. R. \& Slate, J. R. (2000). Work ethic measurement of vocational students in Georgia. Journal of Vocational Education Research, 25(4), 503531.

Borg, W. R. \& Gall, M. D. (1979). Education research: An introduction. New York, NY: Longman. 
Brauchle, P. E. (1979). Self and supervisor perceptions of affective work competencies in CETA trainees: A comparative study (Doctoral dissertation, University of Missouri-Columbia, 1979). Dissertation Abstracts International, 41, 2026A.

Brauchle, P. E., Petty, G. C., \& Morgan, K. R. (1983). The factorial validity of the affective work competencies inventory. Educational and Psychological Measurement, 43(2), 603-609.

Buchholz, R. A. (1978). An empirical study of contemporary beliefs about work in American society. Journal of Applied Psychology, 63, 219-227.

Cohen, J. (1988). Statistical power analysis for the behavioral sciences. ( ${ }^{\text {nd }}$ ed.). Hillsdale, NJ: Lawrence Erlbaum Associates, Publishers.

Cohen, J., \& Cohen, P. (1983). Applied multiple regression/correlation analysis for the behavioral sciences ( $2^{\text {nd }}$ ed.). Hillsdale, NJ: Lawrence Erlbaum Associates, Publishers.

Custer, R. L., \& Claiborne, D. M. (1992). Critical skills cluster for vocational education. Journal of Vocational Education Research, 17(4), 15-40.

Custer, R. L., \& Claiborne, D. M. (1995). Critical skills cluster for vocational education: The employers' perspective - A replication study. Journal of Vocational Education Research, 20(1), 7-33.

Furnham, A. \& Muhiudeen, C. (1984). The protestant work ethic in Britain and Malaysia. Journal of Social Psychology, 122, 157-161.

Gaither, N. (1996). Production and operations management. Belmont, CA: Duxbury Press.

Gilbert, J. B. (1977). Work without salvation. Baltimore: The John Hopkins University Press.

Goodale, J. (1973). Effects of personal background and training on work values of the hard-core unemployed. Journal of Applied Psychology, 57, 1-9.

Hall, G. S. (1990). Work attitudes of traditional and non-traditional technical community college students. Unpublished master's thesis. The University of Tennessee, Knoxville.

Hall, G. S. (1991). Do older college students have different attitudes about work as compared with younger traditional students? Tennessee Education, 21(2), 2729.

Hatcher, T. (1995). From Apprentice to Instructor: Work ethic in apprenticeship training. Journal of Industrial teacher Education, 33(1), 24-45.

Hill, R. B. (1992). The work ethic as determined by occupation, education, age, gender, work experience, and empowerment. (Doctoral dissertation, The University of Tennessee, Knoxville, 1992). Dissertation Abstracts International, 53, 2343. 
Hill, R. B. (1996a). History of work ethic [On-line] Available: http://www.coe.uga.edu/ rhill/workethic/hist.htm [Retrieved December $1,2001]$.

Hill, R. B. (1996b). Work ethic differences in vocational education students and fulltime employed workers. Journal of Vocational Education Research, 21(3), 1329.

Hill, R. B. (1997). Demographic differences in selected work ethic attributes. Journal of Career Development, 24(1), 3-23.

Hill, R. B., \& Rojewski, J. W. (1999). Double jeopardy: Work ethic differences in youth at risk of school failure. Career Development Quarterly, 47(3), 267-279.

Hill, R. B., \& Petty, G. C. (1995). A new look at selected employability skills: A factor analysis of the occupational work ethic. Journal of Vocational Education Research, 20(4), 59-73.

Huitt, W. G. (1997). Success in the information age: A paradigm shift [On-line]. Available: http://www.valdosta.edu/ whuitt/psy702/context/infoage.html [Retrieved on December 1, 2001].

Kazanas, H. C. (1978). Affective work competencies for vocational education. Columbia, MO: University of Missouri. (ERIC Document Reproduction Service No. EJ 075 733).

Kerlinger, F. N. (1973). Foundations of behavioral research. New York, NY: Holt, Rinehart and Winston, Inc.

Korth, B. (1975). Exploratory factor analysis. In D. J. Amick, \& H. J., Walberg (Eds.), Introductory multivariate analysis (pp. 113-146). Berkeley, CA: McCutchan Publishing Corporation.

Law, C., Knuth, R. A., \& Bergman, S. (1992). What does research say about schoolto-work transition? [On-line]. Available: http://www.ncrel.org/sdrs lareas/stw_esys/7sch2wrk.htm [December 1, 2001].

Lipset, S. M. (1990). The work ethic - then and now. Public Interest. Winter 1990, 61-69.

MacDonald, A. P. (1972). More on the protestant work ethic. Journal of Consulting and Clinical Psychology, 39, 125-127.

Manufacturers' News, Inc. (2000). 2000 Illinois Manufacturers Directory. Chicago, IL : Author.

Maywood, A. G. (1982). Vocational education and the work ethic. Canadian Vocational Journal, 18(3), 7-12.

Miller, W. F. (1986). Emerging technologies and their implications for America. USA Today, 115, November 1986, 60-65. 
Minton, L. W. (1997). The impact of a workplace readiness course on the selfperceived work ethic of students (Doctoral dissertation, North Carolina State University, 1997). Dissertation Abstracts International, 58-06A, 2147.

Natriello, G. (1989). What do employers want in entry-level workers? An assessment of the evidence. (National Center for Education and Employment Occasional Paper No. 7). New York: Columbia University.

Olson, C. L. (1976). On choosing a test statistic in multivariate analysis of variance. Psychological Bulletin, 83, 579-586.

Parker, M. (1998). Sampling with replacement and sampling without replacement. [On-line]. Available: http://rene.ma.utexas.edu/users/parker/sampling /woreplshort.htm [Retrieved December 1, 2001].

Petty, G. C. (1995). Adults in the work force and the occupational work ethic. Journal of Studies in Technical Careers, XV(3), 133-140.

Petty, G. C., \& Hill, R. B. (1994). Are women and men different? A study of the occupational work ethic. Journal of Vocational Education Research, 19(1), 71-89.

Petty, G. C., Kazanas, H. C., \& Eastman, R. M. (1981). Affective work competencies of workers, supervisors, and vocational educators. Journal of Vocational Education Research, IV, 55-71.

Rose, M. (1985). Reworking the work ethic: Economic values and socio-cultural politics. London: Schocken.

Rodgers, D. T. (1978). The work ethic in industrial America, 1850-1920. Chicago: The University of Chicago Press.

Sherer, M., \& Eadie, R. (1987). Employability Skills: Key to success. Thrust, 17(2), 16-17.

Smith, B. N., Jones, C., \& Lane, J. (1997). Employers' perceptions of work skills. Business Education Forum, 51(4), 11-17.

Stevens, J. (2002). Applied multivariate statistics for the social sciences. Mahwah, N.J. : Lawrence Erlbaum Associates.

Tabachnick, B. G., \& Fidell, L. S. (1983). Using multivariate statistics. New York, NY: Harper \& Row.

Tang, T. L. (1989). Effects of work ethic and task labels on task performance. The Journal of Psychology, 123(5), 429-438.

Tang, T. L. \& Tzeng, J. Y. (1992). Demographic correlates of protestant work ethic. The Journal of Psychology, 126(2), 163-170.

Tilgher, A. (1930). Homo faber: Work through the ages (D.C. Fisher, Trans.). New York: Harcourt Brace.

Toffler, A. (1981). The third wave. New York, NY: Bantam. 
Wang, G. T. (1996). A comparative study of extrinsic and intrinsic work values of employees in the United States and Japan. New York: The Edwin Mellen Press, Ltd.

Wayne, F. S. (1989). An instrument to measure adherence to the Protestant ethic and contemporary work values. Journal of Business Ethics, 8, 793-804.

Wilkinson, L., \& Task Force on Statistical Inference.(1999). Statistical methods in psychology journals: Guidelines and explanations. American Psychologist, 54, 594-604. [On-line] Available: http://www.apa.org/journals/amp/ amp548594.html \#c13 [Retrieved December 1, 2001].

Wollack, S., Goodale, J. G., Witjing, J. P., \& Smith (1971). Development of the survey of work values. Journal of Applied Psychology, 55, 331-338.

\section{The Authors}

Md. Shafiqul Azam can be contacted at Pro-Tech Search, Inc., 400 Chatham Road, Suite 201, Springfield, IL 62704. Office Phone: (217) 7932790.

Paul Brauchle is Professor and Director, Bureau of Training and Development, and Associate Director, The Center for Mathematics, Science \& Technology, Department of Technology, Illinois State University, Room 210K Turner Hall, Campus Box 5100, Normal, IL 61790-5100. Phone: (309) 438-2696. E-mail: pebrauc@ilstu.edu. 
Journal of Vocational Education Research, 28(3), pp. 217-258.

(C)2003

\title{
Entrepreneurial Careers of Women in Zimbabwe
}

\author{
Lisa B. Ncube \\ Ball State University \\ James P. Greenan \\ Purdue University
}

\begin{abstract}
The purpose of this study was to investigate the pathways of entrepreneurial career development and the processes involved for women to become entrepreneurs in Zimbabwe. Women entrepreneurs were studied to gain an understanding of why women chose self-employment and how local enterprise programs should be designed to benefit them. The study examined how women's experiences, the environment, and other contextual factors have assisted to shape women's entrepreneurial careers; and examined programs and policies for supporting skill and technology acquisition and development in small and medium enterprises. It was the intention of the study was to identify the priority needs of individual women entrepreneur.

A hermeneutic phenomenological life-course approach to women's careers in Zimbabwe was used to investigate entrepreneurship. This holistic approach captured the complexity of women's entrepreneurial careers. Accumulating various forms of economic, social, and cultural capital facilitated the development of entrepreneurial careers. Women's agency or the ability to carry out initiatives was critical to overcoming social and economic subjugation in the colonial and post-colonial states. Entrepreneurial outcomes included gain in capital and power as well as construction and acquisition of skills. In addition, women entrepreneurs became increasingly visible as they developed more power within society. Technology played an important role in the development of enterprises.
\end{abstract}

\section{Introduction}

Although the economy of Zimbabwe has experienced an annual growth of approximately 4\% since independence in 1980, the 1990's and the 2000's have been difficult for the Zimbabwean economy. Economic indicators have fluctuated throughout the decade. The introduction of the World Bank's and International Monetary Fund's Economic Structural Adjustment Program (ESAP) in 1990, and Zimbabwe Program for Economic and Social Transformation (ZIMPREST) in 1995, led to a negative impact on the economy. Droughts in 1992 and 1995, and the 
economic prosperity of neighboring countries, caused the gross domestic product (GDP) of Zimbabwe to decrease during those years. Unemployment figures have continued to increase over $60 \%$. While short- and medium-term prospects for reversing the negative economic trend appear bleak, the small and medium enterprises sector offers some hope.

Limited opportunities in the formal sector and high unemployment rates in many African countries have resulted in increased attention on the small enterprise sector (Daniels, 1998). In Zimbabwe, a large source of employment has been, historically, in the formal sector. However, with unemployment figures rising and the economy in turmoil, the informal sector has become a very lucrative source for many Zimbabweans. Although, the position of the small and medium enterprises is not clearly defined as to whether it belongs to the formal or informal sectors, its importance in economic development has become increasingly evident since independence. There has been a significant commitment by government and other organizations to elevating the role of small and medium enterprises. In addition to its importance in creating employment, the small and medium enterprises sector contributes significantly to economic growth and equity.

It is undeniable that women entrepreneurs are major actors and contributors to economic development and are becoming increasingly visible in the local economies of developing countries. The rapid growth of women entrepreneurs represents one of the most significant economic and social developments in the world; although, inadequate attention has been focused on the study of women in small and medium enterprises (SME), especially in developing economies. Research on the entrepreneurial career development of women in general and, in small and medium enterprises in particular, has been minimal. Concurrently, small business ownership has become increasingly important as an area for female economic achievement in developed and developing economies. Insufficient research on women's enterprises, in developing countries, including Zimbabwe, has resulted in a lack of wellarticulated women's entrepreneurial development policies and programs.

Entrepreneurial activities are gendered in terms of access, control, and remuneration (Spring \& McDade, 1998). However, the current understanding of an entrepreneur's life is primarily a male-dominated understanding of his public world and working life (Burgess-Limerick, 1993). A further limitation is that most studies do not focus on women, but include them incidentally in the data and then desegregate the analyses by gender. Women in Development (WID) research contends that growth-oriented strategies, used in many studies, exclude women (Dignard \& Havet, 1995). Women's enterprises are viewed as small, marginally profitable, and offering minimal potential for contributing to the macro-economy. The importance of women's incomes to human capital investment and family welfare is largely ignored. Characterizations of women enterprises as small and generally lacking potential for growth ignore the work that has been completed in transforming women's traditional activities into dynamic and productive ones. These 
characterizations misguidedly suggest to policy makers and international donor agencies that women's enterprises are not worthy of attention (Downing, 1995).

There is a paucity of theories that explain the paths of entrepreneurial career development, women entrepreneurs, and the process of entrepreneurship (Katz, 1994a). Theories that relate to developing countries are even more limited. It is not obvious from the literature that the experiences of women in small and medium enterprises in Zimbabwe, are documented let alone understood, and whether these experiences are attributable to entrepreneurial ventures. It is crucial that research investigates the scope and nature of events and processes in becoming a woman entrepreneur within a particular context. Models should recognize the diversity of development that reflects the different situations of women entrepreneurs. Transitions through various stages require the development of appropriate skills and abilities, and a desire to meet the demands of new roles in successive stages. Progression also depends upon accessibility to suitable opportunities. An understanding of entrepreneurial careers and processes and the experiences of women entrepreneurs in Zimbabwe will contribute to a better understanding of entrepreneurship, especially within the African context. A lack of knowledge of women entrepreneurs in small and medium enterprises could result in policies and programs for education and training, micro-credit and financing, allocation of resources, and aid that do not meet the needs of women entrepreneurs.

It is important to note that most enterprises operated by women in Zimbabwe are small- and medium-scale and women constitute the vast majority in this sector. The benefits and importance of skills and technology in economic development and in the raising of living standards of the nation has long been recognized. Government and private agencies have indicated great interest in human resource development and training programs. Upon independence, the Government of Zimbabwe assumed responsibility for apprenticeship and training skilled workers, expanded its technical training base through the establishment and expansion of polytechnic and technical colleges and universities, and promoted free enterprise in facilitating and collaborating with private institutions in training the workforce. However, in the process of renewing and reaffirming the importance of skill acquisition by the public and private sectors, skill development among girls and women has been neglected (Butler \& Brown, 1993). This oversight has contributed to voids in knowledge and understanding of the processes, constraints, and consequences of construction and acquisition of skill and work by women entrepreneurs operating small and medium enterprises.

Assessing women entrepreneurs' work will help determine the skills, vocational training, and education they need. Steinberg (1990) claimed that the treatment of skilled work as the outcome of the labor market and political struggles, or as an objectively measurable set of mental and political job characteristics, has been greatly influenced by conventional conceptions of male-dominated managerial, professional, and craft work. She further points out that the term skill is gendered and 
perceived by women to include those skills that are validated by formal training and certification, which many women small and medium enterprises (WSMEs) entrepreneurs do not have.

In this study, the concept of skill was approached from a social rather than technical perspective. Therefore, it ceases to appear as a tangible entity, a capacity for work that some people have and others do not have (Jackson, 1991). How individuals construct and perceive skill becomes an important determinant of the capabilities and abilities they believe they have to perform certain tasks and jobs. Furthermore, "skill" is a concept that serves to differentiate between different kinds of work and workers and to organize the relations among them. Jackson noted that it has been used to protect the interests of those who have power. It has come to express the interweaving of the technical organization of work with hierarchies of power and privilege between men and women, blacks and whites, and old and young. Skill designations are deeply implicated in the gender equity struggles.

\section{Literature Review}

\section{Historical Perspective of Women and Entrepreneurship in Zimbabwe}

The subordination of women in Zimbabwe had strong historical roots that were reinforced by contemporary legal codes, raising controversies and questions about historical continuity of the colonial and post-colonial states. Sylvester (1991) cited the example of whether all Zimbabweans came from distant lands or simply emigrated from neighboring countries. She pointed out that economic policies and political decisions that the Zimbabwean government adopted raised questions about whether the new Zimbabwean state is really new or an extension of the Rhodesian state, following a development path that diverges from or simply builds on the political economy of Rhodesia. Jolly (1994) noted that the relation between the colonial and the post-colonial codes of engendered ethnicity was not just one of discontinuity or continuity. There were questions of reconstructions or rearrangement of meaning in post-colonial situations, of terminologies that had prevailed in colonial contexts.

Colonization in Zimbabwe brought with it new social and economic forces on the indigenous population. Jolly (1994) contended that in southern Africa, the relations between colonizer and colonized were often inscribed through women's bodies. Missionaries and colonial administrators judged women as primarily responsible for the perceived depravity of African society (Schmidt, 1991). Colonial forces including Christianity and capitalism, together with traditional patriarchal structures collaborated to control the behavior of women. Subjugation of women was used as a general strategy to maintain control over indigenous African people and resources (Van Hook, 1994). In most cases, there was no conflict between the traditional and colonial systems as they were separate but supportive of one another 
within the national economy (Imani Development, 1996). African men were able to reassert their authority over women while the colonialists by controlling African women were able to obtain cheap male labor (Schmidt, 1991). These forces and structures worked in tandem to restrain the advancement of Africans with severe consequences for women; for instance, where convenient, colonial policy makers were willing to uphold traditional gender relations. One such instance was the creation of "customary law." Customary law was developed by the colonial administrators in consultation with traditional "legal experts" of chiefs, headmen, and elders, all of whom were men as a mechanism of controlling and subordinating women. While custom had been both flexible and sensitive to extenuating circumstances, customary law was not (Schmidt, 1991).

Colonial administrators designed policies that treated women as either dependents or mothers. They had different educational programs for girls and boys to impose their vision of women's proper role on Zimbabwean society. Girls and women were discriminated against by the colonial state's education policy in terms of access to and equity within the school system. The formal and hidden curricula were biased in favor of boys, preparing girls for domesticity and boys for work outside the home (Gordon, 1996). Western ideals of women as homemakers dominated curricula and the important role women traditionally played in agriculture were ignored (Seidman, 1984). The few African women who managed to complete their education with the necessary qualifications for entry into the modern economy faced further discrimination by race and gender in the work place. This was reflected in their wages, employment rates, and the types of jobs they held. African women were employed mainly in the public sector as nurses and teachers in institutions catering to Africans. They earned less than men because of the dubious breadwinner concept. Upon marriage, women were given temporary staff status and required to resign from their jobs to have children and reapply after delivery with no entitlements. In fact, they had to start at the bottom of the pay scale. Women's incomes were heavily taxed, since they were considered supplemental to their husbands' incomes.

The traditional background, which most aspiring entrepreneurs represented, hindered their ability to become entrepreneurs. The social and economic structures in traditional African society were based on a higher degree of collective responsibility and communal ownership of natural resources as compared with colonial structures (Imani Development, 1996). Advancement of individuals within the various traditional social settings depended mostly on a set pattern of responsibilities and privileges that came with each person's maturity. An individual desiring to advance outside those lines had a more difficult time. Although there were exceptions to the norm, it would be a risk, as these individuals would be perceived as a threat to traditional authority.

As a result of colonial and traditional pressures, entrepreneurship was generally not encouraged. However, a few black businessmen owned small retail 
stores in African townships. Various laws were used to restrict and prohibit enterprise development among the indigenous population that resulted in legal entrenchment of racial exclusion (Imani Development, 1996). The colonial government deliberately discouraged and marginalized the development of indigenous enterprises. Entrepreneurship among the African indigenous population has become a post-colonial phenomenon, especially among women.

\section{Economic Development in Post-colonial Zimbabwe}

Zimbabwe attained its independence in 1980. Seidman (1984) noted that the position of women in post-colonial Zimbabwe was the result of complex interactions among three distinct legacies. These included the traditional patriarchal culture which subordinated women, colonialism which entrenched the inequalities of the sexual division of labor, and the experience of the war of liberation which created new aspirations for women in Zimbabwe. Men and women had high expectations of enjoying the fruits of independence. For women, this implied improvement in their social, economic, legal, and political status. During the liberation struggle, black Zimbabwean women had described their goals in terms of freedom from racial, economic, and gender oppression (Seidman, 1984).

Although the government of Zimbabwe assumed the task of removing the distinct legal injustices, societal attitudes, and resistance to change, the majority of women continue to live under the same conditions that existed before independence. Therefore, their lives have not changed, in spite of the many legal changes that have occurred since independence. Another objective of the government was to bring all citizens into the mainstream of development and social transformation. This would ensure equality, regardless of race, color, creed, political affiliation, or sex. However, some articles in the Bill of Rights of the Zimbabwean Constitution refer to individuals and do not mention gender, and this has constituted the major barriers in realizing the transformation.

Although the economy of Zimbabwe has experienced an average growth rate of approximately $4 \%$ since 1980 , in the 1990's, and 2000 's, the growth rate decreased, in part, because of excessive government expenditure compounded by inappropriate and ill-conceived economic liberalization policies, and severe droughts in 1992, 1995, and 2002. Under pressure from the International Monetary Fund and World Bank, the Zimbabwe government adopted economic reforms. Ghosh (1996) defined economic liberalization as economic and industrial restructuring along the lines of capitalism in which private ownership, profit making, and a market framework regulated activity. In many developing countries, they have taken the form of neo-liberal packages of adjustment measures associated with financial support from the IMF and the World Bank. The current economic strategies attempt to combine stabilization and structural adjustment under an umbrella of liberalization. However, economic structural adjustment has not been very successful and its impact has not been uniform. Evidence suggested that women have been the 
most susceptible to the adverse effects of these policies (Organization for Economic Cooperation and Development, 1994).

Zimbabwe has its own history, which negatively impacted on the development and participation of women in the informal sector. The system of economic controls established before independence provided white Zimbabwean firms with monopolies and other privileges to control markets for the most profitable products. Many of these controls remain in place. In Zimbabwe, as in South Africa, laws that prohibited Africans from operating certain businesses remained until the 1990s, resulting in an underdeveloped informal sector (McPherson, 1996). The drastic impact these factors have had on women is demonstrated by a World Bank survey of women entrepreneurs in Zimbabwe. Only 5 percent of the respondents had obtained formal credit, while 75 percent of the respondents received financing from personal savings or family grants and loans (Downing, 1995). However, the Growth and Equity through Microenterprise Investments and Institutions (GEMINI) data for Southern Africa indicated that women (84\% in Swaziland, $73 \%$ in Lesotho, 62\% in South Africa, and $67 \%$ in Zimbabwe) own most of the SMEs (McPherson, 1998). The gender data suggest the important role of women within the SMEs.

Further analysis of the sub-sector indicates a dominance of women in retail trade. However, the growth rate of enterprises owned by men surpasses that of women. The GEMINI Southern Africa data suggest that women have more barriers than men in the development of their SMEs (McPherson, 1996). For example, it was revealed that employment growth rates for women's enterprises were generally lower than those for men's, and, remained the same size regardless of location along the urban-rural continuum. Frequently cited problems for women entrepreneurs included under-capitalization and inadequate market demand.

\section{Women Entrepreneurs in Developing Countries}

The decision to engage in WSMEs is an important one for many African women. A number of factors and issues promote or constrain their participation Environmental, cultural, and other socio-economic factors are important considerations in studying women's small and medium enterprise participation and activities. For example, the entrepreneurial activities of fresh produce market women in Harare, Zimbabwe evolved from historical circumstances, cultural work ethics, and individual resiliency (Horn, 1994). They developed a marketing niche based on their ability to adapt rurally generated skills to an urban environment.

The ability of women to further develop their enterprises requires official government recognition of their integral role in the maintenance of their families, education of the next generation, and development of the urban community (Dignard \& Havet, 1995). Development will be highly problematic if the economic structural adjustment program or similar policies continue to undermine women's entrepreneurial activities. It is also equally important to recognize other WSMEs and 
not aggregate them in the same category as market women, as the needs of each group are distinctly different. Women in Zimbabwe were engaged in entrepreneurial small- and medium-scale capitalist ventures, typically in productive sectors such as light manufacturing. Since independence women entrepreneurs have shifted from manufacturing related operations into trading and, to a smaller extent, serviceoriented firms. Table 1 shows the industrial sector distribution of small and medium enterprises in Zimbabwe.

Table 1

Sector Distribution of Small and Medium Enterprises in Zimbabwe

\begin{tabular}{lcc}
\hline Sector & \% SMEs & Distribution of \\
WSMEs (\%)
\end{tabular}

Note. Source: McPherson, 1998.

While women occupy a dominant position in the SMEs sector, in Zimbabwe they face particular problems. Women entrepreneurs are discriminated against when seeking loans and other support. Many regulations and controls on markets for raw materials, technology imports, and zoning by-laws target female-dominated sectors such as textiles, food processing, leather works, and retail sub-sectors. According to the Zimbabwe Ministry of Finance and Economic Planning, female self-employment in Zimbabwe experienced five times the growth rate of male self-employment in 1995. While the total of women-owned businesses has fallen $3.8 \%$ since 1991, one or more women currently owned $58 \%$ of the enterprises. Women owned nearly $75 \%$ of the SMEs in 1998 (McPherson, 1998). 


\section{Entrepreneurial Career and Skill Development}

To understand how WSMEs emerge, grow, and remain a vibrant and dynamic sector of the economy it is important to investigate women's entrepreneurial career and skill development. In addition, the strategies women develop for occupying this sector need to be understood in developing policies to support them. Life history approaches can assist to better understand women's entrepreneurial careers (Scheibel, 1999). These acknowledge the role played by various factors in a woman entrepreneur's life. Since entrepreneurship is a capitalist venture through which an individual accumulates capital, examining the strategies a woman entrepreneur has used to develop her capital base provides insight into entrepreneurial career development. A wide range of factors, many of them deeply embedded in the gendered nature of culture and society, serve to prevent women from participating equally with men in education and training and; thereafter, in employment and selfemployment (Leach, 1996). In general, formal education and training in developing countries appear not to acknowledge the involvement of women in economic activities, and does little to provide them with relevant skills. The gendered nature of the curriculum serves to reinforce rather than weaken the social and economic constraints operating against the equal participation of women in the labor market, which is both highly competitive and discriminatory.

Although a sound general education provides young people with the best foundation for their future participation in employment or entrepreneurship, additional training and skill development is necessary for a successful career as an entrepreneur (Leach, 1996). Traditional apprenticeship has been the main mode of transmission of skills from generation to generation and is pervasive throughout many small and medium enterprises in Africa. However, there still is a need for improvement and intervention. McLaughlin (1989) identified three reasons to justify interventions in training: (a) inadequate capacity, (b) inadequate acquisition of knowledge or skill by trainees, and (c) the perception that conventional modes of skill acquisition do not satisfy the needs of entrepreneurship. Literature has indicated that training for women entrepreneurs in Africa remains very limited. Its emergence, in part, is a result of the recognition that SMEs have potential for sustainable economic development.

Vocational opportunities for girls, when available, have been restricted to careers traditional to women such as home economics, secretarial studies, dressmaking, and cosmetology, which are largely an extension of home-based activities and usually have low remuneration (Leach, 1996). Therefore, the function of education has been largely to prepare young women for their assumed adult roles as housewives and mothers. In contrast, boys have been prepared for higher paying technical jobs and careers. Schools have served to reflect and to reinforce the gender bias that prevails throughout the labor market as in all social relations. Likewise, initiatives to introduce entrepreneurship into the school curriculum are unlikely to 
assist women significantly unless the needs of women are taken into consideration in the design and development of such curricula, and deliberate efforts in equalizing opportunity for men and women are made by policy makers (Leach, 1996).

It is clear that career development pathways are very ambiguous. It becomes necessary to seek alternative conceptualization of women's entrepreneurial careers. Entrepreneurial career development could be theorized from Bourdieu's (1986) perspective of forms of capital. Entrepreneurial career development can also be viewed as an acquisition of various forms of capital. The forms and the extent of the accumulation reveal varying career patterns among entrepreneurs. The concept of capital as presented by Bourdieu is broader than the monetary definition of capital, more often used in economics. Capital is a generalized "resource" that can assume monetary and non-monetary, as well as tangible and intangible forms (Anheier, Gerhards, \& Romo, 1995). The social world is amassed history and, therefore, it is necessary to consider the idea of capital and all its effects.

"Capital is accumulated labor in its materialized form or its "incorporated" embodied form. ... [it] takes time to accumulate and has a potential capacity to produce profits and reproduce itself in identical or expanded forms" (Bourdieu, 1986, p241).

Depending on the area in which it functions, and the cost of the expensive transformations which are the precondition for its usefulness, capital exists in economic, cultural, and social forms. Economic capital refers to income and other financial resources and assets. It is defined as that which is "immediately and directly convertible into money and may be institutionalized in the form of property rights" (Bourdieu, 1986, p243). Less tangible than economic capital, cultural capital can be invested and earn profit or increase in value (Dinello, 1998). Cultural capital includes long-standing dispositions and habits acquired through the socialization process, and the accumulation of valued cultural objects such as formal educational qualifications and training (Bourdieu, 1986; Coleman, 1988). Cultural capital defines and legitimizes cultural, moral, and artistic values; standards; and styles (Dinello, 1998).

Social capital refers to social relationships that form resources that individuals can use in their personal and professional lives. It is comparable to the financial and human capital relationships of economics and a linkage to social structure (Hofferth, Boisjoly, Duncan, 1999). Social capital is the actual and potential resources that can be accumulated thorough membership in social networks of individuals and organizations (Anheier, Gerhards, \& Romo, 1995). It is defined in terms of resources that individuals may access through social ties (Frank \& Yasumoto, 1998). These ties may affect one individual's action that is directed toward another based on the social structure in which the actions are embedded and the history of transactions between people. Social capital can also be described as the resources of social relations and networks that are useful for individuals. It facilitates action through the generation of trust; the establishment of obligations, expectations, and reciprocity; and the creation and enforcement of norms and sanctions (Coleman, 1988, 1990; Putnam, 1995). It 
also refers to the ability to form and sustain associations (Portes, \& Landolt, 1996). Further, social capital has other distinctive characteristics including the expectation of reciprocity that distinguishes it from economic capital. These characteristics of social capital may impose restrictions on individual freedom and business initiatives. Close social networks can also undermine business initiatives through downward leveling pressures.

Economic, social, and cultural capital can be converted one into another. However, they differ in liquidity and convertibility and in their potential for loss through attrition and inflation. Economic capital is the most liquid and readily convertible into social and cultural capital (Anheier, Gerhards, \& Romo, 1995). By comparison, the convertibility of social capital into economic capital is more expensive and conditional. Social capital is less liquid, "stickier," and less likely to lose value. While it is more difficult to convert social into cultural capital, the conversion of cultural into social capital is easier.

The differences in the liquidity, convertibility, and loss potential of capital entail different scenarios for persons in social fields. Bourdieu (1986) further noted that high volumes of economic capital with lower volumes of cultural and social capital characterize some positions. Other positions will rank high in terms of cultural capital, yet somewhat lower in other forms. The "nouveaux rich," for example, are typically well endowed with economic capital relative to a paucity of cultural capital. International business consultants rely on high levels of social capital relative to cultural and economic capital. In contrast, intellectuals typically accumulate larger amounts of cultural and symbolic capital than they do economic and social endowments. The entrepreneurial careers of women appear to require a balance in the different forms of capital. Economic capital provides the base required to create a new venture. However, access to economic capital is facilitated by the social capital an individual possesses. Cultural capital in the forms of class, educational background, and ethnicity can provide contacts with certain members of society; thereby, contributing to the social capital of the woman entrepreneur.

\section{Methodology}

\section{Theoretical Framework: Hermeneutic Phenomenology}

Phenomenology is the study of human phenomena and focuses on the "lived experience"; whereas; hermeneutics refers to the interpretation of the experience (Wilson \& Hutchinson, 1991). According to Van Manen (1990), phenomenological research is the explanation of phenomena as we become aware of them. In seeking to determine, "Who is a woman entrepreneur in Zimbabwe?" the study examined and described the experiences of women entrepreneurs in Zimbabwe and their interpretation of the world, situating them in the colonial and post-colonial state. It focused on the questions, "What is the structure and essence of experience of the 
entrepreneurial phenomenon for these women?" and "What experiences have these women had and how do they interpret the world around them?"

It was the intention of the researcher to attempt to examine the experience of becoming an entrepreneur in Zimbabwe while gaining a deeper understanding of the nature or meaning of the everyday experiences of entrepreneurial women. Also, the study intended to contextualize phenomena and allow for the exploration of the experiences of participants from their own perspectives and words (Richie, Fassinger, Linn, Johnson, Prosser, \& Robinson, 1997). From a phenomenological perspective, it was important to realize that there was no objective or separate reality; there was only what the women knew based on their experiences and what these experiences signified to them.

Phenomenology has played a critical role in establishing and detailing the complexities of human experience (Maranhão, 1986). The assumption in phenomenology is that there is an essence(s) to shared experiences, which represent the core meanings mutually understood through a phenomenon of common experiences and that the phenomenon by itself has no inherent meaning. The experiences of people are categorized and compared to identify the essences of the phenomenon. Phenomenology is the systematic attempt to uncover and describe the structures and the internal meaning structures of the lived experience (Patton, 1990). It focuses on the shared world of meanings through which social action is generated and interpreted. The phenomenon is represented by the interpretations of members of a society. All situations have meanings, and are revealed and related to other meanings and meaning systems (Jain, 1985).

The purpose of hermeneutics is to discover meaning and achieve understanding rather than extracting theoretical terms or concepts at a higher level of abstraction (Wilson \& Hutchinson, 1991). Hermeneutic phenomenology, therefore, becomes an interpretation of people's text of their experiences. Hermeneutics emphasizes the human experiences of understanding and interpretation and is presented as an individual's detailed stories or "thick description." These serve as exemplars and paradigm cases of everyday practices and "lived experiences." The practices and experiences are identified, described, and interpreted within their given contexts.

"The aim is to understand how people experience the world pre-reflectively, without taxonomizing, classifying or abstracting it." (Van Manen, 1990 p.9).

Hermeneutic phenomenological research informs the personal insight, contributing to thoughtfulness, and the ability to act toward others, children or adults, with tact or tactfulness (Van Manen, 1990). Hermeneutical phenomenology attempts to construct a full interpretive description of some aspect of the world, with a full understanding that the lived life is always more complex than any explanation of meaning can reveal. The focus is on interpretation and understanding social interactions and those experiences that influence the development of the individual's life. Life-course perspectives used in phenomenology and hermeneutics emphasize 
how women's attitudes, orientations, and commitments to entrepreneurship are constantly renegotiated and not fixed over time (Scheibel, 1999).

A methodological commitment to the specific cultural and historical processes grounded in the activities and practices of women highlights the importance of social agency and resistance (Lal, 1995). The concept of agency, which articulates women's freedom to respond to social constraints proactively, has been absent from many discussions in the study of women's entrepreneurial careers (Scheibel, 1999). In discussing women's agency, the emphasis is placed on the creative mechanisms employed differentially by women entrepreneurs to ensure the development of their careers. It also expresses women's capacity to devise strategies for expressing their autonomy and satisfying some of their interests. The concept of structure is also required to uncover the reality of power inequalities and gender differences that are deeply embedded within organizational structures. This study did not seek to aggregate women's understandings, perceptions, and constructions of their careers into a single construct. It attempted to present the full range and variety of experiences (Guba \& Lincoln, 1994).

\section{Feminist Theory}

A feminist lens was used to focus on those salient features about gender relations and gender identity without reproducing patriarchal bias. This study sought to conceptualize the experiences of women entrepreneurs in Zimbabwe in the development of their careers from their standpoint. In seeking to understand the process of female entrepreneurship, it would have been inadequate to "add women" to the current understanding of entrepreneurship which fails to consider the realities of women's experiences in business, "and stir" (Green \& Cohen, 1995). A reformulation that considers the central tenet that women's lives are important was necessary. Accordingly, feminist standpoint epistemology was most appropriate.

Standpoint epistemologies have provided some of the most important challenges to the conventional view that true knowledge is objective, value-free, disinterested, and universal (Pels, 1996). Standpoint epistemologies take women's experience as a starting point for feminist and sociological discourse (New, 1998). Black feminist thought is comprised of ideas produced by black women that illuminate a standpoint of and for black women (Hill-Collins, 1990, 1991). Accordingly, three key assumptions underlie black feminist thought. First, while others may record black feminist thought, black women produce it. The second assumption is that black women have a unique standpoint that is different from other women. Third, universal themes included in black women's standpoint may be experienced and expressed differently as a result of diversity of class, region, age, and sexual orientation. By conveying new meaning to these core themes of black women's standpoint is extrapolated to African women. It is evident that African women's experiences with racial and gender oppression result in needs and problems 
quite distinct from white women, western women, and men. African women struggle for equality as women and as Africans.

Feminist standpoint epistemology as a lens was relevant to this study as it recognized the fact that women are diverse and socially positioned in other areas that affect their lives. Consequently, their ways of understanding their own situations and perspectives of the world are diverse (New, 1998). It is important to consider women's experiences as a beginning to gain knowledge of these understandings and perspectives. Feminist standpoint epistemology is a method of speaking that is not appropriated by the discourses of those in power (New, 1998).

Standpoint texts are organized in terms of several assumptions (Denzin, 1997). The starting point was the experiences of persons including women, persons of color, post-colonial writers, gays, lesbians, and others who had been excluded from the dominant discourses in the human disciplines. The experiences of African women entrepreneurs in post-colonial Zimbabwe were in the focus of this study. Standpoint epistemologies question the standpoint from which traditional, patriarchal social science had been constructed. Secondly, in standpoint epistemology, the categories that classify people are necessarily non-essentializing. Standpoint epistemologies attempt to discover new knowledge regarding how the world works in the lives of oppressed people. It also intends to recover and derive value to knowledge that has been suppressed by existing epistemologies. Denzin further noted that feminist standpoint epistemology begins with the subject who knows the "world directly through experience." The argument is that experience as the starting point for social change has the potential for empowerment.

This study sought to address the richness and complexities of entrepreneurship as part of a woman's life. In addition, the study also sought to give voice, make visible, place at the center, and challenge entrepreneurial career development models that are directly or indirectly influenced by dominant constructions of gender (Avis \& Nickerson, 1996). A feminist lens allowed the examination of the ways in which the colonial and post-colonial state impacted the development of women's entrepreneurial careers. From this perspective, the state ceases to be a neutral overseer of national affairs. Its actions are examined to determine complicity in the subordination of women through legislation and policies.

Williams (1991) contended that there was a tendency to decontextualize the subject matter by making categorical statements about men and women that obscure the experience of gender by different social groups and in various contexts. The criticism of western feminism focuses on the need to understand African women's problems and issues from their perspective rather than adding ethnocentric biases derived from the experiences of non-African women and their cultures (Gordon, 1996). In addition, there is a need to recognize the diverse ways African women perceive and deal with women's issues. Further, there is a need to incorporate these ways into the development programs and other reforms designed to help African 
women; rather than impose western strategies and solutions that are insensitive to cultural beliefs and practices.

\section{Research Design}

This study was designed to understand and explain the processes and mechanisms of the entrepreneurial career development of women in Zimbabwe from individual and institutional perspectives. It was intended to examine how layers of recurring themes and relationships among the various aspects of the careers of women entrepreneurs in Zimbabwe were manifested using naturalistic methods. The naturalistic inquirer operates under a set of assumptions different from the positivist inquirer concerning the nature of reality, epistemology, and generalizability (Lincoln $\&$ Guba, 1985). The intent is to develop shared constructions that illuminate a particular context and provide working hypotheses for the investigation of others (Erlandson, Harris, Skipper, \& Allen, 1993).

To illuminate the intricate and complex nature of women entrepreneurship, a multi-method research design incorporating interviews, observations, and case studies was used. The use of multiple methods or triangulation was an attempt to secure an in-depth understanding of the phenomenon in question (Fine, M., Weis, L., Wessen, S. \& Wong, L., 2000). It is impossible to capture objective reality in any study, especially in a qualitative study. The combination of multiple methods, empirical documents, perspectives, and observations in a single study was a strategy that added rigor, breadth, and depth to the investigation (Fine, M., Weis, L., Wessen, S. \& Wong, L., 2000). Case studies were used to collect data as the phenomenon under study was closely related to the context (Yin, 1993). Further, inclusion of context created a richness such that the study could not rely on a single data set. Case study as a method is especially suited to capturing the phenomenon of "experiential descriptions," by studying the uniqueness of the particular, an understanding of the universal is developed (Elliot, 1990; Simons, 1996). Elliot (1990) described this phenomenon as the paradox of the case study.

\section{Research Questions}

The following research questions regarding women entrepreneurs in small and medium enterprises in Zimbabwe were posited:

1. Who is a woman entrepreneur in Zimbabwe?

2. What are the mechanisms and processes experienced by, and resources available to, women in developing entrepreneurial careers?

3. What is the role of the colonial and post-colonial states in Zimbabwe in the development of women entrepreneurs in Zimbabwe? 


\section{Data Sources}

The identification and selection of participants was a difficult task because entrepreneurs were completely self-managed. Since many women entrepreneurs were not accountable to any particular organization or authority, obtaining their consent for interviews was not easy. At this stage, the purpose was to conduct as many interviews as possible to allow a representative selection of participants for case study. During this phase, various government, non-government, and private establishments that impacted the development of entrepreneurial careers were visited. Women were selected based on uniqueness of enterprise, educational background, turnover, and willingness to participate in the study. This allowed for a cross-section of the various enterprises.

\section{Setting and Selection of Participants}

The site of this study was urban Zimbabwe, located in the two largest cities of Harare and Bulawayo. Zimbabwe, a former British colony is located in southern Africa. It shares boarders with South Africa to the south, Mozambique to the east, Zambia to the north, and Botswana to the southwest. It is completely landlocked

Purposive sampling was used to identify and choose participants for the study. Purposive sampling permitted a selection of informants that would provide rich detail of the phenomenon. The sampling procedure deliberately sought both the typical and the divergent data that the emergent insights suggested was relevant to the study. Purposive and directed sampling through human instrumentation increased the range of data and maximized the researcher's ability to identify emerging themes that adequately accounted for contextual conditions and cultural norms (Erlandson, Harris, Skipper, \& Allen, 1993). Three participants were selected for detailed case studies. Participants were studied in their natural settings enabling the researcher to ground observations and concepts. Career and life histories were obtained during unstructured interviews. Women entrepreneurs were asked to explain their primary and secondary reasons or motivations for entering business.

\section{Data Collection}

The interviews explored the perceptions of the women about their work; their skills, families, social and business networks; and identified barriers they had encountered in their entrepreneurial carriers and plans for the future. Each interview was uniquely different. No attempt was made to maintain any position of privilege. There was no need to attempt power sharing; subjects were made to feel like they held all the power. They could choose to speak, not to answer some questions, and terminate the interview at any point. Burgess-Limerick (1993) noted that the relationship between interviewer and interviewee creates a unique bond. Interviewing the subjects allowed for the exploration of a range of emotions, which were not always possible to predict. 


\section{Data Analysis}

The data obtained developed a solid basis for identifying patterns, themes, and concepts (Miles \& Huberman, 1994). An inclusive approach to the cases was used as the study sought to capture women entrepreneurs as they experienced their natural, everyday circumstances and offered the researcher understandings in larger social contexts of actors, actions, and motives. The case studies were analyzed initially using case analysis. Case analysis entailed organizing the data by specific cases for in-depth study. This involved immersion in the cases and thorough reading. After immersion in the data, each case was organized. After the case data had been accumulated from the interviews, observations, and documents, case records were compiled by narration.

Case records were compared with each other using cross-case analysis. Crosscase analysis expanded understanding and explanation. Various interpretations within and across cases were compared and contrasted. This entailed comparing themes, metaphors, and explanatory stories across cases. Comparing interpretations led to new insights into the cases. Common patterns across cases coalesced into a grounded theory of the subject (Rossman, 1993). The use of cross-case analysis enhanced the description of data to generate theory by extending beyond just one specific case.

Themes were at a conceptual level of analysis and evolved from systematic reflection on and interpretation of narrative data (Wilson \& Hutchinson, 1991). Patterns and themes common to the cases of the women entrepreneurs were allowed to emerge from the categories developed. The challenge was to develop interpretations sufficiently general and comparable to the other cases, yet grounded in the details of the specific case. Locating themes that transcended cases through the use of inductive coding permitted the identification of recurring themes. The constant comparative method (Glaser \& Strauss, 1967) allowed for the inductive search of emergent patterns, convergences, and divergences in the cases which was guided by the research questions, and conceptual framework (Patton, 1990).

\section{Findings}

Case studies were conducted and detailed accounts of the entrepreneurial careers of three women in Zimbabwe were obtained to answer research questions 1 and 2. Field notes, audiotapes, and other secondary sources including newspapers and magazine articles were used to obtain an understanding of the woman entrepreneur. The accounts of three participants followed a general pattern of a vision in venture creation. The impetus for developing vision was derived either from negative experiences such as being laid off, or positive experiences such as promotion that inspired and motivated self-employment. 


\section{Case Study 1: Angela - Interior Design Company}

Angela owned Interior Design Company (IDC). The company was operated as a loose partnership with a sister-in-law. The main activities of the company were soft furnishings, carpeting, tiling, and upholstering. The company also dealt with upholstery, furniture supply, and exclusive garment making. The IDC was the first and only distributor of pinch pleat drapery in Zimbabwe and the second manufacturer of pinch-pleated drapes in Southern Africa. Major markets for the company were homes, corporate offices, and hotels. The main processes at the company factory, located in downtown Harare, were design, cutting, and sewing.

The company had a range of machinery, but the production system was not automatic. There were no automated production machines. The company had some computers for accounting and other activities. It had a retail outlet on the same premises as the factory. The company made and sold soft furnishings and ethnic African women's clothing. The company had high-tech equipment with excellent labor relations. The administrative manager rated the products average since some products had previously been returned for poor workmanship. She also considered their product inspection methods as average. In terms of profitability and working capital, she considered them above average. The company stated as a major problem was collection of debt.

Born and raised in an African township in Harare, Angela had impressive academic achievements. She held a B.A. degree from a university in the United Kingdom and a M.A. degree from Sweden. She was now studying for a Ph.D. in enterprise development. The experience she gained in transforming her company from a backyard business into a successful enterprise, despite the numerous obstacles, had been helpful in dealing with the problems and challenges. The IDC had 18 employees and was recognized as one of the country's top emerging industries. Angela had been successful, in part, because of perseverance and her ability to analyze a situation or problem and transform it into a business opportunity. "I look at every problem with a different eye from others. Where some people see a hurdle, I see a business opportunity. I find a way of turning a situation into a business opportunity... I have done that on many occasions," she said.

Through hard work and ingenuity, Angela was able to establish her interior design and décor firm. The company she started as a cottage industry in 1991 had grown into a fully fledged business with an impressive clientele. It had taken a lot of patience and perseverance for her to get where she was today. As a mother of four, she had to make many sacrifices. Angela considered herself aggressive with a vision. She was innovative and had the ability to transform obstacles or problems into business opportunities. Angela became Africa's first certified window fashions professional. The Window Fashions Certified Professional designation indicated to her customers and industry peers that she was a professional, committed to the highest levels of accomplishment and knowledge in the window treatment industry. The IDC was also highly rated internationally. She was able to expand her company 
very rapidly. "The challenge for us now is putting in new systems since the business is growing," she asserted (Ncube, 1997).

\section{Case Study 2: Evelyn-Women Building Contractors}

Zimbabwean women were increasingly entering into business sectors formerly regarded as male domains. But as many will note, it was not easy, as determination and the will to succeed were vital. Evelyn fought great odds, venturing into the construction industry. Evelyn, who owned a construction company in Harare's neighboring city of Chitungwiza, admitted that it was not all-smooth sailing. She encountered a number of problems, which included delays in registering her company with the Zimbabwe Building Contractors' Association. The association was skeptical of a woman seeking to assert herself in the construction business. However, when her company was finally registered, she met a lot of resistance in the competitive male-dominated industry where it was the survival of the fittest.

The former volunteer worker owned Women Building Contractors (WBC). Despite numerous problems encountered during the initial stages of establishing the company, WBC was well established and competed with major contractors for tenders. Some of the successful construction projects were 20 houses in a highdensity suburb of Harare and a contract with an insurance company, which experienced the construction of several houses in low-density suburbs. The company also successfully completed another project of 50 houses in another high-density suburb in Harare.

In the early 1980's, Evelyn had worked as a volunteer with the Boy Scouts in the Chitungwiza schools. In 1983, she was among the volunteers chosen by the Swedish Scouts Association to receive training as bricklayers. They were trained onthe-job building Blair toilets (brick pit-latrines) in Epworth, a high-density suburb near Harare. Upon completion of the three-year project, she was certified as a bricklayer. Once the project was over, she found it was very difficult to find formal employment. "As a woman, it was difficult to secure formal employment and I began doing 'self-help jobs' on a small scale in the suburb," she said. With a few jobs to her credit, she was able to secure employment in the then Ministry of Public Construction and National Housing as a bricklayer and worked there for six years before being retrenched.

By the time Evelyn was retrenched, she had already carried out a market survey and had started making plans to venture into private business. Her employment severance package was not enough to procure the needed equipment so she sought financial assistance, a futile exercise. "I got no joy from financial institutions. The question that I was being asked suggested to me that the officers had no faith in me simply because I was a woman. I almost gave up had it not been the encouragement I got from my husband." Later, she approached the Social Dimensions Fund (a government social security fund) and obtained $Z \$ 80,000$ which 
she used to buy basic equipment and to secure offices. With hard work and determination, her company flourished and employed 18 people including five women. Evelyn and her husband performed all the office work and trained staff.

Reflecting on 1992, Evelyn recalled the problems and resistance she encountered. She had proved that she could, indeed, compete in the construction industry. She remarked, "I feel I was not designed for anything other than building. I love my job because I understand it, and, mind you, building is not done by someone who needs a push from somebody [else]." Among major projects she had completed was the construction of several houses in Harare's suburbs of Budiriro, Msasa Park, Waterfalls, and Warren Park. She said that even today, men still do not believe a woman could own and operate a construction company. Some were not happy with her leadership position and threatened to quit after realizing she was in charge. Such attitudes did not bother her much since employees were quick to realize her capabilities.

Evelyn believed that the time had come for Zimbabwean women entrepreneurs to prove to the nation that they had an important role to play in the economic development of the country. She believed that nothing should be reserved for a particular gender because individuals had their own talents.

\section{Case Study 3: Katherine - Kathy Products}

Katherine was well known throughout Zimbabwe. She owned Kathy Products and manufactured cosmetic products. A tough hard-working woman, she was also known for helping to change the Zimbabwean people's attitudes toward women entrepreneurs. In the 1990's, she campaigned for the indigenization of businesses.

Katherine experienced all the frustrations of being discriminated against as a black woman through racism and patriarchal attitudes. The experience molded her into a very determined campaigner for women's rights. Her experience in business taught her that women could do as well or even better than their male counterparts if afforded the opportunity. Her inspiration to start her business came from the plight of black people yearning to have cosmetics appropriate for their skin type. Katherine then started manufacturing skin products from her backyard, unaware that her products would become a regional phenomenon (Saburi, 1996). While living in Europe, she adjusted to the temperate climate, but upon returning to Zimbabwe in the late 1970's, she found the Southern African climate extremely dry and hot. All her cosmetics became unsuitable for the environment. As a model and actress, she chose not to gamble with cosmetics and developed an enterprising idea to make black cosmetics.

In 1978, Katherine opened a hairdressing salon at a local shopping center, using the small savings from her salary as a nurse and $\mathrm{Z} \$ 2,000$ borrowed from her father. A hairdressing salon was not enough to satisfy an ambitious woman with a keen interest in the small-scale manufacturing of cosmetics for African women. The 
popularity she had gained while featuring in movies and television in London led to her fame. During her three-year stint in the London film industry, Katherine had performed with world-renowned actors. Katherine began to experiment with the small-scale production of cosmetics for African women with the help of a pharmacist. At the time, she was operating from her Waterfalls (a suburb of Harare) home. During the same year, she diversified and opened a boutique in downtown, Harare. Unfortunately, this venture did not succeed. Katherine thought that she did not have the skills required to operate a boutique. She abandoned the venture and returned to black cosmetics. Working from her kitchen, it soon became too small to accommodate large orders placed by retailers. In 1980, she formed a joint venture with another woman, contributing Z $\$ 5000$ each and a car to start a factory.

This marked the beginning of Kathy Products. The business did so well that in 1984, Katherine won the Businesswoman of the Year Award from a local chamber of commerce. In 1987, her partner withdrew from the joint venture. Her businesses employed 184 people specializing in hair and skin care. Exports gained acceptance in regional countries such as Tanzania, Malawi, Mozambique, and Zambia.

Joining the male-dominated business world was not easy for Katherine at the time since there was much debate regarding the role of women in society. She often confronted uncompromising attitudes from many men and sometimes women. People would close doors in her face just for being a woman in business. However, this did not deter her as each time the door was closed she knocked even louder. She fought patriarchal, traditional beliefs and misconceptions about women participating in the mainstream of the economy. Katherine maintained that much needed to be done to change people's attitudes. She suggested that the first step would be to begin by having parents educate their boys to respect girls and for girls to believe in themselves.

Katherine was a very hard-working woman and won recognition for her sterling efforts. A passionate fighter for women's rights, she was a pioneer of the Indigenous Business Women Organization and was elected secretary general of the organization. During the same year, she was appointed to a development corporation board. She was appointed as a trustee of a children's foundation. She had been a board member of other development organizations.

Katherine said she planned to open two more businesses outside Zimbabwe that would specialize in the production of cosmetics. In addition, she would use her strength and influence to mobilize and raise awareness among women who wanted to enter into business. Financial problems were also major issues facing women entrepreneurs. Katherine said she had survived by utilizing profits earned from her external operations to finance the Zimbabwean business.

Although she had managed to establish a large venture using her meager resources, she said the government should introduce incentives to encourage the formation of more businesses. Vast commitments in business had forced her to abandon modeling and acting, however, she remained involved in the film industry. 
She left a mark with her successful production of a $Z \$ 2,5$ million feature film. She was married with two children. "I had all the support from my family." Katherine had now expanded her business to the south of Zimbabwe in Johannesburg, South Africa and Gaborone, Botswana.

\section{Case Analyses}

\section{Categorization and Narrative Composition}

Events considered as important in the entrepreneurial career development process were identified and summarized. Events were then categorized and used to clarify the chronology for each of the three cases. Accounts were compared with regard to how categories were ordered chronologically, their roles or significance of in the story, and the relationships of the categories with each other. In this way, different patterns or plots were identified (Miles \& Huberman, 1994). Categories were grouped into themes, a commonality that possesses both descriptive content and evaluative significance within a story, focusing on the events and outcomes. The analytic emphasis of categorization requires a complementary analysis, synthesis, and interrelation within a whole narrative (Rossman, 1993).

Angela reported a number of incidents and events associated with the establishment and operation of her business. She met many challenges and problems which she was able to overcome through perseverance. She attributed success to her mother and family support.

Katherine's narrative revolved around the sense of challenging and placing herself in new and demanding situations. The narrative was one in which she transitioned from being a nurse to a self- employed hairdresser, to a backyard manufacturer, and finally to a full-scale cosmetic manufacturer.

Evelyn was a contrast with the other two women. Evelyn was not highly educated and chose an entrepreneurial career in a field non-traditional to women. Her business developed from being laid off and experiencing difficulty finding employment as a female builder. All the women had strong political connections. Participants manifested eight common themes in the development of their entrepreneurial careers (see Table 2).

\section{Themes}

1. Vision. The development of an entrepreneurial career started with an idea that was developed into a vision. The woman entrepreneur was able to see into the future what many others did not see, she had vision. The vision motivated her to create a new venture. Women mentioned that they always desired to own their own business, be independent, and earn more money.

Angela's vision was the introduction of pinch pleat into the Zimbabwean market. The IDC firm was the only factory in the country producing pinch-pleat 
Table 2

Case Analyses: Development of Themes of an Entrepreneurial Career

\begin{tabular}{|c|c|c|c|}
\hline Themes and Categories & Case 1: Angela & Case 2: Evelyn & Case 3: Katherine \\
\hline \multicolumn{4}{|c|}{ 1. Vision in Venture Creation } \\
\hline Idea/Innovation & Pinch pleat drapes & $\begin{array}{l}\text { Woman building } \\
\text { constructor }\end{array}$ & Afro-cosmetics \\
\hline Motivation & Independence & Retrenchment & Independence \\
\hline Risk-taking & New product & $\begin{array}{l}\text { Non-traditional } \\
\text { career }\end{array}$ & New product \\
\hline $\begin{array}{l}\text { 2. Opportunity } \\
\text { Initiative, exploration, } \\
\text { and information- } \\
\text { seeking }\end{array}$ & $\begin{array}{l}\text { Consult with experts } \\
\text { and investigations }\end{array}$ & market research & Market research \\
\hline \multicolumn{4}{|l|}{ 3. Self-concept } \\
\hline $\begin{array}{l}\text { Independence/Need for } \\
\text { power }\end{array}$ & Aggressive & Self-motivated & Hard-working \\
\hline Need for achievement & Perseverance & Dedication & Determination \\
\hline Creativity & Innovative & Inspired & Resourceful \\
\hline Gender consciousness & $\begin{array}{l}\text { Awareness of } \\
\text { women's issues }\end{array}$ & $\begin{array}{l}\text { Belief in women's } \\
\text { capabilities and } \\
\text { membership in } \\
\text { women's } \\
\text { organizations }\end{array}$ & $\begin{array}{l}\text { Women's right } \\
\text { campaigner and } \\
\text { membership in } \\
\text { women's } \\
\text { organizations }\end{array}$ \\
\hline $\begin{array}{l}\text { Coping ability, } \\
\text { frustration tolerance, } \\
\text { and stress management }\end{array}$ & Adaptability & Tolerance & Flexibility \\
\hline \multicolumn{4}{|c|}{ 4. Acquisition and Construction of Skill } \\
\hline Managerial capability & $\begin{array}{l}\text { Acquisition of } \\
\text { technology }\end{array}$ & Diverse workforce & Large workforce \\
\hline Entrepreneurial spirit & $\begin{array}{l}\text { Certified } \\
\text { professional }\end{array}$ & Use of acquired skill & $\begin{array}{l}\text { Application of life } \\
\text { experiences }\end{array}$ \\
\hline Analytical ability & $\begin{array}{l}\text { Perception of } \\
\text { opportunity }\end{array}$ & $\begin{array}{l}\text { Market research prior } \\
\text { to business venture }\end{array}$ & $\begin{array}{l}\text { Development of } \\
\text { culturally appropriate } \\
\text { product }\end{array}$ \\
\hline Communication skills & College level & Primary level & College level \\
\hline Interpersonal skills & $\begin{array}{l}\text { Excellent relations } \\
\text { with employees }\end{array}$ & $\begin{array}{l}\text { Ability to retain male } \\
\text { employees }\end{array}$ & $\begin{array}{l}\text { High employee } \\
\text { retention rate }\end{array}$ \\
\hline Technical skills & Constructed & Acquired & Constructed \\
\hline \multicolumn{4}{|c|}{ 5. Challenges and Adversity } \\
\hline Capitalization & Under-capitalized & Under-capitalized & Under-capitalized \\
\hline $\begin{array}{l}\text { Source of start-up } \\
\text { capital }\end{array}$ & Savings & Savings and loan & Savings \\
\hline $\begin{array}{l}\text { Perception of } \\
\text { difficulties }\end{array}$ & $\begin{array}{l}\text { Work-home mesh, } \\
\text { macro-economic } \\
\text { environment: ESAP } \\
\text { physical facilities } \\
\text { and technology }\end{array}$ & Patriarchal attitudes & $\begin{array}{l}\text { Macro-economic } \\
\text { environment - ESAP, } \\
\text { patriarchal attitudes }\end{array}$ \\
\hline
\end{tabular}

Table 2 con'd 


\begin{tabular}{|c|c|c|c|}
\hline Themes and Categories & Case 1: Angela & Case 2: Evelyn & Case 3: Katherine \\
\hline \multicolumn{4}{|l|}{ 6. Survival } \\
\hline Technology acquisition & $\begin{array}{l}\text { High tech } \\
\text { equipment }\end{array}$ & $\begin{array}{l}\text { Appropriate } \\
\text { technology }\end{array}$ & High tech equipment \\
\hline $\begin{array}{l}\text { Resourcefulness/sense } \\
\text { of agency }\end{array}$ & $\begin{array}{l}\text { Problem solving } \\
\text { skills }\end{array}$ & Showed initiative & Showed initiative \\
\hline Division of Labor & 18 employees & 18 employees & 184 employees \\
\hline \multicolumn{4}{|l|}{ 7. Networks } \\
\hline Social & Family and friends & Family and friends & Family and friends \\
\hline \multirow[t]{3}{*}{ Business } & Confederation of & Building & Secretary general- \\
\hline & Zimbabwean & Construction & Indigenous Business \\
\hline & $\begin{array}{l}\text { Industries (CZI), } \\
\text { Zimbabwe National } \\
\text { Chamber of } \\
\text { Commerce (ZNCC), } \\
\text { Bank }\end{array}$ & Association member & $\begin{array}{l}\text { Women Organisation } \\
\text { (IBWO), Million- } \\
\text { Dollar Round-Table, } \\
\text { CZI, ZNCC }\end{array}$ \\
\hline Political & $\begin{array}{l}\text { Ruling party } \\
\text { member }\end{array}$ & Ruling party member & Ruling party member \\
\hline \multicolumn{4}{|c|}{ 8. Growth and Expansion } \\
\hline $\begin{array}{l}\text { Hopeful about the } \\
\text { future }\end{array}$ & $\begin{array}{l}\text { Acquiring more } \\
\text { technology }\end{array}$ & Expanding & Continued expansion \\
\hline Long-term planning & $\begin{array}{l}\text { Plans to build a } \\
\text { factory }\end{array}$ & $\begin{array}{l}\text { Secure bigger } \\
\text { government tenders }\end{array}$ & Expand in sub-region \\
\hline Recognition & $\begin{array}{l}\text { Business Woman of } \\
\text { the Year, 1994, } \\
\text { 1998. Newspaper } \\
\text { articles }\end{array}$ & Newspaper articles & $\begin{array}{l}\text { Business Woman of } \\
\text { the Year, 1984, } \\
\text { Newspaper articles }\end{array}$ \\
\hline
\end{tabular}

drapes. Angela capitalized on an idea to start a business and capture a niche in the market. Evelyn ventured into the construction industry, and although this was a maledominated field, she envisioned possibilities for herself. Katherine entered cosmetics manufacturing with the vision of making products specifically targeted for black people.

2. Opportunity. Participants shaped circumstances in a favorable way or received the benefit of circumstances being shaped by others. For Angela, her opportunity emerged because she was able to obtain the required capital through the banks and donor aid. For Evelyn, the opportunity came when she was among Boy Scout leaders who were chosen to train as bricklayers overseas. Katherine had adequate savings to start a partnership with someone who had the knowledge and skills to manufacture cosmetics.

3. Self-Concept and Self-fulfillment. All women were very much aware of the patriarchal attitudes that prevailed in Zimbabwean culture. They had a strong need for independence and achievement. Angela described herself as aggressive. She had the vision to create a venture. She succeeded in the face of much adversity. She was adaptable and able to tolerate high levels of frustration. Evelyn was self- 
motivated and very dedicated to her work. Katherine was hard working and prevailed because of her determination. Her business was very successful and had expanded to the sub-region.

The experience of being an entrepreneur was voiced in terms of selffulfillment and agency, the capacity to respond to social constraints proactively. Angela who operated an interior design firm stated, "For me, there is no looking back. The sky is the limit and I am going to do everything within my means to ensure that my business grows and that we women take a greater active part in economic development." Independence, flexibility, and a sense of self are other ways in which they spoke about the impacts of their experiences in entrepreneurship. Evelyn identified with her occupation and said, "Generally women hesitate... some are not willing to put on overalls so it needs someone with a 'so-what' attitude. Dirt or no dirt, I love my job."

4. Acquisition and Construction of Skills. How individuals constructed and perceived skill became an important determinant of the abilities they believed that they possessed to perform certain tasks and jobs. Through attending training courses, volunteering, previous work experiences, and market research, participants engaged in various activities that allowed them not only to acquire skills but also to construct reality. Reality construction ranged from gaining an understanding of general economic conditions to learning about particular lines of work. In situations where women entrepreneurs had not acquired the required skills through training or previous experiences, they constructed these skills. Participants used skills acquired in previous experiences to construct new and required skills. For example, a woman entrepreneur may never have been in a managerial position, but to operate an enterprise, she required managerial skills. The entrepreneur, in such cases, would create a new repertoire of skills to accomplish the work.

Angela had B.A. and M.A. degrees and was currently working toward a Ph.D. From her educational background, she had accumulated skills and was able to transfer them to operating a business. Although Angela did not have the specific training and technological background in her chosen venture, she had a large enough repertoire of skills that gave her the confidence and belief that she would be able to successfully operate a soft furnishings venture using new technology. Evelyn, who only completed junior high school, compensated for her limited educational background by obtaining training as a bricklayer.

5. Challenges and Adversity. In the creation of a new venture, women entrepreneurs faced many challenges and much adversity in the forms of competitors, distracters, and patriarchal attitudes. Women entrepreneurs were confronted with all the growth problems that their male counterparts did and more including dealing with problems related to family, education, gender discrimination, lack of extensive networks. Sexton (1989) argued that all of these problems impacted on the women's personalities and their abilities to manage or expand their businesses. All of the women faced a lot of problems with under-capitalization. Banks would not initially 
approve loans to start their enterprises. They also encountered problems acquiring facilities. The macro-economic environment was deteriorating which made it very difficult for the women to profitably operate their businesses.

Angela had many problems early in establishing her venture. She had difficulty securing the necessary premises and capital. However, she persevered through determination and having the confidence that she would prevail. Evelyn had a difficult time breaking into the male-dominated field. She endured patriarchal attitudes that opposed and discouraged her from operating a building construction enterprise. Through resilience, she was able to survive. Katherine had also faced problems with patriarchal attitudes.

6. Survival. The survival of an enterprise depended on many factors. General ability was required for the successful operation of the business. Education and the skills acquired composed much of general ability. Specialized ability involved knowledge of a specific trade and leadership skills. Woman's agency, the ability to improvise and innovate in the face of adversity was a required characteristic of women entrepreneurs.

Creative ways of solving problems were required of women entrepreneurs to survive the challenges and adversity. They acquired the necessary technology and hired the required employees. They needed to have perseverance, determination, and resilience. Perseverance implied the will to continue in the enterprise in spite of obstacles, opposition, or discouragement. Determination was the resolve to prevail in the venture. Resilience was a set of attributes providing people with the strength and fortitude to confront overwhelming obstacles (Sagor, 1996).

7. Networks. Personal networks consisted of all those persons with whom a woman entrepreneur had direct or indirect contacts. These included partners, suppliers, customers, bankers, creditors, distributors, association memberships, family members, and friends. Participants had personal networks that facilitated opportunities, resources, capitalization, and venture creation. People in their networks provided support in the forms of encouragement, advice, information, and approval.

Networks were an effective means of broadening the management skills and access to resources for women entrepreneurs. Aldrich (1989) noted that direct ties between an entrepreneur and contacts were important for the indirect access to resources they provided. Indirect ties enabled entrepreneurs to further increase their access to information and resources; thereby, enhancing what was available through their direct ties.

The personal networks of women entrepreneurs and their positions in larger social networks had a significant impact on women's access to information and advice, resources, and social support. It has been indicated that women generally inhabited a "female world" in which they deal mainly with other women on women's issues, generally in the private domain. This female world only partially overlapped 
the "male world" which was the public world of government, business, commerce, and other arenas. The extent and diversity of women's networks were limited in many important regions of social life by divisions and barriers (Aldrich, 1989). Women lacked extensive networks.

Angela had a well-extended support network. She had her immediate and extended family support and operated the venture with a sister-in-law. In recognition of businesswomen's efforts, a local bank in Zimbabwe annually awarded the "Business Woman of the Year" trophy. Angela was awarded the prestigious "Business Woman of the Year" trophy twice. The First Lady of Zimbabwe also commissioned her enterprise in recognition of her business skills. In addition, Katherine won the coveted "Business Woman of the Year" trophy in 1984. Evelyn's personal network was well extended within the community she lived. She was a wellknown and respected woman. She had strong political, legal, and business connections.

8. Growth and Expansion. After their businesses were established and successful, women entrepreneurs developed long term plans to expand their businesses. Sexton (1989) noted that growth was neither good nor bad. It may be a measure of success to some but not to others. Lack of growth should not be viewed as failure, especially when applied to women-owned businesses. Growth should be viewed as the result of a choice made by the entrepreneur.

Women entrepreneurs in Zimbabwe were severely limited by the effects of the macro-economic environment. Both the ESAP and ZIMPREST have had very negative impacts on the Zimbabwean economy as a result of liberalizations, globalization, reduction of budget and fiscal deficits through reductions in social spending in education and health, and devaluation of the national currency. Evidence suggested that women and children were the most susceptible to the effects of drastic reductions in social spending (Ghosh, 1996).

\section{Conclusions}

The purpose of the study was not to generalize to the population of entrepreneurs but rather for exploration, model building, and theory development. An objective of the study was to use a phenomenological perspective to elicit a unique image while examining the entrepreneurial careers of women. By using a life-course approach to women's entrepreneurial careers, the role of social constraints in shaping women's capacity and agency for commitment to entrepreneurial careers is recognized (Carroll \& Mosakowski, 1987). Such constraints include patriarchal and traditional attitudes toward women and the household responsibilities as wife and mother.

This hermeneutic study suggested that the entrepreneurial careers of Zimbabwean women were very complex and varied. The overall picture of women's entrepreneurial careers that emerged was more complex than has been commonly 
presented. Women entrepreneurs were not a homogenous group in terms of their backgrounds, motivations, challenges, adversity, survival, and growth strategies. There was no single profile that described a Zimbabwean woman entrepreneur. The experience of Zimbabwean women entrepreneurs was unique in terms of historicity, culture, abilities, and the impact of contextual factors such as structural adjustment programs. It was evident from the findings that women entrepreneurs accumulated different forms of capital over time

Women in the study implied that entrepreneurship was an improvement over previous occupations and roles. Entrepreneurship allowed women in the study to find a better place in the social order; virtually all of them constructed its meaning in positive terms (Young \& Richards, 1987). However, their careers were interwoven with other aspects of their lives in complex ways. The interaction of private and public responsibilities and roles was evident.

Due to the small size of their ventures, women entrepreneurs were often engaged in the full range of activities of the enterprises with their employees rather than specializing in management and administration. Women's agency (personal autonomy) played a critical role in the development of their careers. They did not always have the necessary management and technical skills that would have enabled them to access finance and operate their businesses efficiently. However, they had the agency to develop innovative ways of overcoming their skill limitations. Acquisition of required skills through training and the construction of new skills was one such mechanism women used to overcome their skill deficiencies.

Major constraints to expanding the small and medium enterprises sector appeared to be a lack of capital, infrastructure, and relevant skills in operating a business. Unavailability of and difficulties in obtaining finance were, in part, responsible for the limited technology in the WSME sector. Another reason for the limited technology in the WSMEs was a lack of knowledge and information about new and available technologies that could enhance productivity within the WSME sector.

Technology is generally regarded as a key element in competitiveness. The acquisition of technology in the WSMEs was limited. A World Bank study indicated that SMEs in Zimbabwe were less active in investing in new productive technology than large firms (Biggs, Shah, \& Srivastava, 1997). Further, evidence suggested that the SMEs were less innovative and less technologically capable than larger enterprises. This inadequate acquisition of technology in the WMSEs had a negative impact on productivity and the extent to which the WMSEs were able to compete in the domestic and international markets.

Women's subjugation and oppression appeared to act as barriers to the development of women's entrepreneurial careers in Zimbabwe. Women were oppressed and subordinated through the cultural and socio-economic organizational structures. Patriarchy was the embodiment of capitalism, traditional culture, and Christianity. These forces worked together in the subjugation of women. Women 
entrepreneur's oppression and subordination was both subtle and overt. It was subtle when women entrepreneurs were denied loans and other forms of support. It was overt in the negative attitudes of society in general and men in particular, especially toward non-traditional women's enterprises. Although Goffee and Scase (1983) suggested that venture creation may be a response to labor market and/or domestic subordination and did not provide women with an easy path to self-determination; in the case of Zimbabwean women entrepreneurs, it provided a possibility of overcoming structural power inequalities and gender differences entrenched in society.

\section{Entrepreneurial Career Development Model}

Findings of the study and Bourdieu's (1986) theory of capital were used to develop the career development model for women entrepreneurs. The descriptions provided by the women in regard to their experiences as entrepreneurs included the accumulation of different forms of capital. Accumulation of capital allowed for the development of an entrepreneurial vision and venture creation. The creation of an entrepreneurial venture had certain outcomes that were not limited to monetary or material gain (economic power) but also immaterial gain including social class (social power), skills, and experience (cultural including political) power. Figure 1 provides a framework for examining how the careers of women entrepreneurs develop over time.

Economic Capital. Economic capital played a crucial role in the establishment of a new venture. Most women entrepreneurs had start-up problems due to a lack of economic capital. During the early stages of their careers, women entrepreneurs accumulated limited economic capital. Most of the women came from middle class working families whose incomes were limited by the type of employment. However, once they started their ventures, they were able to accumulate a sizeable amount of economic capital.

Social Capital. The establishment of social networks was important in building an entrepreneurial career. Social networks included business, social, political, and religious associations. Social associations also included a woman entrepreneur's family and friends. These networks provided access to capital, connections, socio-economic status, and the education and training of an individual. The education and training impacted the work history. The kinds of employment and positions an individual was able to obtain were typically related to their education and training. All forms of capital combined with contextual attributes had a direct impact on the economic and social outcomes of entrepreneurs.

Gender identity was an important aspect in the entrepreneurial careers of women. The various stages of career development were an affirmation of the gender identity process that allowed them to mature as individuals and expand their independence. Gender identity became an effective opposition to patriarchy and 
Figure 1. Career development model for women entrepreneurs

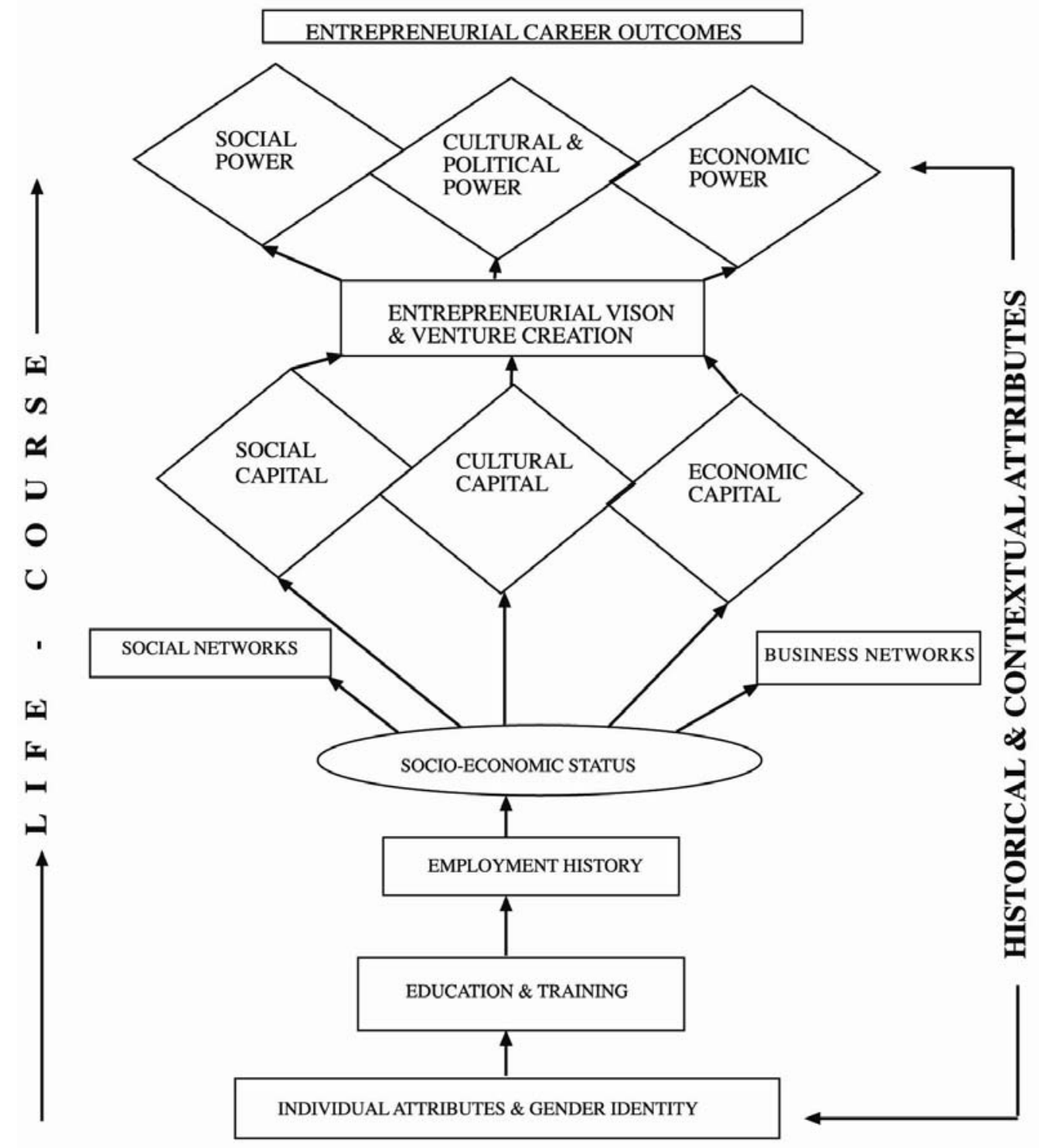


traditional structures. Zimbabwean women entrepreneurs were social actors who reestablished the balance of power in gender relations.

\section{Economic and Social Outcomes of Women's Entrepreneurial Careers}

The careers of entrepreneurial women had certain outcomes that contributed to their professional and personal development and the economic development of the nation by creating employment. The emergence of more women entrepreneurs and ventures into fields non-traditional to women appeared to be a positive force in changing gender relations within Zimbabwean society. Although women entrepreneurs were operating in a male-dominated economy, they were able to maintain independence from creditors, clients, and employees and the viability of their businesses without seriously jeopardizing their autonomy.

Women had agency and acted independently on the choices they made regarding their entrepreneurial careers. The sector trends in women's enterprise development suggested that women were creating businesses in fields where they were comfortable based on their experiences in education, training, employment, and the home. However, these trends concealed women's agency and the innovative elements that characterized many women enterprises. These included innovation in traditionally female occupations through the creation of a new product or service for a particular market, such as tourist lodges and the manufacture of original soft furnishings. Nevertheless, women's enterprises were not absent from either high technology fields such as advanced business and information system services or the male-dominated branches such as the construction trades.

Women often demonstrated agency and innovation in their approaches to entrepreneurship and working relations. They displayed creativity, flexibility, and a human and personal approach to business management. They focused attention on social and cultural goals, not merely financial ones, in the operation of their businesses. Many women spoke of employing the family members of their workers and providing housing and transportation. There was attention to the social needs of their employees.

An important outcome of entrepreneurial women's careers was the development of power with the creation of a venture. While economic gain was important, women entrepreneurs were motivated by the opportunity to be autonomous and independent. Women entrepreneurs were in control of their enterprises and valued being in decision-making positions. Although not all women enterprises were high income earners, the entrepreneurial environment in which women made decisions that impacted their lives and those of others afforded them immense power and personal gratification.

The relationship between entrepreneurial women and power was much wider than a direct connection of wealth and power as suggested by Folala (1995) in the case of Yoruba market women in Nigeria. However, unlike market women, women 
in small and medium enterprises did not remain in the periphery of the national economy. To begin with, the capital accumulated by women entrepreneurs was more than economic. They also accumulated cultural and social capital. These different forms of capital were translated into an acquisition and construction of power. The term 'empowerment' has been overused and appears to have lost definition. Rather than explain specific circumstances of women's "empowerment," it refers to any situation that seems to have a positive impact on women. Therefore, rather than use empowerment, sources and forms of power developed by women entrepreneurs are discussed.

The various strategies that women entrepreneurs developed in operating their enterprises enabled them to affirm their identity and expand their autonomy. Women entrepreneurs obtained legitimacy and credibility as proprietors and were able to move from the margins and become visible in society. The women became visible with the development of power from resources they had accumulated. They had economic power by virtue of being employers and contributing to the national economy. Social and cultural capital translated into political and social power through networks and contacts. The women had influence at both the political and social levels. Power brought with it responsibility, recognition, and respect from society. The power they acquired elevated the status of women entrepreneurs in society. They became effective agents of social change. Through their activities, they were changing power relations in society. Women entrepreneurs challenged the patriarchal norms of Zimbabwean society which culturally expected men to hold positions of power.

Entrepreneurial careers provided women with concrete ways of dealing with the power inequalities in Zimbabwean society. Most women entrepreneurs attained power and influence individually and corporately through businesswomen's organizations such as the Indigenous Business Women Organization, Women in Business, and Zimbabwe Women's Finance Trust. Through the development of viable business concepts into successful ventures, female entrepreneurs satisfied their professional and economic aspirations. Entrepreneurship was a viable route for Zimbabwean women to overcome economic and social subjugation and create social change through economic development.

Women's entrepreneurial careers provided outcomes that were fulfilling, satisfying, and tangible to the women. These careers allowed women to acquire, construct, and experience new skills and to explore the entrepreneurial process of creating and nurturing a new venture. This involved more than problem solving in a typical management position. Entrepreneurs had to identify, evaluate, and develop opportunities by overcoming many challenges and problems in their venture creations.

Women entrepreneurs were able to realize certain career aspirations including self-employment, venture creation, and the acquisition of technology. Before the start of their ventures, most women entrepreneurs did not have entrepreneurial skills. 
However, through the creation of a new venture, women entrepreneurs were able to acquire, develop, and construct skills that allowed them to effectively operate a small to medium enterprise. They developed basic business skills such as planning, bookkeeping, costing, production management, and marketing. Research has revealed that the character of work and skill in female dominated occupations is systematically obscured and understated (Butler \& Brown, 1993; Jackson, 1991). However, entrepreneurial careers assisted in the recognition of women's work, skills, and capabilities.

\section{Colonial and Post-colonial States in Women's Entrepreneurial Career Development}

Small and medium enterprises in Zimbabwe have played an important role in the development of the national economy in terms of increased employment and an improved gross domestic product. However, questions of continuity and discontinuity that have plagued the Zimbabwean nation were central in women's entrepreneurial careers. Gordon (1996) argued that the Zimbabwean post-colonial state continues to depend on foreign capital and this should be viewed as problematic not only in terms of the accumulation of foreign debt, but also as a lack of autonomy and a perpetuation of the colonial state. Similarly, the role played by the neo-colonial state in the creation and reproduction of systems that effect the subordination and exploitation of women should be confronted.

The colonial and post-colonial states have been complicit in the lack of development of women's entrepreneurial careers. As a newly independent nation, Zimbabwe had continued to operate under the same legislative measures inherited from the colonial government. Such legislation made it difficult for women to venture into entrepreneurship. Until the $1990 \mathrm{~s}$, there had been no culture of entrepreneurship among the indigenous women population. Women entrepreneurs in colonial Zimbabwe had been restricted to subsistence level micro-enterprises. In addition, the educational and training system in Zimbabwe did not prepare women for entrepreneurial careers. Therefore, it was not surprising to find that the majority of WSMEs had been in operation for a significantly short period of time, less than five years, even after almost twenty years of independence.

Since 1990, the government of Zimbabwe had embarked on an indigenization program to transfer local industry to the indigenous population and reduce the gap between large enterprises and the SMEs. However, the gap between the SMEs and large enterprises, particularly the productivity of added values, was quite large and there was no clear prospect for reducing the gap. While there had been some successful individual cases, by and large, indigenization had not been successful. The recent acceleration of inflation and interest rates and fall of the Zimbabwe dollar on the foreign exchange market, were manifestations of the impact of structural adjustment programs and poor performance of the country's macro-economy. These 
events have caused many difficulties for the management of the WSMEs. Inadequate and unavailable finances for the SMEs, especially the WSMEs, have resulted in financial management crises.

\section{Implications and Recommendations}

This study suggested the need for researchers interested in developing theory to examine the entrepreneurial careers of women from a broader perspective and to include women from developing countries. The use of phenomenology and lifecourse perspectives uncovered realities about women's entrepreneurial careers that have not been revealed by traditional approaches. Systematic analyses of the contexts and women's strategies and coping mechanisms can help to portray the trends in entrepreneurial careers and the nature of patriarchal systems operating in the culture. Such analyses dissolve some of the artificial divisions apparent in theoretical discussions of relationships among race, class, and gender since several levels of constraints shape the strategies of women entrepreneurs (Goffee \& Scase, 1983). These emerging trends clearly underscore the increasing importance of gaining insights into the nature and dynamics of women entrepreneurs careers. Implications for policy and research are, therefore, gleaned from the findings of the study.

This study had implications with respect to vocational theory specific to the entrepreneurial careers of women. The character of work and skills in traditional female occupations has been systematically obscured and understated by routine bureaucratic mechanisms of job definition (Jackson, 1991). The socio-cultural environment that women entrepreneurs participate reinforces the inequitable division of labor and gendered acquisition of skills. Recognition of women's skills in entrepreneurial ventures allows for the development of vocational theory that considers women's needs. Sverrisson (1994) noted that the main prerequisite for the successful and gradual acquisition of technology is vocational training and practical experience. Since technology assumes an important role in the development of women's enterprises, it is necessary that vocational training for women entrepreneurs should include technology training. Effective transfer technology to women's enterprises greatly enhances productivity.

The importance of career outcomes for women entrepreneurs is clear in the development of the national economy. However, women entrepreneurs have faced challenges and adversity that their male counterparts have not had to confront. Women were greatly influenced by what was occurring in their personal and family lives. Many women entrepreneurs had family members working in their businesses that frequently created overlapping and conflicting roles. They also lacked systematic structural support from the private and public sectors.

Multi-sector cooperation is needed to develop an environment within the country that is conducive to the development of WSMEs. This study, like most studies, had several limitations. The setting was urban Zimbabwe, while women 
entrepreneurs in rural areas were excluded from the study. Although the purpose of the study was not to generalize to other populations, insights gleaned from the rural population would have been useful in providing a more complete description of women entrepreneurs in Zimbabwe. In addition, there was no quantitative definition of SMEs in Zimbabwe. A lack of definition made it difficult to identify WSMEs on the micro-economic level. Therefore, it was challenging to target economic policies to a specific group of enterprises. Further, without a quantitative definition, it is somewhat problematic to replicate the study. However, these limitations were perceived as practical and did not necessarily constrain the methods, findings, and conclusions of the study.

Women entrepreneurs should be recognized as diverse and heterogeneous. Assistance programs targeting women should respond, accordingly. The needs of women entrepreneurs were varied and required distinct and often specialized skills, services, and information. For women entrepreneurs to succeed, policies should address their specific needs. Policy articulation in the MSE sector in Zimbabwe has been ill-conceived since it failed to address the specific needs of women. Legislation and policies that were inherited from the colonial state and placed women at a disadvantage should not be retained. An integrated approach that combines a number of strategies is necessary to create equity for women entrepreneurs.

Acknowledging their contribution to income and employment, many nongovernmental, donor, and government organizations have attempted to assist the MSE sector through increased access to credit and training (Daniels, 1998). However, these organizations have concentrated overwhelmingly in the development of micro-enterprises and on training women in traditional skills such as tailoring, embroidery, knitting, and food production. These organizations need to provide technical skills, information, and training in production management to enable them to advance into small and medium enterprises. The number of MSEs that had been assisted through these programs was limited. Only $0.4 \%$ of all MSEs in Zimbabwe received assistance from nine of the largest MSE assistance programs in 1993 (Daniels, 1998). Assistance for this sector needs to increase substantially if it is to have any significant impact.

Multi-agency cooperation among government and non-government organizations, industry, and commerce in the development of training programs of women is essential. Women require training in business administration and management, accounting, market research, business proposal preparation, and technical skills focused toward specific enterprise needs. They also require opportunities to train and upgrade their skills with continuing career guidance services. Technical and vocational training should be combined with basic business marketing and entrepreneurial skills. It is important that the training methods used be appropriate to the needs and constraints of women entrepreneurs.

Informal re-entry courses in continuing education are necessary for women entrepreneurs. Research had suggested that there was an inadequate provision of 
informal re-entry courses to ensure that women entrepreneurs can gain entry to a wide range of educational and training programs (Leach, 1996; Osirm, 1992). The main institutional barriers encountered by women entrepreneurs that must be addressed include:

- absence or inaccessibility of information and guidance opportunities,

- insufficient educational and training measures for women entrepreneurs, and

- inaccessibility of training due to cost, time, timing, suitability, and location.

Access to education and training for women is inadequate for increasing their participation in the labor market on equal terms with men (Leach, 1996). In many cases, training may not be as important as access to credit, whether through a sponsoring agency or through the banking system. Access to credit is rarely easy for women. A combination of factors including gender discrimination; lack of collateral, experiences, and skills; non-registration; and lack of licenses for operating enterprises restricted access to credit for women entrepreneurs.

A coordination of lending activities with the provision of support services to women entrepreneurs was crucial for a successful enterprise promotion strategy (Osirim, 1992). Local NGOs, government agencies, and domestic and international lenders can collaborate to establish comprehensive programs of business support for women entrepreneurs. Banks should be persuaded through awareness campaigns and government incentives to make financing more accessible to women. Approaching banks, accessing finance, and overcoming the problems of collateral for loan finance are crucial. Access and financing equipment and machinery is vital for the development of women's enterprises. The WSMEs in Zimbabwe have generally lacked modern technology which negatively impacts their productivity and efficiency levels. Viable projects should be encouraged with loans, technical assistance, and entrepreneurship training.

Although entrepreneurship has allowed women to break the "veil of invisibility," by and large, women entrepreneurs remain invisible. Mead and Liedholm (1998) suggested that MSE programs should be proactive and seek them out, exploring and assisting them to address their problems. Women-owned enterprises were concentrated in low-return activities where growth prospects were bleak. Further, particular attention should be focused on increasing the supply of working capital.

As an understanding of the relationships between the factors impacting entrepreneurial careers continues to emerge, practice should change to reflect the desired creation of new ventures by women and the implementation of effective strategies. Women entrepreneurs in Zimbabwe generally operated in areas traditional to women such as cosmetology, dressmaking, and food processing. Women will require assistance to enter into new areas of economic activity since they are likely to face hostility and resentment from men who perceive their livelihoods as threatened (Leach, 1996). 
A major barrier faced by women entrepreneurs in Zimbabwe is access to capital. Women entrepreneurs should develop viable business proposals, and an understanding of the requirements of financial institutions and criteria for obtaining loans. They also should proactively seek information to remain current in regard to policies and technological changes. Women entrepreneurs must fully realize the importance of skill acquisition and participate in continuing vocational education to become updated with respect to developments in the field. It is critical that current and future women entrepreneurs recognize the value of social and business networks as possible approaches to access capital. Women entrepreneurs must actively cultivate networks by becoming involved in business and women's organizations.

African women's participation in micro-enterprises is well documented (Horn, 1994; Folala, 1995, House-Midamba, 1995). However, there has been a paucity of research that focuses on the more economically productive small and medium women's enterprises. As more women become entrepreneurs, further research is needed to develop an understanding regarding how WSMEs emerge, survive, and flourish within adverse economic conditions. In addition, little work has been reported in career theory related to entrepreneurs (Dyer, 1994; Katz, 1994b). Career theory and research must better consider women and the processes involved in entrepreneurship.

A theory of entrepreneurial careers that employs a broad definition of careers to encompass these more complex roles and dynamics of women entrepreneurs and the process of entrepreneurship is necessary. Additional research is required in the area of sustainability and the development of women's enterprises in developing countries. Further research with respect to developing theoretical quantitative models that explain women's entrepreneurial careers is desirable. Explanatory factors such as accumulation of capital including economic, social, and cultural; and the development of power could be used. In addition, future naturalistic studies should further investigate the role of women's agency in the development of entrepreneurial careers. Organizational structures, power, and gender relations as they impact women's careers also require further investigation.

\section{References}

Aldrich, H. (1989). Networking among women entrepreneurs. In O. Hagan, C. Rivchun, \& D. Sexton (Eds.), Women-owned businesses (pp.103-132). New York: Praeger Publishers.

Anheier, H. K., Gerhards, J., \& Romo, F. P. (1995). Forms of capital and social structure in cultural fields: Examining Bourdieu's social topography. American Journal of Sociology, 100, 859-903.

Avis, J. M., \& Turner J. (1996). Feminist lenses in family therapy research: Gender, politics, and science. In D. H. Sprenkle \& S.M. Moon (Eds.). Research methods in family therapy. (pp. 145-169). New York: Guilford Press. 
Biggs, T., Shah, M., \& Srivastava, P. (1997). Technological capabilities and learning in African enterprises. World Bank Technical Paper Number 288. Africa Technical Department Series. Washington, D. C.: The World Bank.

Bourdieu, P. (1986). The forms of capital. In J. Richardson (Ed.), Handbook of theory and research for the sociology of education. New York: Greenwood.

Bowden, V. (1997). The career states system model: A new approach to analysing careers. British Journal of Guidance \& Counseling 2, 473-490.

Bowen, D. D., \& Hisrich, R. D. (1986). The female entrepreneur: A career development perspective. Academy of Management Review, 11, 393-407.

Burgess-Limerick (1993) A work-home mesh? Understanding the lives of women who own small businesses. Feminism \& Psychology, 3, 356-362.

Butler, E., \& Brown, M. (1993). A-gendering skill, conversations around women, work and skill: An Australian perspective. EEE703 Project Development Plan 2. Victoria, Australia: Deakin University (ERIC Document Reproduction Service No. ED 384 692).

Carroll, G. R., \& Mosakowski, E. (1987). The career dynamics of self-employment. Administrative Science Quarterly, 32, 570-589.

Coleman, J. S. (1988). Social capital in the creation of human capital. American Journal of Sociology, 94, 95-120.

Coleman, J. S. (1990). Foundations of Social theory. Cambridge, MA: The Belknap Press of Harvard University Press.

Daniels, L. (1998). What drives the small-scale enterprise sector in Zimbabwe: Surplus labor or market demand? In A. Spring \& B. E. McDade (Eds.), African entrepreneurship: Theory and reality (pp. 51-68). Gainesville, FL: University of Florida Press.

Denzin, N. K. (1997). The standpoint epistemologies and social theory. Current Perspectives in Social Theory, 17, 39-76.

Dignard, L. \& Havet, J. (1995). Introduction. In L. Dignard \& J. Havet (Eds.), Women in micro- and small-scale enterprise development (pp.1-24). Boulder, CO: Westview Press.

Dinello, N. E. (1998). Forms of capital: The case of Russian bankers. International Sociology, 13, 291-310.

Downing, J. (1995). The growth and dynamics of women entrepreneurs in Southern Africa. In B. House-Midamba \& F.K. Ekechi (Eds.), African market women and economic power (pp. 177-196). Westport, CT: Greenwood Press.

Dyer, W. B. (1994). Toward a theory of entrepreneurial careers. Entrepreneurship Theory and Practice, 19(2), 7-22.

Elliot, J. (1990). Validating case studies. Westminster Studies in Education, 13, 4760. 
Erickson, B. H. (1996). Culture, class, and connections. American Journal of Sociology, 102, 217-251.

Erlandson, D. A., Harris, E. L., Skipper, B. L., \& S. D., Allen (1993). Doing naturalistic inquiry: A guide to methods. Newbury Park: Sage Publications.

Fine, M., Weis, L., Wessen, S. \& Wong, L. (2000). For Whom? Qualitative research, representations, and social responsibilities. Denzin, N.K. \& Lincoln, Y. S. (Eds.), Handbook of qualitative research (pp.107-132). Thousand Oaks, CA: Sage Publications, Inc.

Folala, T. (1995). Gender, business, and space control: Yoruba market women and power. In B. House-Midamba \& F.K. Ekechi (Eds.), African market women and economic power (pp. 23-40). Westport, CT: Greenwood Press.

Frank, K. A., \& Yasumoto, J. A. (1998). Linking action to social structure within a system: Social capital within and between subgroups. American Journal of Sociology, 104, 642-686.

Ghosh, R. (1996). Economic liberalization and its impact on women and women's education. The Alberta Journal of Educational Research, 42, 115-120.

Glaser, B. G., \& Strauss, A. L. (1967). The discovery of grounded theory; strategies for qualitative research. Chicago: Aldine Publishing Company.

Goffee, R., \& Scase, R. (1983). Business ownership and women's subordination: A preliminary study of female proprietors. Sociological Review, 31, 625-648.

Gordon, A. A. (1996). Transforming capitalism and patriarchy: Gender and development in Africa. Boulder, CO: Lynne Rienner.

Gordon, R. (1996). Legislation and educational policy in Zimbabwe: The state and the reproduction of patriarchy. Gender \& Education, 8, 215-229.

Green, E. \& Cohen, L. (1995). 'Women's Business': Are women entrepreneurs breaking new ground or simply balancing the demands of 'women's work' in a new way? Journal of Gender Studies, 4, 297-314.

Guba, E. G., \& Lincoln, Y. S. (1994). Competing paradigms in qualitative research. In N. K. Denzin \& Y. S. Lincoln (Eds.), Handbook of qualitative research (pp.105-117). Thousand Oaks, CA: Sage.

Hill-Collins, P. (1990). Black feminist thought: Knowledge, consciousness, and the politics of empowerment. (Perspectives on gender, Volume 2). New York: Routledge.

Hill-Collins, P. (1991). Learning from the outsider within: The significance of Black feminist thought. In M. M. Fonow, \& J. A. Cook. (Eds.), Beyond methodology: Feminist scholarship as lived research (pp. 145-183). Bloomington: Indiana University Press.

Hofferth, S. L., Boisjoly, J., \& Duncan, G. J. (1999). The development of social capital. Rationality and Society, 11, 79-110. 
Horn, N. E. (1994). Cultivating customers: Market women in Harare, Zimbabwe. Boulder, CO: Lynne Rienner Publishers.

House-Madimba, B. (1995). Kikuyu market women traders and the struggle for economic empowerment in Kenya. In B. House-Midamba \& F.K. Ekechi (Eds.), African market women and economic power_(pp. 81-98). Westport, CT: Greenwood Press.

Imani Development (1996). Analysis of the operating environment for small enterprises in Zimbabwe. Canadian Association for the Private Sector in Southern Africa (CAPSSA).

Jackson, N. (1991). Skills formation and gender relations: The politics of who knows what. EEE701 Adults Learning: The Changing Workplace. Victoria, Australia: Deakin University (ERIC Document Reproduction Service No. ED 384 703)

Jain, A. (1985). Understanding a presented problem from a phenomenological perspective. Journal of Sociology \& Social Welfare, 12, 413-430.

Jolly, M. (1994). Introduction. The Australian Journal of Anthropology, 5, 1-9.

Katz, J. A. (1994a). Modeling entrepreneurial career progressions: Concepts and considerations. Entrepreneurship Theory and Practice, 19(2), 23-40.

Katz, J. A. (1994b). Guest editorial: Career approaches to entrepreneurship. Entrepreneurship Theory and Practice, 19(2), 5-7.

Lal, B. B. (1995). Symbolic interaction theories. American Behavioral Scientist, 38, 421-441.

Leach, F. (1996). Women in the informal sector: The contribution of education and training. Development in Practice, 6, 25-36.

Lee, G. \& Cochran, L. (1997). Becoming self-employed. The Career Development Quarterly, 46, 98-109.

Lincoln, Y. S. \& Guba, E. G. (1985). Naturalistic inquiry. Newbury Park: Sage Publications.

Maranhão, T. (1986). The hermeneutics of participant observation. Dialectical Anthropology, 10, 291-309.

McLaughlin, S. (1989). Skill training for the informal sector: Analyzing the success and limitations of support programs._Education and Employment Division, Population and Human Resources Department. World Bank: Washington D.C.

McPherson, M. A. (1996). Growth of micro and small enterprises in southern Africa. Journal of Development Economics, 48, 253-277.

McPherson, M. A. (1998). Zimbabwe: A nationwide survey of micro and small enterprises. GEMINI Technical Report. Bethesda, MD.

Mead, C. M. \& Liedholm, C. (1998). The dynamics of micro and small enterprises in developing countries. World Development, 26, 61-74. 
Miles, M. B., \& Huberman, A. M. (1994). Qualitative data analysis: An expanded sourcebook. Thousand Oaks, CA: Sage Publications, Inc.

Ncube, I. (1997, September 27). First distributors of pinch drapery. The Herald (Zimbabwe), p. 6.

New, C. (1998). Realism, deconstruction and the feminist standpoint. Journal for the Theory of Social Behavior, 28, 349-372.

Organization for Economic Cooperation and Development, (1994). Women and structural change: New perspective._Paris: Author.

Osirim, M. J. (1992). The state of women in the Third World: The informal sector and development in Africa and the Caribbean. Social Development Issues, 14, 74-87.

Patton, M. Q. (1990). Qualitative evaluation and research methods. Newbury Park, CA: Sage Publications, Inc.

Pels, D. (1996). Strange standpoints: Or, how to define the situation for situated knowledge. TELOS, 108, Summer, 65-91.

Portes, A., \& Landolt, P. (1996). The downside of social capital. The American Prospect, 26, (May-June) 18-24, 94.

Putnam, R. (1995). Tuning in, tuning out: The strange disappearance of social capital in America. PS: Political Science and Politics, 28, 664-683.

Richie, B. S., Fassinger, R. E., Linn, S. G., Johnson, J., Prosser, J., \& Robinson, S. (1997). Persistence, connection, and passion: A qualitative study of the career development of highly achieving African American-Black and White women. Journal of Counseling Psychology, 44, 133-148.

Rossman, G. B. (1993). Building explanations across case studies: A framework for synthesis. University of Massachusetts at Amherst. (ERIC Document Reproduction Service No. ED373115).

Saburi, H. (1996, December 12). Kubi Indi, the woman who fought against all odds to achieve success. The Herald, (Zimbabwe), pp. 9, 10.

Sagor, R. (1996). Building resiliency in students. Educational Leadership, 54, 38-43.

Scheibel, F. (1999). Self made women, agency and work commitment. Community, Work \& Family, 2, 117-132.

Schmidt, E. (1991). Patriarchy, capitalism, and the colonial state in Zimbabwe. Signs: Journal of Women in Culture and Society, 6, 732-756.

Seidman, G. W. (1984). Women in Zimbabwe: Post-independence struggles. Feminist Studies, 10, 419-440.

Sexton, D. L. (1989). Research on women-owned businesses: Current status and future directions. In O. Hagan, C. Rivchun, \& D. Sexton (Eds.), Women-owned businesses (pp.183-194). New York: Praeger Publishers. 
Simons, H. (1996). The paradox of the case study. Cambridge Journal of Education, 26, 225-240.

Spring, A. \& McDade, B.E. (1998). Entrepreneurship in Africa: Traditional and contemporary paradigms. In A. Spring \& B. E. McDade (Eds.), African entrepreneurship: Theory and reality (pp.1-36). Gainesville, FL: University of Florida Press.

Steinberg, R. J. (1990) Social construction of skill: Gender, power, and comparable worth. Work and Occupations, 17, 449-482.

Sverrisson, A. (1994). Making sense of chaos: Socio-technical networks, careers and entrepreneurs. Acta Sociologica, 37, 401-417.

Sylvester, C. (1991). Zimbabwe: The terrain of contradictory development. Boulder, CO: Westview Press.

Van Hook, M. P. (1994). The impact of economic and social changes on the roles of women in Botswana and Zimbabwe. Affilia, 9, 288-307.

Van Manen, M. (1990). Researching lived experience: Human science for an action sensitive pedagogy. SUNY Press: London, Ontario, Canada.

Williams, C. L. (1991). Case studies and the sociology of gender. In J. R. Feagin, A. M. Orum, \& G. Sjoberg (Eds), A Case for the case study (pp. 224-243). Chapel Hill: University of North Carolina Press.

Wilson, H. S., \& Hutchinson, S. A. (1991). Triangulation of qualitative methods: Heideggerian hermeneutics and grounded theory. Qualitative Health Research, 1, 263-276.

Yin, R. (1993). Applications of case study research. Newbury Park, CA: Sage.

Young \& Richards, R. (1987). Entrepreneurial women and the relational component of identity: A hermeneutical study of career. In R. A. Young \& A. Collin (Eds.), Interpreting career (pp.117-133). Westport, CT: Praeger.

\section{The Authors}

Lisa Ncube is the Director of Evaluation for the Center for Collaboration in Educational Development which is located in the Department of Educational Psychology at Ball State University, TC 524, Muncie, Indiana 47306. Phone: (765) 285-8500. E-mail: lncube@bsu.edu.

James Greenan is Professor and Chair of Career and Technical Education in the Department of Curriculum \& Instruction, School of Education, 4108 Beering Hall of Liberal Arts \& Education, Purdue University, West Lafayette, Indiana 47907-2067. Phone: 765-494-7314. E-mail: jgreenan@purdue.edu. 


\title{
Developing Authentic, Integrated, Standards-Based Mathematics Curriculum: [More Than Just] An Interdisciplinary Collaborative Approach
}

\author{
Victor M. Hernández \\ Center for Educational Technologies \\ Wheeling Jesuit University \\ Jonathan L. Brendefur \\ Boise State University
}

\begin{abstract}
We analyzed the collaborative process of mathematics and vocational-technical education (VTE) instructors in eight sites, located across the United States, as they developed one authentic, integrated mathematics curriculum unit. Over two years, we collected data on teachers' viewpoints on instruction, integration, and mathematics/VTE reforms. Site visits were conducted to gather additional information on teachers' views, teaching practices, collaboration process, school context, and quality of curriculum units. We found that although the quality of the units varied, the overall analysis suggested that is it is possible for interdisciplinary teams of teachers to create high quality integrated mathematics curriculum units if certain conditions are met. Having support from the school's community, meeting regularly with all the team members, focusing conversations toward student understanding, writing tasks that promote conceptual and integrated understanding of the concepts, and writing the unit together with reflective thought, all seemed to be critical elements in successful integrated unit writing.
\end{abstract}

\section{Introduction}

Over the last decade, interdisciplinary teacher collaboration has been identified as an important avenue for supporting the integration of academic and vocational education in authentic ways (Bottoms \& Sharpe, 1996; Grubb, 1995). This is particularly relevant to advancing the efforts for improving mathematics curriculum, teaching, and learning through contextual, authentic activities advocated in the National Council of Teachers of Mathematics standards documents (NCTM, 1989; 2000) and in strengthening the type of mathematical activities conducted in vocational courses. The problem is we know little about specific dynamics and factors that facilitate the interdisciplinary work of mathematics and vocational education teachers. 
The purpose of this study was to examine and describe an interdisciplinary, collaborative approach to produce and implement curricular units by focusing on three aspects of current reform efforts in mathematics and vocational-technical education: integration, authenticity, and use of standards. Specifically, the study had five objectives: (a) To describe teachers' shared understandings of mathematics and vocational-technical education reform principles and beliefs on authentic teaching practices; (b) to identify team collaboration patterns and strategies; (c) to describe the role of school supports in facilitating teacher collaboration; (d) to determine the level of authenticity (or intellectual quality) of curriculum units produced by interdisciplinary teacher-teams; and (e) to identify conditions promoting or hindering the quality of curriculum units.

The impetus behind this study was the increasing evidence suggesting that American students lack the skills needed for using mathematical knowledge in applied contexts (Mathematical Sciences Education Board, 1995). One reason for this phenomenon is that American teachers' instructional practices often do not align with current school reform principles even though teachers may be familiar with them (e.g., Stigler \& Hiebert, 1999). In general, it appears American teachers have difficulty implementing needed instructional changes and continue to focus on memorization of information, paper-and-pencil work, lecture methods, and extensive content coverage with little relevancy to student's contemporary needs (National Center for Education Statistics [NCES], 1996; Porter, Kirst, Osthoff, Smithson, \& Schneider, 1994; Spillane \& Zeuli, 1999). As a result, researchers, policymakers, and practitioners have called for improved patterns of practice in the context of mathematics reforms. Research has also suggested that successful collaborative efforts should be built around a framework for authentic, standards-based curriculum, teaching, and learning, and should include appropriate teacher supports (Betances, 1999; Newmann \& Wehlage, 1995; Nickolas, 2000).

The conceptual framework for this study linked the principles derived from the National Council of Teachers of Mathematics [NCTM] standards documents (1989, 1991, 1995) and the reform movement in vocational-technical education [VTE] (Dougherty \& Ellibee, 1996). The study was further supported by research addressing the development of organizational capacity in the schools to examine critical supports and processes leading to successful, collaborative curriculum development practices of mathematics and VTE teachers.

\section{Framework for Standards-Based Curriculum}

NCTM has played an active role in promoting reforms in mathematics education. Its vision for curriculum and evaluation provides a comprehensive framework suggesting improvements for K-12 mathematics (NCTM, 1989; 2000). The NCTM vision advocates that all students should participate in powerful mathematics learning, develop confidence through relevant problem solving 
activities, and establish practical, conceptual connections within mathematics and across other disciplines. To guide teachers in this work, teaching and assessment standards were subsequently published by NCTM (1991; 1995). Concurrently, similar reforms have been promoted in the VTE sector. Derived from changing technologies and modus operandi of global markets, new skills involving problem solving, teamwork, reasoning, and communication have been demanded of the workforce and future workers who are prepared in secondary and postsecondary education programs (Gray \& Herr, 1995; Wirth, 1992). To face this challenge, reform advocates proposed to move from a traditional, segregated, job-specific VTE system to one that would bridge vocational and academic education, school and work, and secondary-postsecondary levels (Grubb, 1997; Phelps, 1992; Phelps, Hernández-Gantes, Jones, Sanchez, \& Nieri, 1995; Mathematical Sciences Education Board, 1995).

The reform movements in mathematics and VTE share common grounds: (a) a belief that all students can benefit from challenging education regardless of learning abilities or career interests, and (b) an understanding that learning has to be more relevant to students within the context of today's world. Under these premises, the prospects for linking mathematics and career concepts with an added emphasis on problem solving, critical thinking, and communication skills appeared promising. The combined principles of these two reform movements provide further impetus for systemic reform in curriculum and instruction. The challenges are to develop shared understandings of integrated, authentic, standards-based mathematics curricula and to discover how to encourage collaborative curriculum development of this nature.

Standards-based curricula were defined in this study by teaching and learning that aligned with the parameters proposed by the NCTM Standards for School Mathematics (1989). For two-year colleges, a similar framework has been provided by the Standards for Introductory College Mathematics Before Calculus (American Mathematical Association of Two-Year Colleges, 1995). Concurrently, the National Center for Research in Vocational Education (NCRVE) developed a set of standards for evaluation of high quality school-to-work curricula (Dougherty \& Ellibee, 1996). All of these frameworks share common criteria for good teaching practices, emphasizing problem solving, communication, reasoning, and connections for curriculum integration.

\section{Research on Authentic Curriculum and Instruction}

The notion of authentic curriculum and instruction is an underlying descriptor of intellectual quality. In other words, authentic curricula engage students in work that is grounded in activities with the purpose of building disciplinary knowledge through real and substantive material. The intellectual quality is created when students are encouraged to study material in deep and connected ways that have value beyond doing the work for schools' sake (Brown, Collins, \& Duguid, 1989; Newmann \& Wehlage, 1995). Under this premise, teaching and learning requires 
students to confront problems relevant to them and their surroundings. The goal is to promote increased academic achievement by problem solving, reasoning, and communicating about real-world social and work situations. Both the NCTM Standards and the reform movement in VTE emphasize the contextual nature of authentic student activities. In innovative VTE programs these authentic connections may be emphasized through actual work activities as a means to provide students with opportunities to connect academic and occupational concepts and skills (Grubb, 1995; Phelps, et al., 1995).

Based on the work of Newmann \& Associates (1996), authentic achievement was defined in the study by four components that promote improved student performance: higher-order thinking (HOT), deep knowledge, substantive conversation, and connections beyond the classroom (see also Newmann, Secada, \& Wehlage, 1996; Newmann \& Wehlage, 1995). Higher order thinking is manifested when students manipulate information and ideas by synthesizing, generalizing, explaining, hypothesizing or arriving at conclusions, which produce new meanings and understandings for them. Deep knowledge requires students to address in-depth major mathematical and vocational ideas with the purpose of creating complex student understandings. Substantive conversation is characterized by students engaging in extended exchanges with teachers and/or peers in a way that builds an improved and shared understanding of mathematics and career concepts. The final component of authentic curriculum, connections to the world beyond the classroom, requires students to make meaningful links between substantive mathematics knowledge and occupational applications.

\section{Research on Mathematics and Vocational-Technical Education Integration}

A clear understanding of curriculum integration is also essential for guiding collaborative work of mathematics and VTE instructors. Integrated curricula emphasize understanding of mathematical concepts rooted in occupational contexts. That is, mathematical content can be aligned with broadly defined occupational areas so students become immersed in integrated applications that are relevant to them. In integrated learning, the foundations of mathematics are fused with occupational, career, and life-skill content through models ranging from individual teachers integrating content in lessons to teacher-teams integrating curriculum in career academies (Bottoms \& Sharpe, 1996; Dougherty \& Ellibee, 1996; Grubb, 1997).

The School-to-Work Opportunities Act of 1994 (STWOA) (U.S. Congress, 1994) further encouraged the integration of academic and career competencies that are contemporary and transferable across broadly defined technical fields. STWOA also provided broad guidelines for implementation of suggested reforms that would link both academic and practical skills. However, a national survey of programs featuring mathematics and VTE integration collaborations described these integrated reform efforts as negligible and slowly evolving. In general, simplistic forms of collaboration (e.g., individual teachers integrating content informally) with a weak 
emphasis on the NCTM standards were found in this study (Hernández-Gantes \& Nieri, 1997). Among other factors, a lack of shared understanding of principles behind current reform movements appears to limit the natural evolution of these collaborative efforts (Betances, 1999; Grubb, 1997; Locke, 1999; Porter, et al., 1994; Spillane \& Zeuli, 1999). To fill the integrated (or applied) curriculum void, a number of commercial curriculum products have mushroomed under the label of applied mathematics claiming alignment with the relevant standards. Although helpful in complementing instruction, the generic nature of these products limits their application to individual curricular needs found in a variety of potential integrated contexts (e.g., contextual mathematics in agriculture, electronics, architecture, and manufacturing). Another problem with these applied curriculum materials or courses is the tendency to involve very basic skills rather than higher order thinking skills (Bottoms \& Sharpe, 1996; Stasz, Kaganoff, \& Eden, 1994).

While in theory the integration of mathematics and VTE appears promising, there are a number of institutional obstacles that limit its implementation. Two problems seem to be most prominent: restricted instructor collaboration fostered by traditionally segregated academic and VTE tracks, and applied curricula, which still rely on traditional methods of teaching, learning, and assessment. And yet, there are hints of evidence that in schools where teacher collaboration is encouraged, it is possible to observe highly authentic learning activities that reflect the NCTM standards (Kruse, Seashore, \& Bryk, 1994; Newmann, et al., 1996; Nickolas, 2000).

\section{Research on Collaborative Curriculum Development}

Recent studies have demonstrated that ideas for reform and schools' commitment for implementation do not guarantee success in improving student learning (Locke, 1999; Peterson, McCarthey, \& Elmore, 1996; Porter et al., 1994). More than just commitment for a collaborative approach may be required to develop and implement curricula that meet reform principles. Given these circumstances, it is not surprising that efforts to develop integrated, authentic, standards-based mathematics curricula are generally negligible.

Research on organizational restructuring offers some possible explanations and suggestions for building collaboration to implement reform in terms of curriculum restructuring and classroom instruction (Adajian, 1995; Kruse et al., 1994; Newmann \& Wehlage, 1995; Peterson et al., 1996). Peterson et al (1996) argued that teachers who are committed to change are strongly motivated to improve their practices and will strive regardless of changes in organizational structures. Once teachers begin to share a common understanding of good practice, Peterson et al noted, they also would need new school structures to maintain their efforts. Ultimately, they suggested teachers' commitment to change might be a function of their "beliefs, understandings, and behaviors in the context of specific problems in the classroom" (p. 147). Further, when interdisciplinary work is involved, these 
factors may present serious barriers for promotion of collaborative work (Schmidt, Finch, Faulkner, \& Kandies, 1995).

To foster effective collaboration it may be necessary to involve both mathematics and vocational-technical instructors in the conversation on restructuring and to share leadership responsibilities with representatives from each group (Hernández-Gantes \& Nieri, 1997). Research on organizational restructuring suggests that systemic reform is an institution wide enterprise requiring a professional community of instructors (Adajian, 1995). In schools where instructors share this sense of professional community, they are more likely to collaborate. But collaboration alone is not a guarantee that integrated curriculum development and teaching will improve or increase academic achievement. To nurture successful integrated activities and support for sustained quality of collaborative work, schools should provide instructors with time to reflect on common challenges, observe each other's teaching, agree on student expectations, and develop shared understandings of principles which underlie school reform (Kruse et al., 1994; Newmann \& Wehlage, 1995).

To summarize, while it is important for instructors to have converging frameworks for developing integrated, authentic, standards-based mathematics curricula, it is equally critical to understand the conditions that enable and hinder them in this process. By examining teacher-teams committed to interdisciplinary collaborative work in designing such curricular units, it may be possible to build an understanding of the supporting factors for developing authentic, standards-based curriculum.

\section{Method}

Data for this research derived from the evaluation component of a collaborative curriculum development effort supported by a national integration demonstration project. Throughout this document, this project is referred to as MathNet.

\section{Participants}

Project staff collaborated with 20 instructors and curriculum specialists who represented seven high schools located in California, Kentucky, Michigan, Minnesota, New Jersey, South Carolina, and Wisconsin, and a two-year community college located in Texas. Teams were composed of two-three members including at least one mathematics and one VTE instructor, as well as a curriculum specialists in some instances. The role of the curriculum specialists was to advise the local team on curriculum writing. Due to the nature of its proposed curriculum unit, one of the teams also included a science teacher. 
Selection of teams was done through an initial national nomination process that resulted in a pool of 82 schools. The initial screening involved a review of the extent of integration of vocational education and mathematics with particular emphasis on implementing the NCTM standards. Based on this screening, a third of the schools were invited to submit an application for participation. Upon review of applications, eight teacher-teams were selected based on the extent of integration efforts, experience in curriculum development, working vision for implementing the NCTM standards, and the quality of the team's proposed plans for developing integrated curriculum. The review process involved ratings from five project staff and input from the project's advisory group. The highest-rated teams from urban, suburban, and rural sites were chosen for participation in the project. A brief description of the schools is provided in the Appendix. The charge for selected teams was to produce, field test, and revise one authentic, integrated curriculum unit for use in grades 9-12 and two-year, college-level mathematics as appropriate.

\section{MathNET Support}

All selected teams participated in a weeklong summer institute in Years 1 and 2. In the initial summer institute teachers were provided with technical assistance leading to the development of understandings about integration, implementing standards, and curriculum writing. Initial ideas for curriculum units resulted from participation in the first summer institute. With consulting support from project staff, teams spent the following school year developing a curriculum unit. Support staff was comprised of an experienced mathematics teacher on both the implementation of NCTM standards and integration practices. A second member provided assistance on assessment issues. A third member contributed with expertise on VTE curriculum and collaborative practices.

Further assistance in refining final versions of curriculum units and on strategies to evaluate products was provided to teams during and after the second summer institute. Throughout the two-year project, two staff members visited each team for 1-2 days to provide on-site technical assistance, observe units being taught, discuss observations with team members, and answer questions related to writing the units as needed. In addition, staff members were available to consult with teams on issues related to the development of their curriculum units. After each summer institute, support staff tracked progress on curriculum units, conducted reviews of team products, and provided ongoing feedback.

\section{Research Questions and Data Sources/Instrumentation}

Drawing on previous research and related literature, five major questions guided the study:

1. What are the participants' shared understandings of mathematics/VTE reform principles and beliefs on authentic teaching practices? 
2. What are the patterns and strategies for team collaboration?

3. What school supports and structures facilitate teacher collaboration?

4. What is the level of authenticity of integrated curriculum units?

5. What conditions promote high quality of curriculum units?

To answer these questions, various sources of data were collected and analyzed through qualitative research techniques (Merriam, 1998; Spradley, 1979; Stake, 1994; Strauss, 1987; Wolcott, 1994). Table 1 summarizes the areas of interest for data collection, data sources, instrumentation, and frequency of data collection.

\section{Data Collection and Procedures}

Initially, the participants were requested to complete an extensive preliminary instructor survey. The survey was complemented with an individual semi-structured interview to collect data on teachers' typical classroom practices. The teams then participated in a week-long summer institute which allowed them to begin developing their units and to learn more about the three major features of expected curriculum development efforts: integration, authenticity, and use of standards. Team, semi-structured interviews were also used during the middle of the project and again at the end to determine supports and barriers that led to the creation and implementation of highly authentic units (Newmann \& Associates, 1996). Data was also collected through classroom observations and evaluation of curriculum units. Additional data was collected through discussions of follow-up technical assistance provided by MathNet staff to all teams. The trail of interactions between project staff and teams provided insights on team understandings, collaboration factors, and curriculum development strategies.

\section{Analysis}

For the analysis aligned with research questions 1 and 2, data from the preliminary instructor survey was summarized using descriptive statistics and used as baseline reference. Complementary data from individual and team interviews was analyzed using a systematic comparative method (Glaser \& Strauss, 1967; Merriam, 1998). Under this method, we first compared critical perspectives and ideas deemed important by participants under broad themes. Next, we characterized each theme using categories of perspectives/ideas. The categories were further verified for consistency within and across teams.

To address question 3, the analysis of school supports was guided by Lisa Adajian's (1995) model of professional community. Through a systematic approach of examining the interview data, each team was rated on the four criteria listed below.

1. De-privatization: Access to other teachers' classroom by visiting, observing, or assisting in some way. 
Table 1

Data Collection Strategies: Areas of Interest, Sources, Instrumentation, and Frequency.

\begin{tabular}{|c|c|c|}
\hline $\begin{array}{l}\text { Area of } \\
\text { Interest }\end{array}$ & Data Sources and Instrumentation & $\begin{array}{c}\text { Frequency of Data } \\
\text { Collection }\end{array}$ \\
\hline $\begin{array}{l}\text { Baseline } \\
\text { Information }\end{array}$ & $\begin{array}{l}\text { Application materials. Provided } \\
\text { preliminary information on school context, } \\
\text { team characteristics, integration efforts, and } \\
\text { experience in collaborative work. } \\
\\
\text { Preliminary Instructor Survey. Provided } \\
\text { baseline data on teachers' background } \\
\text { including beliefs on instruction and } \\
\text { professional development needs. }\end{array}$ & $\begin{array}{l}\text { Collected once and } \\
\text { used for team } \\
\text { selection purposes. } \\
\text { Collected at the } \\
\text { outset of the project. }\end{array}$ \\
\hline $\begin{array}{l}\text { Collaborative } \\
\text { Curriculum } \\
\text { Development } \\
\text { Process }\end{array}$ & $\begin{array}{l}\text { Individual and Team Interviews. The } \\
\text { interview protocols addressed teachers' } \\
\text { ideas about pedagogical issues, } \\
\text { collaboration, and perspectives on quality } \\
\text { curriculum development. } \\
\text { Classroom Observations. The protocol for } \\
\text { classroom observations yielded behavioral } \\
\text { data on instructional practices in relation to } \\
\text { criteria for authentic pedagogy. } \\
\text { Consulting Documentation. Trail of } \\
\text { correspondence between teams and project } \\
\text { staff in electronic and paper form provided } \\
\text { insights on general curriculum development } \\
\text { issues. }\end{array}$ & $\begin{array}{l}\text { Collected at two } \\
\text { summer institutes } \\
\text { and 1-3 site visits } \\
\text { depending on } \\
\text { location. } \\
\text { Collected during site } \\
\text { visits (1-3 site visits } \\
\text { depending on } \\
\text { location). } \\
\text { Collected during } \\
\text { year following } \\
\text { participation in } \\
\text { summer institutes. }\end{array}$ \\
\hline $\begin{array}{l}\text { Curriculum } \\
\text { Units }\end{array}$ & $\begin{array}{l}\text { Curriculum Review Form. The review form } \\
\text { provided data on the quality of curriculum } \\
\text { units in relation to criteria for authenticity. } \\
\text { Documentation of Feedback and Follow- } \\
\text { Up. Trail of correspondence between teams } \\
\text { and project staff in electronic and paper } \\
\text { form provided insights on specific } \\
\text { curriculum development issues and } \\
\text { strategies for improving curriculum units. }\end{array}$ & $\begin{array}{l}\text { Collected from at } \\
\text { least two drafts of } \\
\text { curriculum units. } \\
\text { Collected during } \\
\text { year following } \\
\text { participation in } \\
\text { summer institutes. }\end{array}$ \\
\hline
\end{tabular}


2. Shared sense of purpose: Colleagues shared similar pedagogical beliefs.

3. School-wide collaboration: Staff met regularly to discuss ideas such as integration, standards, or authenticity.

4. Structural supports: Administration encouraged and assisted them in combining classes and adjusting school schedules to meet the needs of the integrated units.

Each team received two points if they met the criteria, one point if it was mixed, and zero points if no evidence was found. Evidence was documented through interview data and notes collected during site visits.

To address question 4, project staff reviewed initial drafts of curriculum units using criteria derived from the NCTM standards framework and authentic instruction (Newmann et al., 1996) to determine the extent and nature of integration and authenticity. This information was used as a baseline of the degree to which the units were meeting the criteria for integration, standards, and intellectual quality or authenticity, and to assist teams of teachers in rewriting their units. The criteria for authenticity included depth of understanding, conceptual grounding of content, elaborated communication, and experience beyond success in school. These constructs were adapted from scales developed by the Center on Organization and Restructuring of Schools (CORS) (see Secada \& Byrd, 1993; Brendefur, 1996).

The first domain, depth of understanding, examined whether the unit required or encouraged students to organize, interpret, evaluate, synthesize, or, in some other way, work with complex information to understand a particular concept, claim, problem, or issue. Depth of understanding requires focused attention on a particular problem, issue, or question. It is promoted when the lesson calls for awareness of alternative solutions, perspectives, or points of view, even though a single answer or solution may be considered unequivocally the best by diverse authorities. The second domain, conceptual grounding of content, examined whether the unit required students to work with significant and substantive material and with approaches to inquiry important to mathematics and vocational-technical courses. Each lesson must consider the appropriateness and accuracy of the content and processes encountered by students in the two disciplines. The third domain, elaborated communication, examined whether lessons required students to elaborate on their ideas and conclusions through extended writing or oral presentations. A lesson was regarded as being more authentic when students had ample opportunities to explain generalizations, classifications and relationships relevant to a situation, problem, theme, or to justify their thinking. Examples included attempts to argue, convince, or persuade and to develop or test hypotheses. When the lesson required little more than giving results or asking students to show little work or to write brief sentences, it was regarded as less authentic. 
Finally, experience beyond success in school, examined the extent to which lessons had meaning to students so that they could make concept connections with real-world situations. This construct shares two essential features: (a) whether the problem, question or issue posed by the lesson is or is likely to connect students with situations beyond the classroom setting, and (b) whether students can communicate results to an audience other than the teacher and peers (e.g., worksite mentors). Important findings on effective collaborative practices and processes emerged from our constant comparative analysis of data within and across participating instructorteams.

Guided by these constructs, complementary analyses of interviews, classroom observations, and documentation of technical assistance were conducted following the constant comparative techniques to address question 5 (Merriam, 1998). This overall analysis yielded insights on conditions that facilitated or hindered the quality of curriculum units produced by teacher-teams.

\section{Findings}

We introduce the findings with the teachers' notions of integration and authenticity. Next, we present team collaborative patterns and highlight the school context in which teams worked. This is followed by results on the quality of curriculum units produced by teacher-teams. We close with a presentation of findings on factors and conditions that promote high quality integrated curriculum units.

\section{Teachers' Notions of Integration and Authenticity}

The understanding of the twenty participating teachers about integration and authenticity was captured through an initial questionnaire and individual interviews. Each member was rated on whether their beliefs were consistent, mixed, or inconsistent with project definitions of the two constructs.

Notions on integration. The teachers' understandings of integration of mathematics and VTE were classified into five categories: applied mathematics, theoretical foundations for integration, mathematics modeling derived from integration, mathematics in real-world situations, and impact on improving students' understanding of integrated content.

In the first category, the teachers' notions of applied mathematics focused on using mathematical rules and algorithms in occupational contexts or related to VTE courses carrying titles such as Applied Math, Basic Math, or Occupational Math. In general, mathematics is trivialized in these applied courses. Even though applications to real-world problem situations may be emphasized, they are usually disjointed and removed from students' interests since connections to a series of sequenced and coherent career concepts are not possible. Furthermore, students are encouraged to memorize one specific way to solve problems. Five of the twenty teachers' responses 
fit into this category. These five teachers were dispersed among the different teams, indicating that each team had to overcome differences in basic understandings about applied versus authentic mathematics. The second category, application of theoretical foundations for integration, examined how an occupational context can be used as an example to help explain a mathematical theory. Some teachers clearly articulated that integration is using vocational contexts to develop and reinforce a mathematical concept or theme. Both of these first two categories show a misapplication or trivialization of one course of study over the other.

The third category examined integration in terms of mathematics modeling. In this category math is used as a method to explain or model what is happening in a real-world context. Only two teachers characterized integration in this particular powerful way. However, this is still not seen as true integration in that the mathematics (or mathematics course) is being driven by the vocational-technical activities or situations.

The fourth category, real-world use of mathematics, was initially articulated by seven of the twenty teachers, more than in any other category. Integration was perceived as a way to include real-world situations in a mathematics class to either motivate students or to see where mathematics might be used in the real-world context. Here the mathematics course is using the vocational-technical concepts to assist furthering the mathematical concepts.

Finally, the fifth category focused on improving students' understanding of both mathematics and career concepts. Three of the teachers stated that the integration of mathematics and VTE would increase students' understanding of the content in both areas as well as how concepts are interconnected across disciplines. This type of integration is the most difficult to achieve because it asks instructors from both courses of study to modify their curriculum in a way that supports each other's ideas as well as support student understanding. It might be the case that this integrated unit could be taught equally well in both a mathematics course and vocational-technical course without a loss of content to one subject over the other.

Notions of authenticity. Authenticity was described earlier in this study as student work that requires deep understanding of mathematical and career concepts and contexts by producing or constructing knowledge through in-depth exploration and substantive conversations of topics that have some value beyond the classroom. The analysis indicated that most teachers only understood authenticity as math being relevant to real-world or occupational settings. For example, teachers described authenticity as "showing connections relevant to use in a work situation" or "going beyond the classroom and really hitting on what's out there in the world." Many of these teachers added that real-world situations were useful to motivate students and to help them see where mathematics might be applied.

Only five of the teachers were able to connect the concept of authenticity to other important factors that went beyond relevancy to realistic situations. For these teachers who were aware of the broader implications for designing authentic 
curricula, authenticity implied opportunities to problem-solve and think critically about problems.

\section{Interdisciplinary Collaborative Patterns and Strategies}

A shared understanding of effective curriculum development served as the backdrop for examining collaboration patterns and strategies used by teacher-teams to produce curriculum units.

Collaboration Patterns. Five of the eight teams had previously worked together on integrating mathematics and vocational contexts, while the other three had formed an ad hoc team for the project. The teams who had worked together in the past, and who were building upon course material previously taught, designed units that showed a more coherent understanding of integration ideas. In contrast, teams who had not worked together before tended to rely on the individual expertise of "dominant" members who appeared more knowledgeable and whose ideas seemed to be expressed with more passion and vigor. As collaboration continued and changes were made that challenged perspectives of mathematics and VTE teachers, teams began to realize that each member had something valuable to contribute. During the first year, evolution toward more democratic input between team members took shape within six of the eight groups.

The collaborative process also varied between teams from highly collaborative to individual efforts. For instance, the collaborative process of one of the more highly collaborative teams could be best described as an iterative process of reflection, writing, and pilot testing. The members of the team would usually ask the question, "What do we really want them to learn?" as the critical element pervading each meeting. They mused over this question during the entire project.

In the individually-led efforts, which included four of the eight teams, the process for refining curriculum ideas was more cumbersome. Here, individual teachers took it upon themselves to provide the leadership in developing curriculum ideas for the team and bringing everybody else into the fold. The dominant member would seek specific input from other team members and the responsibility for developing ideas concentrated on the team leader.

Team strategies. An important factor influencing the development of curriculum units was the strategies each team used in creating the unit. Each team's approach to writing a unit was classified by whether main ideas originated during the project or from an activity done before by a member. Half of the teams' initial ideas for integrated curriculum units stemmed from prior integration work or ideas. For example, one team's unit derived from the technology teacher's bridge-building activity, which he had used previously in his class. At this point, the math and physics teachers discussed from their respective disciplines critical ideas in bridge building. Substantive conversations ensued, resulting in richer activities for the 
students. These activities incorporated mathematical models to test important ideas in physics related to bridges such as tension, compression, and torque.

Another strategy to facilitate collaborative work was the approach each team followed to address the focus of the unit. Three teams emphasized instructional activities that focused on student understanding of mathematics and its applications: the fifth category of integration discussed earlier. After pilot-testing their units, these teams restructured lessons, refined their questions, and created more mathematical situations throughout the entire unit to focus on the development of student understanding. As one teacher put it: "We really focused on asking one question and then tried to have the students investigate that particular question and come up with an answer for one idea, one question — not to make it too broad, too general."

The other five teams were more interested in featuring "interesting" student activities to get students engaged in "hands-on" learning. This approach was related to their beliefs that integration of mathematics and vocational-technical ideas should motivate students to learn something "interesting." In these cases, curriculum units tended to focus on applied learning activities reflecting more traditional pedagogical practices (e.g., step-by-step procedures).

\section{The Role of School Supports}

Based on research suggesting that a school's context (or professional community), affects classroom practices (Adajian, 1995), we examined each school on four areas: de-privatization, shared sense of purpose, extent of staff collaboration within the school, and structural supports. Data about each school's context were collected through semi-structured team and individual interviews, and each area was rated on a three-point scale (see Figure 1).

De-privatization practices were defined as access to other teachers' classrooms by visiting, observing, or assisting in some way. Five teams (CA, KY, $\mathrm{MI}, \mathrm{NJ}$, and SC) enjoyed various levels of de-privatization ranging from somewhat to highly supportive practices. The New Jersey team depicted their administration as supportive, allowing de-privatization and collaboration among staff about issues they felt important, but the administration did nothing else to encourage teachers to integrate. Only one district administrator had visited their classrooms to watch the unit being taught, not the principal, not the department chair. Other staff members were indifferent towards integration.

Finding a shared sense of purpose (colleagues sharing similar pedagogical beliefs) within each of the participant schools was more problematic. Interview data showed a strong commitment toward improving the quality of students' learning at only two sites (KY and $\mathrm{NJ}$ ) and a weak shared commitment at three other sites (CA, $\mathrm{MI}$, and SC). In these latter cases, this shared purpose did not meet total agreement on integration issues, but the school culture encouraged the development of rigorous 
curriculum for students. In the rest of the sites, the shared purpose was either very traditional or non-existent.

School-wide collaboration (the extent to which staff met regularly to discuss ideas such as integration, standards, or authenticity) at participant sites was characterized as very limited. In only one site-Kentucky-was there strong evidence of school-wide collaboration. In this school, teachers worked together and constantly shared ideas. Other structural supports, such as the school's flexible schedule, also supported de-privatization, allowing teachers to team-teach one or two classes, have students move from one teacher to another, and have common preparation periods. At three other sites (MI, NJ, and SC) the picture of collaboration was mixed. At those sites, only a handful of innovative, yet isolated, teachers showed work on integration practices while the majority of their peers saw this work as cumbersome or not worth trying.

Figure 1. Degree of Professional Community Observed for Each Team.

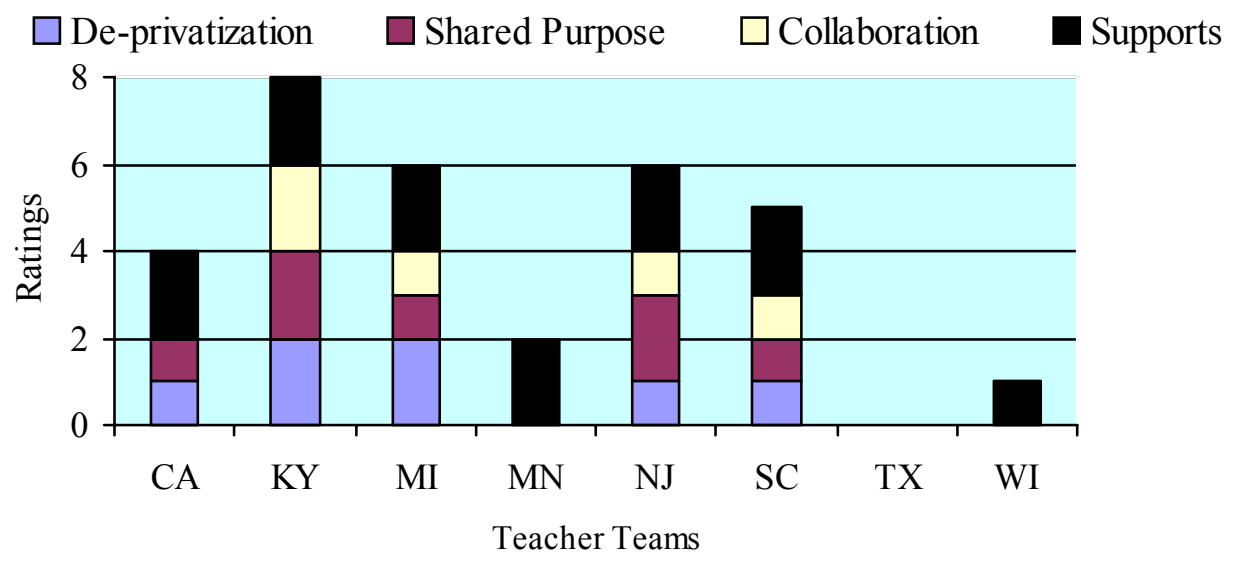

In six sites (CA, KY, MI, MN, NJ, and SC), structural supports were highly visible enabling teachers to work on integrated activities. At the Kentucky school site the community and administration supported integration activities. Each technical (e.g., welding, plastics, drafting, desktop publishing) teacher was assigned to be on a team with a mathematics, science, and communication teacher. The school's mission statement stated that through integrated course work students would learn to be effective workers in society. The administration allowed these different instructors to team-teach, move the same group of students from one teacher to the next, or use any plausible teaching scenario to get students to use technology. The rest of the teams experienced similar support with the exception of two teams whose school support was limited or nonexistent. 


\section{Quality of Curriculum Units}

Overall, all teams slowly began writing units, negotiating perspectives on integration, content coverage, and teaching ideas. Much discussion took place but the collaborative process lacked a method for clarifying ideas in writing. Leadership within each team floundered due to lack of time and differing views on major ideas underlying proposed units. Initial drafts reflected a disjointed process, which was characterized by sketchy information loosely connecting integration, authenticity, and standards-based instructional activities. To address this issue, MathNet staff encouraged teachers to clarify ideas and express changes in writing, and teams finally realized the necessity of documenting their ideas and subsequent changes. At this point, teams began to express their curriculum ideas in detailed writing. It was only then that teams could go back to review weak ideas and make sense of changes. This new approach to developing curriculum was quite a contrast from the teams' beginning attempts in which revisions were difficult because little written documentation of ideas existed.

Throughout their curriculum development process, some teams produced three versions of their integrated units, each representing a different stage of development and quality. Due to unexpected conflicts in schedules some teams were only able to produce two versions. As expected, later versions rated higher on authenticity scales. The mean rating for initial versions of units was 14 (maximum rating possible $=45$ ). The average rating improved five points (to 19) for the second version, and increased another two points (to 21) for the final version of the units (see Brendefur, Hernandez-Gantez, \& Webb, 1998, for details).

What does this mean? To begin, the initial units across teams, on average, contained few, if any, questions or tasks requiring students to make sense of information, think deeply about central ideas of the disciplines and topics, discuss or elaborate on ideas or products, or make connections to real-world situations. By the final version, two teams had units with a substantial amount of questions that required students to make sense of an important topic, examine the material with some thoroughness, discuss important ideas with each other, and see the relevance of their work to the real world. Another four units moved in this direction.

Although the quality of units improved as teams made revisions and learned from multiple implementations of the unit, the overall result signaled the difficulty in facilitating interdisciplinary curriculum development work.

\section{Conditions that Impact Quality of Curriculum Units}

Three important conditions appeared to have an impact on the quality of integrated curriculum units produced by teacher-teams. The conditions were associated with teachers' teaching practices, school supports, and collaborative patterns. 
Authenticity of teaching practices. In general, teams with teachers whose practices were rated higher on the scales of authenticity tended to create team conditions to develop units that rated high on similar scales. This may be because these teachers already know how to ask and write questions that engage students in authentic types of activities. It also appeared that teachers whose pedagogical skills were rated higher tended to influence the type of activities/tasks found in the units (see Brendefur et al, 1998 for details). In short, a unit's score reflected the ideas of the teachers who scored highest on these scales. This may be because the member whose practices were more consistent with the project goals (integrated, authentic, and standards-based) tended to take more of the responsibility of writing and implementing the unit.

School context's impact on unit rating. Overall, half of the sites that showed moderate to high levels of support also showed higher ratings on the authenticity scales. The other half showed little school support and tended to rate low on the scales. It was clear from observations and interviews at the schools that the level of school support encouraged or hindered team members in going further in meeting authentic criteria. For example, school context might be one explanation for the Kentucky team's large gain on the scales of authenticity as compared to any of the other participating schools. The school was actively pursuing integration activities, and featured a career academy where integration of academic and VTE was encouraged. The team was used to giving and receiving feedback on curriculum development and instructional practices, and was receptive to suggestions for improving their integrated unit. In contrast, in schools with little collegial support, little teacher collaboration and no attempts to team-teach, and lack of a clear focus for integration efforts, the level of authenticity tended to rate low.

Impact of teacher collaboration on unit ratings. Overall, teams with high collaboration produced units that rated higher on the scales of authenticity. The New Jersey team typified this trend. Team members spent many hours each week individually and collectively discussing: (a) the content and concepts in the unit, (b) how students would and did react to tasks and questions, and (c) how to modify tasks and questions in the unit. This focus on conceptual knowledge and reflection of what works was an important factor in the success and high rating of the unit. Further, teams who had been working together for some time and were building upon prior integration ideas were more focused in writing integrated units. Even in cases where the team had to refocus the original idea, because they were building upon these prior experiences and collaboration, they were able to make continuous progress. In comparison, teams with problematic dynamics, lack of focused collaboration, and little prior teamwork usually showed lower ratings of curriculum units.

\section{Conclusions and Discussion}

The analysis of teachers' conceptions about integration and authenticity, the collaborative curriculum development process, school context, and quality of units 
were consistent with research on developing school organizational capacity (Kruse et al., 1994; Newmann \& Wehlage, 1995), academic and VTE integration (Bottoms \& Sharpe, 1996), and implementation of mathematics reform (Porter et al., 1994; Spillane \& Zeuli, 1999). Several conclusions emerged from the analysis of our findings.

The first conclusion derived from the study of teachers' understandings of integration and authenticity: When integrating mathematics and VTE, conflicting notions of what constitutes high quality integrated, authentic curriculum and instruction are magnified. Thus, the need to develop a base of shared "big-picture" understandings becomes an absolute necessity. For example, mathematics teachers brought to their teams strong ideas of content coverage, which favored procedural behaviors and guided instruction. VTE instructors contributed with show-and-tell ideas, but the teachers' collective beliefs missed making the natural connections to move curriculum and instruction to a higher level of authenticity. Although instructors believed in the benefits of mathematics and vocational-technical integration, their notions were those of "applied" curriculum. As a result, their units still lacked challenging student activities, which would elicit high levels of problem solving, reasoning, and communication from students. To create the foundations for successful and productive collaboration, instructors need to develop a base of shared understandings about important collaborative work concepts and opportunities for substantive interactions in the school (Betances, 1999; Bottoms \& Sharpe, 1996; Locke, 1999; Newmann \& Wehlage, 1995; Nickolas, 2000).

Research on authentic instructional practices have documented that traditional beliefs on teaching practices are pervasive and translate into classroom activities which feature rote memorization and passive learning (Newmann \& Associates, 1996; Romberg \& Carpenter, 1986). Newmann and Associates suggested that teachers should agree upon high expectations for student achievement and criteria for high-quality instruction (i.e., authenticity). It is indispensable to reach this consensus to build a base for designing highly authentic integrated mathematical tasks, yet bridging mathematics and VTE education perspectives add extra difficulties for reaching this agreement.

A second conclusion emerged from the analysis of the interdisciplinary collaborative process: When integrating mathematics and VTE guided by standards, it is critical to foster effective team dynamics and democratic discourse for successful collaborative curriculum development. Otherwise, teachers with strong beliefs and personalities will dominate the conversation imposing their ideas on others. Seniority may play a role in team dynamics and prevent open discourse and democratic input, especially if members have had no previous interdisciplinary collaboration experience. Furthermore, considering traditional, stereotypical perceptions of the inherent worth of mathematics compared to that of vocationaltechnical education, team dynamics might reflect an unwritten hierarchical status of players. The result of this hierarchical status on curriculum development might be 
reflected in low-levels of authenticity or curriculum, which is heavily biased toward one particular discipline. The theory on developing organizational capacity suggests a number of criteria to create an environment where teachers collaborate as a community of professionals. Time for shared planning, discussing ideas, and appreciating the contributions of each other in a holistic fashion are key elements for successful teacher collaboration (Adajian, 1995, Kruse et al., 1994; Newmann \& Wehlage, 1995; Schmidt et al., 1995).

A third conclusion underscores the importance of the school context in facilitating interdisciplinary teacher collaboration: Effective interdisciplinary collaborative curriculum development is most likely to happen in schools that provide opportunities to collaborate across disciplines, foster a shared sense of purpose, and provide programmatic supports and flexible structures needed for genuine collaboration. Our findings were consistent with the literature on organizational capacity and teacher collaboration (Peterson, et al., 1996; Betances, 1999; Locke, 1999; Schmidt et al., 1995). It was evident from observations and interviews that interdisciplinary teacher collaboration is a time-consuming activity with important implications for school culture and administrative supports. The focus of teacher collaboration may be easily lost or hindered in school environments where administrators and peers are not entirely convinced of the value of interdisciplinary activities. By comparison, it was clear that teams with supportive school environments and structural supports to collaborate, were able to stay focused and progressively refine the design of the teaching and learning activities included in their proposed units. It is imperative for schools to understand that it is not enough to encourage teachers to collaborate. Schools must be willing to provide needed structures, resources, and supports to facilitate productive collaboration.

Regarding the quality of curriculum units, a fourth conclusion reflects the holistic nature and conditional possibility of successful curriculum development: Highly authentic, integrated, and standards-based curriculum units could be produced if interdisciplinary teams collaborate under a set of favorable conditions. What are these conditions? Interdisciplinary teacher-teams should share similar conceptions of authenticity and integration, have prior experience collaborating in teams, work in a school committed to collaboration, and focus on teaching for increased understanding of concept connections and applications in occupational contexts. Based on our observations, interviews, and ratings of curriculum units, it was evident that successful collaborative curriculum development entailed more than just a collaborative approach. To be successful, it appears that all conditions should be in place. Even teams with strong backgrounds on one or two conditions but weak in others had difficulty developing high quality curriculum units. The implications for school-wide collaboration, for developing communities of learners in schools, and for professional development for both administrators and teachers are key elements in producing quality integrated units (Peterson et al., 1996; LoucksHorseley, Stiles, \& Hewson, 1996). 
Finally, our last conclusion is tied to the implications for professional development: Genuine collaborative curriculum development occurs when teams engage in reflective dialogue grounded in their own experiences, needs, and resources. The success of team collaborations can be enhanced by facilitating reflective dialogue rather than by directing the process with rigid models for technical assistance. Our analyses showed that teams could have developed curriculum units much faster if MathNet staff had provided more directed guidance from the beginning of the project as had been expected by teams. However, a "fill-inthe-blanks" model would have prevented important reflective dialogue about high quality, integrated, authentic instructional activities more relevant to the teams. Team dynamics would have been restricted to contrived individual contributions motivated by completing assigned sections in the way designated by project staff. In contrast, by encouraging teams to experiment and explore their own design approaches, a vehicle for self-examination was constructed, team dynamics began to evolve, and intrinsic motivation for genuine collaboration was generated. In this regard, a number of recommendations for professional development, which feature flexible collaboration and reflective dialogue have been recently emphasized to help teachers implement high quality curricula in the schools (Hernández-Gantes \& Nieri, 1997; Kruse et al., 1994; Loucks-Horsley et al., 1996; Newmann \& Wehlage, 1995; Nickolas, 2000).

In sum, although the quality of the units varied, our findings suggested that it is possible for interdisciplinary teams of mathematics and VTE teachers to create high quality integrated curriculum units if certain conditions are met. Team dynamics, teachers' beliefs, and school supports, in particular, appeared to be critical to sustain productive collaborative curriculum development work. It appeared that having support from the school's community, meeting regularly with all the team members, focusing conversations toward student understanding and writing tasks that promote conceptual and integrated understanding of the concepts, and writing the unit together with reflective thought, all seemed to be critical complementary conditions in successful integrated unit writing.

\section{Implications}

An array of policy recommendations are presently calling for, among other changes, increased attention to authentic and integrated learning, work-based learning and community service, professional collaboration among teachers, and the use of alternative assessments to build systems for continuous learning and school improvement (Grubb, 1997; National Council of Teachers of Mathematics, 2000; Mathematical Sciences Education Board, 1995). While implementing these new modes of educating is widely advocated, there are only a limited number of systemic efforts underway to assist educators in developing locally responsive approaches to these challenges. Furthermore, the research base for conducting interdisciplinary curriculum integration initiatives in secondary schools and post-secondary 
institutions is largely undeveloped. In this context, the findings of this study are both humbling and promising. Results are humbling because they show the difficulties in breaking down traditional beliefs of curriculum and instruction for the development of highly dynamic collaborations. Concurrently, in spite of the many interdisciplinary barriers which slow down the development of shared understandings about integration and authenticity, our analysis also suggests promising prospects for developing integrated, standards-based curricula. When given appropriate programmatic support, adequate time, and conceptual guidance, mathematics and vocational education instructors can develop effective collaborative efforts to write curriculum materials that integrate mathematical and career concepts, are based upon common principles which underlie both mathematics and VTE reform, and represent high quality authentic student work.

It is important to realize that if we are to have an impact on both teaching constituencies, professional development programs have to include topics that are relevant to integrated curriculum development collaboration, allow teachers to provide input on program design, and provide funding opportunities for continued collaboration. Schools should promote holistic understandings of common reform principles and encourage teachers to agree upon criteria for high student achievement, integrated curricula, instructional practices, and assessment strategies. Research on the impact of school culture and leadership on interdisciplinary teacher collaboration and, in turn, the impact of integrated curricula on students' mathematics learning and career development must be conducted. This line of research is particularly important to determine whether some forms of supports and integration are more effective than others and to measure the effects on mathematics learning and students' career development.

\section{References}

Adajian, L.B. (1995). Teachers' professional community and the teaching of mathematics (collaboration). Unpublished doctoral dissertation, University of Wisconsin-Madison.

American Mathematical Association of Two-Year Colleges. (1995). Crossroads in mathematics: Standards for introductory college mathematics before calculus. Memphis, TN: Author.

Betances, C. A. (1999). From professional development to practices: Factors in the implementation of standards-based curriculum and instruction. Unpublished doctoral dissertation, George Washington University.

Bottoms, G., \& Sharpe, D. (1996). Teaching for understanding through integration of academic and technical education. Atlanta, GA: Southern Regional Education Board.

Brendefur, J. (1996). Creating and revising authentic curriculum units. MathNet News, $l(1), 5,7$. 
Brendefur, J., Hernández-Gantes, V., \& Webb, N. (Fall 1998). MathNet Evaluation Report.Center for Education and Work: University of Wisconsin-Madison.

Brown, J. S., Collins, A., \& Duguid, P. (1989). Situated cognition and the culture of learning. Educational Researcher, 18(1), 32-42.

Dougherty, B., \& Ellibee, M. (1996). Curriculum quality standards for school-towork: A guidebook. Berkeley, CA: National Center for Research in Vocational Education.

Glaser, B.G. \& Strauss, A.L. (1967). The discovery of grounded theory: Strategies for qualitative research. Chicago: Aladine Publishers, CO.

Gray, K. C., \& Herr, E. L. (1995). Other ways to win: Creating alternatives for high school graduates. Thousand Oaks, CA: Crown Press.

Grubb, W.N. (1997). Not there yet: Prospects and problems for "education through occupations." Journal of Vocational Education Research, 22(2), 77-94.

Grubb, W.N. (Ed.). (1995). Education through occupations in American high schools. Volume I: Approaches to integrating academic and vocational education. New York, NY: Teachers College Press.

Hernández-Gantes, V. M., \& Nieri, L. A. (1997). Linking the NCTM standards to emerging vocationalism. Berkeley, CA: National Center for Research in Vocational Education.

Kruse, S., Seashore, L. K., \& Bryk A. (1994). Building professional community in schools. Issues in Restructuring Schools, Report No. 6, pp. 3-6. Madison, WI: Center on Organization and Restructuring of Schools.

Locke, M. S. (1999). Teacher attitudes toward implementation of school-based learning components, work-based learning components, and connecting activities, and use of instructional strategies related to school-based learning. Unpublished doctoral dissertation, University of La Verne.

Loucks-Horsley, S., Stiles, K., \& Hewson, P. (May, 1996). Principles of effective professional development for mathematics and science education: A synthesis of standards. NISE Brief, 1(1), pp. 1-6.

Mathematical Sciences Education Board. (1995). Mathematical preparation of the technical workforce: Report of a workshop. Washington, DC: National Research Council.

Merriam, S.B. (1998). Qualitative research and case study applications in education. San Francisco: Jossey-Bass.

National Center for Education Statistics. (1996). Pursuing excellence. A study of U.S. eighth-grade mathematics and science teaching, learning, curriculum, and achievement in international context (NCES 97-198). Washington, DC: U.S. Government Printing Office. 
National Council of Teachers of Mathematics. (1989). Curriculum and evaluation standards for school mathematics. Reston, VA: Author.

National Council of Teachers of Mathematics. (1991). Professional standards for the teaching of mathematics. Reston, VA: Author.

National Council of Teachers of Mathematics. (1995). Assessment standards for school mathematics. Reston, VA: Author.

National Council of Teachers of Mathematics. (2000). Principles and standards for school mathematics. Reston, VA: Author.

Newmann, F. M., \& Associates. (1996). Authentic achievement: Restructuring schools for intellectual quality. San Francisco, CA: Jossey-Bass.

Newmann, F. M., \& Wehlage, G. G. (1995). Successful school restructuring: A report to the public and educators. Madison, WI: Center on Organization and Restructuring of Schools, University of Wisconsin.

Newmann, F. M., Secada, W. G., \& Wehlage, G. G. (1996). A guide to authentic instruction and assessment: Vision, standards and scoring. Madison, WI: Wisconsin Center for Education Research.

Nickolas, M. (2000). Teacher collaboration: A survey of factors, attitudes, and preferences affecting implementation in mathematics. Unpublished doctoral dissertation, University of Pennsylvania.

Peterson, P. L., McCarthey, S. J., \& Elmore, R. F. (1996). Learning from school restructuring. American Educational Research Journal, 33(1), 119-153.

Phelps, L. A. (1992). Designing effective education-work linkages. Issues in Education and Work. Madison, WI: University of Wisconsin, Center on Education and Work.

Phelps, L. A., Hernández-Gantes, V. M., Jones, J., Sanchez, D., \& Nieri, A. H. (1995). Students' indicators of quality in emerging school-to-work programs. Journal of Vocational Education Research, 20(2), 75-102.

Porter, A. C., Kirst, M. W., Osthoff, E., Smithson, J. L., \& Schneider, S. A. (1994). Reform of high school mathematics and science and opportunity to learn. New Brunswick, NJ: Rutgers University, Consortium for Policy Research in Education.

Romberg, T. A., \& Carpenter, T. C. (1986). Research on teaching and learning of mathematics: Two disciplines of scientific inquiry. In M. C. Wittrock (Ed.), Handbook of research on teaching (3rd ed., pp. 850-873). New York: Macmillan Publishers.

Schmidt, B. J., Finch, C. R., Faulkner, S. L., \& Kandies, J. (1995). Preparing teachers to successfully integrate vocational and academic education: A case study approach. Berkeley, CA: National Center for Research in Vocational Education. 
Secada, W., \& Byrd, L. (1993). Classroom observation scales: School level reform in teaching of mathematics. Madison, WI: National Center for Research in Mathematical Sciences Education, University of Wisconsin-Madison.

Spillane, J. P., \& Zeuli, J. S. (1999). Reform and teaching: Exploring patterns of practice in the context of national and states mathematics reform. Educational Evaluation and Policy Analysis, 21(1), 1-27.

Spradley, J. (1979). The ethnographic interview. New York: Holt, Rinehart, \& Winston.

Stake, R.E. (1994). Case studies. In N. K. Denzin, \& Y. S. Lincoln (Eds.), Handbook of qualitative research, 236-247. Thousand Oaks, CA: Sage Publications.

Stasz, C., Kaganoff, T., \& Eden, R. (1994). Integrating academic and vocational education: A review of the literature, 1987-1992. Journal of Vocational Education Research, 19(2), 25-72.

Stigler, J., \& Hiebert, J. (1999). The teaching gap. New York, NY: Freedom Press.

Strauss, A.L. (1987). Qualitative analysis for social scientists. Cambridge: Cambridge University Press.

United State Congress. (1994). School to Work Opportunities Act of 1994 (P.L. No. 103-239). Washington, DC: Author.

Wirth, A. G. (1992). Education and work for the year 2000: Choices we face. San Francisco: Jossey-Bass.

Wolcott, H.F. (1994). Transforming qualitative data: Description, analysis, and interpretation. Thousand Oaks, CA: Sage.

\section{Appendix}

\section{Urban High Schools}

Kentucky School. An urban high school where minorities are bused from inner city projects. The school has an enrollment of 1,200 students and is a Magnet Career Academy for Public Safety Careers. The school has a record of support for teacher collaborative practices.

Minnesota School. An urban high school located in a federally-designated enterprise community serving 1,150 students from diverse backgrounds. The teacher-team enjoyed district support but was working together for the first time.

Wisconsin School. This urban high school has an enrollment of about 1,600 students. Teachers had been working on the integration of mathematics and VTE for several years but had no sustained collaborative efforts.

\section{Suburban High Schools}

New Jersey School. A suburban high school located 12 miles west of New York and serving about 775 students. The teacher-team had been working together for several years in a sustained effort to integrate mathematics and technology in a variety of grade and ability levels. 
California School. The high school is located in Southern California and serves about 1,876 students a year. Several teams of teachers team-teach in various areas but had no sustained collaborative efforts in the integration of mathematics and VTE.

\section{Rural High Schools}

Michigan School. This Vocational Center serves 15 school districts from three counties and has an annual enrollment of 867 students. The center offers a Manufacturing Academy in cooperation with a local community college. The teacher-team enjoyed school support but was working together for the first time.

South Carolina School. This is a rural high school serving 576 students a year. The school is 21 miles away from the nearest metropolitan area. The school has a record of support for collaborative efforts and is one of 18 Advanced Integration Model Sites with the Southern Regional Education Board.

\section{Post-Secondary}

Texas Community College. The college serves about 20,000 full-time/part-time students. Teachers had been formally working on integration efforts for several years under Perkins Grant initiatives. The teacher-team enjoyed college support but was working together for the first time and team members were located in different campuses.

\section{The Authors}

Victor M. Hernandez is Senior Educational Researcher in the Center for Educational Technologies at Wheeling Jesuit University, 316 Washington Avenue, Wheeling, West Virginia 26003. [E-mail: vmgantes@cet.edu]. His research interests are contextual teaching and learning, professional development, and impact of career-oriented programs on student learning and career development.

Jonathan L. Brendefur is Assistant Professor of curriculum and instruction at Boise State University, 1910 University Drive, Boise, Idaho 83725. [E-mail: jbrendef@boisestate.edu]. His research interests are mathematics education, curriculum development, students' thinking, and professional development. 


\title{
Perceptions of Traditionally and Alternatively Certified Career and Technical Education Teachers
}

\author{
Sheila K. Ruhland \\ University of Minnesota \\ Christine D. Bremer \\ University of Minnesota
}

\begin{abstract}
This study describes traditionally and alternatively certified secondary career and technical education (CTE) teachers' perceptions of their first year teaching experience. On a national level, there is an increase in the number of states providing alternative certification as an option to enter the teaching profession. Critics have argued that alternatively certified teachers are inferior to traditionally certified teachers. Results from this study reported secondary CTE teachers who completed a traditional certification program had better pre-service preparation in pedagogy. In contrast, alternatively certified teachers felt more prepared in knowledge of subject matter. The reported likelihood of remaining in the teaching profession did not vary based upon type of teacher certification program. Policymakers, state departments of education, and schools and colleges of education providing teacher preparation programs must help assure that teachers who are alternatively certified will be prepared to enter the teaching profession.
\end{abstract}

\section{Purpose}

Many alternative certification procedures for secondary academic and CTE teachers exist (Ruhland \& Bremer, 2002). However, few studies report how CTE teachers' preparation and teaching experiences vary. The primary purpose of this study was to report differences, if any, in recently certified CTE teachers' experience based upon the type of teacher certification program completed. The two types of teacher certification programs reported for the purpose of this study were traditional and alternative. Traditional certification programs were identified as the completion of a baccalaureate degree in education or fifth-year or post-baccalaureate program. These programs, while classified as alternative by Feistritzer and Chester (2000), share many characteristics with traditional teacher certification programs. Alternative certification refers to non-traditional routes to enter the teaching profession. These routes include, but are not limited to occupational competency, professional experience, and completion of a baccalaureate degree in the subject area. 
Often the terms licensure and certification are used interchangeably. Many use the term licensure only to refer to the process of obtaining an initial teaching credential. The license is the document or "permit" used to identify the teaching credential. In effect, one must be certified (by documenting successful completion of the requirements and processes) to obtain a license (permit to teach). In this study, however, the term certification is used broadly to refer to the entire range of policies, procedures, and practices employed to award credentials--a license--to teach in public schools. Each state has rules of certification prescribed by that state's governing board of education. The research questions for this study were:

1. Are there differences in ratings of pre-service preparation based upon type of certification program completed?

2. Are there differences in ratings of factors important to continue or not continue teaching based upon type of certification program completed?

3. Are there differences in ratings of support services used based upon type of certification program completed?

4. Are there differences in the likelihood to continue in the teaching profession based upon type of certification program completed?

\section{Literature Review}

The No Child Left Behind Act of 2001 (NCLBA) has caused state and district officials to focus on teacher quality in order to meet the requirements of the act for teachers to be highly qualified by the end of the 2005-2006 school year (United States General Accounting Office, 2003). To comply with NCLBA teachers must have state certification. As a result, state officials are reviewing laws regulating teacher education programs, licensure, initial certification, and re-certification of teachers.

Concerns about teacher preparation and qualifications have gained greater visibility due to the growing interest in education reform during a time of teacher shortages. Driving these changes is a growing sense that the traditional methods of preparing teachers, developed during the first half of the twentieth century, have not worked as well as they should have (Fraser, 2001). In the United States, state departments of education have established standard paths by which prospective teachers may obtain the credentials necessary to teach in public schools. However, there is no national agreement concerning the requirements for teaching; policies vary considerably from state to state. According to Goldhaber and Brewer (2001) "there is no single licensure system but instead fifty different systems. The rules that govern the alternative pathways into teaching also vary considerably" (p. 84).

\section{Issues and Challenges to Alternative Teacher Certification}

Alternative certification refers to non-traditional routes to enter the teaching profession (Ruhland \& Bremer, 2002). Alternatively certified individuals often have 
not completed an undergraduate degree in the field of education. Alternative certification encompasses a wide range of practices, ranging from emergency certification given to those with no teaching background or training, to programs designed to license or certify individuals who have an undergraduate degree in the field in which they plan to teach (Feistritzer \& Chester, 2001).

Nationwide, Feistritzer and Chester $(2000,2001)$ have identified 10 classes of alternative teacher certification routes. Nine of the classes represent categories of alternative certification available to individuals entering the teaching profession for the first time; the remaining category is used for states having no alternative certification routes. Following are the 10 classes of alternative certification routes identified by Feistritzer and Chester (2001):

1. Class $\mathrm{A}$ is a program designed for the explicit purpose of attracting talented individuals who already have at least a bachelor's degree in a field other than education into elementary or secondary school teaching. The program is not restricted to shortages, secondary grade levels or subject areas. Alternative teacher certification programs in these states involve teaching with a trained mentor, and formal instruction that deals with the theory and practice of teaching during the school year-and sometimes the summer before and/or after.

2. Class B is a teacher certification route that has been designed specifically to bring talented individuals into teaching who have at least a bachelor's degree in teaching. These programs involve specially designed mentoring and formal instruction. However, these states either restrict the program to shortages and/or secondary grade levels and/or subject areas.

3. Class $\mathrm{C}$ entails a review of academic and professional background, transcript analysis. They involve specially (individually) designed inservice and course-taking necessary to reach competencies required for certification, if applicable. The state and/or local school district have major responsibility for program design.

4. Class D entails a review of academic and professional background, transcript analysis. They involve specially (individually) designed inservice and course-taking necessary to reach competencies required for certification, if applicable. An institution of higher education has major responsibility for program design.

5. Class $\mathrm{E}$ is post-baccalaureate programs based at an institution of higher education.

6. Class F is basically an emergency route. The prospective teacher is issued some type of emergency certificate or waiver, which allows the individual to teach, usually without any on-site support or supervision, while taking the traditional teacher education courses requisite for full certification.

7. Class $\mathrm{G}$ are programs for persons who have few requirements left to fulfill before becoming certified through the traditional approved college teacher education program route, e.g., persons certified in one state moving to 
another; persons certified in one endorsement area seeking to become certified in another.

8. Cass $\mathrm{H}$ is a route that enables a person who has some "special" qualifications, such as a well-known author or Nobel Prize winner, to teach certain subjects.

9. Class I provides no alternatives to the approved college teacher education program route for licensing teachers.

10. Class $\mathrm{J}$ is designed to eliminate emergency routes. They prepare individuals who don't meet basic requirements to become qualified to enter an alternate or traditional route leading to teacher licensing. (p. 37)

While some critics argue that alternatively certified teachers are inferior to traditionally prepared teachers, Kwiatkowski (1999) maintained that alternative certification strategies will attract more competent and diverse candidates, individuals interested in and committed to teaching in urban schools, and decreasing need for emergency credentialing. Darling-Hammond, Chung, and Frelow (2002) however found reasons to criticize the use of alternative certification routes. They analyzed 1998 data from a survey of beginning teachers in New York City according to individual teacher education program and by pathway to teaching. DarlingHammond et al. reported that teachers who completed traditional teacher preparation programs reported feeling better prepared to teach than those who completed alternative programs. While there was substantial variation across programs and pathways, it was found that teachers' sense of being well prepared was correlated with their sense of teaching efficacy, feeling responsible for student learning, and planning to stay in the teaching profession.

Shen (1997), while agreeing that alternative certification can help diversify the teaching workforce and alleviate shortages, also had concerns about the value of alternative certification. In a study based on the 1993-1994 Schools and Staffing Survey conducted by the National Center for Education Statistics, Shen reported that: (a) alternatively certified teachers appeared to have lower academic qualifications than traditionally certified teachers; (b) relatively few individuals were recruited from other fields through alternative certification, while new college graduates took advantage of alternative programs to avoid the rigors of traditional ones; and (c) a lower percentage of alternatively certified teachers reported expecting that teaching would be their lifelong career, raising concerns about retention. Further, in Shen's view, the larger proportion of alternatively certified teachers employed in inner city schools raised questions about quality of teaching and educational equity for lowincome students.

Laczko-Kerr and Berliner (2002) also came to the conclusion that traditional certification was superior to alternative certification. They compared the academic achievement of elementary students taught by teachers from the national Teach for America program with students taught by teachers who had attended regular teacher certification programs at accredited universities and met all state requirements. They 
found that students of regularly-certified teachers performed significantly better in reading, mathematics, and language arts, while students of what they termed undercertified teachers made about $20 \%$ less academic growth per year when compared to students of regularly certified teachers. These authors believe that teachers from Teach for America and similar non-traditional certification programs contribute to the gap in achievement between poor children and children who are more advantaged.

\section{Certification Procedures in Career and Technical Education}

Career and technical education (CTE) has not escaped the issues and challenges confronting teacher certification. Traditionally, teachers in trade and industrial (T\&I) and health occupations have been alternatively certified on the basis of their occupational competence, while the majority of CTE teachers (e.g., agriculture, family and consumer sciences, business, marketing, and technology education) enter the teaching profession via the traditional four-year baccalaureate degree (Walter \& Gray, 2002). In 1994, more than 45\% of secondary trade and industrial education teachers did not have bachelor's degrees (Lynch, 1996). Lynch reported "virtually every state permits an alternative certification or credentialing program for some teachers in vocational and technical education. The primary alternative is to substitute years of occupational experience for higher levels of formal education" (p. 23). The impact of this common practice on teacher preparedness and quality of teachers is unknown.

Ruhland and Bremer (2002) reported multiple alternative certification routes available for secondary academic and CTE teachers. The alternative certification routes available for CTE teachers were similar to those for academic teachers. The most frequently identified alternative certification route varied by CTE area. In agriculture, marketing, and technology, the most common certification route was one designed for individuals who currently have a bachelor's degree. In business, computer science, health careers, and marketing, the most common certification route was one that reviewed an individual's academic and professional background and transcripts, with certification approval the responsibility of the state and/or local school district. For family and consumer sciences, health careers, and trade and industrial, the most common certification route was one that provided individuals with an emergency certificate or waiver to teach.

\section{Teacher Attrition and Retention}

Understanding the factors underlying teacher attrition and retention will help assure quality of teaching in our educational systems. Marlow, Inman, and Betancourt-Smith (1997) researched the impact of support systems on improving retention among teachers with having characteristics that predict attrition. They concluded that beginning teachers need opportunities to interact with "(a) colleagues who have similar ideas about teaching and working cooperatively, (b) administrators 
who encourage and promote teachers' ideas, and (c) a community that feels positively about the educational system and the people in it" (p. 213). They recommended additional support for teachers to include "a combined effort of administration, teachers, and people within the community" (p. 213).

Kirby and LeBude (1998) conducted research to identify retention strategies for beginning vocational teachers in health, agriculture, and biotechnology. The authors suggested two retention strategies for the first five years of a new teacher's career. The first strategy was to assign a support team, rather than a single teacher, to a new teacher. The support team would include a mentor teacher and/or subjectarea peer teacher, administrator, state staff, and teacher educator. The second strategy was to provide assistance to new teachers, such as adequate resource materials, facilities to support curriculum, continuing education reimbursement, and positive work climate.

Employing a mentoring program can reduce early attrition of beginning teachers (Odell \& Ferraro, 1992). For the purpose of this study, mentoring is defined as an "intense caring relationship in which persons with more experience work with less experienced persons to promote both professional and personal development" (Caffarella, 1992, p. 38). Mentors can assist with classroom management issues, locate resources, and provide advice to new teachers. Mentoring programs can be costly, but the money saved on recruiting and rehiring teachers yearly has shown the financial effectiveness of mentoring programs. "Teachers who were still teaching after four years most valued the emotional support that they received from their mentors in their first year of teaching" (Odell \& Ferraro, 1992, p. 203).

Overall, research has indicated that adequate pre-service preparation and inservice support of novice teachers are important to improving both teaching quality and retention. Alternative certification programs vary widely in the amount of preservice preparation provided; individuals with little pre-service preparation and no opportunity to engage in a supervised teaching experience may need higher levels of in-service support in order to be successful. Concerning retention, research indicates that teachers, regardless of teacher certification program, depart their jobs for a variety of reasons. In a study conducted by Ingersoll (1999) teachers reported they departed because they were dissatisfied with their jobs or to seek better career opportunities.

For many teachers, the effort invested in gaining certification can be presumed to be a measure of interest in remaining in the field. Since many career and technical education teachers have had another career and bypass a great deal of the typical teacher preparation process, they may feel less committed to the teaching profession.

\section{Methodology}

This study was exploratory research with data collected using survey methods. The Mann-Whitney U-test (two-tailed) for ordinal and two sample comparisons (traditionally and alternatively certified teachers) was used to test for 
statistical significance when notable differences were found in the descriptive statistics for the two groups. The $p$-value for statistical significance was set at $p \leq$ .05 for all statistical analysis. Further, note that while the subsequent tables may show percentages, all U-test analyses were performed on raw response data.

\section{Participants}

State department of education personnel were contacted by telephone and/or email between February and May 2001 to determine if their state would be able to identify a list of CTE teachers with names and addresses hired between 1996 and 2000. In eight states, state department of education personnel were not able to identify a list of CTE teachers, but provided information that enabled the researchers to obtain names and addresses from local school districts or teacher education programs.

A total of 28 states $(55 \%)$ were able to provide the names and addresses, or provide access to, traditionally and alternatively certified CTE teachers hired between 1996 and 2000 (Table 1). Seven states agreed to mail the letters and surveys directly to the teachers on behalf of the researchers since those states were unable to release teachers' names and addresses due to state privacy issues. Nineteen states $(37 \%)$ were not able to obtain and/or provide a list of teachers' names and addresses within the timeframe requested. Four states failed to respond to the request for information. While the non-participation of some states probably reduces the study's generalizability, the researchers had no control over which to include or exclude in the study. All available participants were included.

The sample for the study consisted of the names provided by the 28 states (Table 1). Each state was asked to provide a random sample of 90 CTE teachers hired between 1996 and 2000. Eight states identified fewer than 90 CTE teachers hired between 1996 and 2000. For these eight states, the entire population was included in the sample. This process yielded names of 2,091 CTE teachers. Not all states were able to provide a list of traditionally or alternatively certified CTE teachers hired between 1996 and 2000. Therefore, results from this study cannot be generalized on a national level.

\section{Design and Procedures}

A two-page survey was designed based upon a review of state department of education certification documents and a survey previously developed by Ruhland (2001). The survey was designed to collect data from CTE teachers regarding demographics, CTE certification area(s), type of teacher certification program, status of teacher certification requirements, pre-service preparation, support services and likelihood to remain in the teaching profession.

To establish content validity of the survey instrument, a panel of six experts was invited in March 2001 to review questions and determine if the survey instrument represented the content of the research questions. Each expert was either 
traditionally or alternatively certified, and familiar with the educational preparation of CTE teachers and the skills and abilities taught in teacher preparation programs. These experts were asked to make recommendations for improving, adding, or deleting survey items to assure each survey question was measuring the question intended. After the panel established content validity a pilot-test was conducted with 12 traditionally or alternatively certified CTE teachers in March 2001. Comments were obtained from six panel experts, and improvements made to the survey. Most

Table 1

Summary of State Participation and Number of Surveys Sent and Received

\begin{tabular}{|c|c|c|}
\hline State $^{\mathrm{a}}$ & Surveys Sent $^{\mathrm{b}}$ & Surveys Received $^{\mathrm{c}}$ \\
\hline Alabama & 90 & 18 \\
\hline Alaska & 90 & 15 \\
\hline California & 90 & 31 \\
\hline Connecticut & $89^{d}$ & 22 \\
\hline Delaware & 15 & 0 \\
\hline Florida & 90 & 27 \\
\hline Idaho & 70 & 13 \\
\hline Illinois & 90 & 23 \\
\hline Iowa & 90 & 30 \\
\hline Kansas & 50 & 15 \\
\hline Kentucky & 40 & 17 \\
\hline Maryland & 90 & 34 \\
\hline Michigan & 90 & 29 \\
\hline Minnesota & 90 & 26 \\
\hline Mississippi & 90 & 14 \\
\hline Missouri & 90 & 21 \\
\hline Nebraska & 90 & 35 \\
\hline New Jersey & 90 & 26 \\
\hline North Dakota & 90 & 46 \\
\hline Oklahoma & 90 & 37 \\
\hline Rhode Island & 8 & 4 \\
\hline South Dakota & 24 & 12 \\
\hline Texas & 90 & 18 \\
\hline Virginia & 65 & 27 \\
\hline Washington & 90 & 38 \\
\hline West Virginia & 20 & 2 \\
\hline Wisconsin & 90 & 24 \\
\hline Wyoming & 90 & 28 \\
\hline
\end{tabular}

${ }^{\mathrm{a}} N=28 ;{ }^{\mathrm{b}} N=2,091{ }^{\mathrm{c}} N=632 ;{ }^{\mathrm{d}}$ Received 90 names, of which one name was a duplicate. 
changes focused on the re-wording of questions to increase clarity. CTE teachers were sent the survey in April and May 2001 with a follow-up postcard sent to each participant two weeks after the initial mailing.

From the $632(30 \%)$ completed surveys received by the end of June 2001 (Table 1), 608 (29\%) were usable. Seventy-one respondents identified they were not certified in a CTE area; therefore these respondents were not included in the data analysis. Of the 608 useable surveys, respondents reported certification in at least one of the eight CTE areas (e.g., agriculture, business, computer science, family and consumer science, health, marketing, technology, and trade and industrial).

\section{Results}

Of the $608(29 \%)$ CTE respondents, $405(67 \%)$ participated in a traditional teacher certification program (i.e. baccalaureate degree in education that leads to certification or fifth-year or post-baccalaureate program that leads to certification) and $203(33 \%)$ respondents participated in an alternative teacher certification program (i.e. non-traditional, occupational experience, certificate program). Survey results indicated $59 \%$ of the traditionally certified teachers were 40 years of age or younger, and $35 \%$ of the alternatively certified teachers were 40 years of age or younger. At the time the respondents began teaching, $79 \%$ of the traditionally certified teachers had completed all the requirements for teacher certification, and $23 \%$ of the alternatively certified teachers had completed all the requirements for teacher certification. Sixty-four percent of the traditionally and $64 \%$ of the alternatively certified teachers rated their teaching experience thus far as very positive.

Research question one asked, "Are there differences in ratings of pre-service preparation based upon type of certification program completed?" To answer this question, respondents were divided and compared based upon type of teacher certification program (traditional or alternative certification). CTE respondents rated the adequacy of pre-service training in four areas as experienced during their first six months of teaching (Table 2). Significant differences were found in the pre-service preparation areas of pedagogy $(p=.0001)$ and knowledge of subject matter ( $p=$ .0005 ) based upon type of certification program. No significant differences were found in ratings of pre-service preparation areas of classroom management skills and strategies for working with special populations.

The second research question was, "Are there differences in ratings of factors important to continue or not continue teaching based upon type of certification program completed?" To answer this question respondents were divided and compared based upon type of teacher certification program (traditional or alternative certification). Respondents were asked to rate a list of 15 factors as to overall importance in the decision to continue or not continue in the teaching profession (Table 3). 
Table 2

Career and Technical Education Teachers' Pre-service Preparation.

\begin{tabular}{|c|c|c|c|c|c|c|c|c|}
\hline \multirow[b]{3}{*}{ Pre-service preparation } & \multicolumn{2}{|c|}{$\begin{array}{c}\text { Not } \\
\text { Adequate }\end{array}$} & \multicolumn{2}{|c|}{$\begin{array}{l}\text { Somewhat } \\
\text { Adequate }\end{array}$} & \multicolumn{2}{|c|}{$\begin{array}{l}\text { Moderately } \\
\text { Adequate }\end{array}$} & \multicolumn{2}{|c|}{$\begin{array}{c}\text { Very } \\
\text { Adequate }\end{array}$} \\
\hline & ${ }^{\mathrm{a}} \mathrm{T}$ & ${ }^{\mathrm{b}} \mathrm{A}$ & $\mathrm{T}$ & $\mathrm{A}$ & $\mathrm{T}$ & $\mathrm{A}$ & $\mathrm{T}$ & $\mathrm{A}$ \\
\hline & $\%$ & $\%$ & $\%$ & $\%$ & $\%$ & $\%$ & $\%$ & $\%$ \\
\hline $\begin{array}{l}\text { Pedagogy or teaching } \\
\text { methods* }\end{array}$ & 8 & 16 & 18 & 31 & 47 & 34 & 25 & 16 \\
\hline $\begin{array}{l}\text { Knowledge of subject } \\
\text { matter* }\end{array}$ & 2 & 2 & 4 & 5 & 35 & 19 & 56 & 72 \\
\hline $\begin{array}{l}\text { Classroom management } \\
\text { skills }\end{array}$ & 10 & 11 & 31 & 32 & 39 & 37 & 19 & 19 \\
\hline $\begin{array}{l}\text { Strategies for working with } \\
\text { special populations }\end{array}$ & 16 & 21 & 39 & 41 & 34 & 23 & 10 & 14 \\
\hline
\end{tabular}

Note. Percentage may not total $100 \%$ due to rounding. $N=608$. Group comparison between traditionally and alternatively certified teachers based upon total question responses. The Mann-Whitney $U$ test was used to compare the responses of traditionally and alternatively certified teachers.

${ }^{\mathrm{a}} \mathrm{T}=$ Traditional certification program. ${ }^{\mathrm{b}} \mathrm{A}=$ Alternative certification program. $* p<.05$

Six (40\%) of the 15 factors received the greatest number of responses as being very important for traditionally and alternatively certified teachers to continue in the teaching profession: (a) positive teaching experience, (b) sense of accomplishment, (c) positive interaction with students, (d) pleasant working conditions, (e) perception of job security, and (f) potential for salary increases. Of the six factors, positive teaching experience, sense of accomplishment, and positive interaction with students were rated by over $50 \%$ of the respondents as very important in determining their intention to continue or not continue teaching. Availability of a mentoring program was rated as not important by $32 \%$ of the traditionally certified teachers and not important by $28 \%$ of the alternatively certified teachers. Significant differences were reported in ratings of three factors to continue or not continue teaching: (a) sense of accomplishment ( $p=.0156)$, (b) availability of a mentoring program $(p=.0245)$, and (c) recognition and support from supervisor $(p=.0360)$.

Research question three asked, "Are there differences in ratings of support services used based upon type of certification program completed?" To answer this question, respondents were divided and compared based upon type of teacher certification program (traditional or alternative certification). Respondents were asked to identify the availability and use of eight support services prior to or during their first six months of teaching (Table 4). Most frequently reported support services available and used to some degree were a teacher handbook and orientation 
Table 3

Career and Technical Education Teachers' Rating of Factors Important to Continue or Not Continue Teaching.

\begin{tabular}{|c|c|c|c|c|c|c|c|c|}
\hline \multirow[b]{3}{*}{ Retention factors } & \multicolumn{2}{|c|}{$\begin{array}{c}\text { Not } \\
\text { Important }\end{array}$} & \multicolumn{2}{|c|}{$\begin{array}{l}\text { Somewhat } \\
\text { Important }\end{array}$} & \multicolumn{2}{|c|}{$\begin{array}{l}\text { Moderately } \\
\text { Important }\end{array}$} & \multicolumn{2}{|c|}{$\begin{array}{c}\text { Very } \\
\text { Important }\end{array}$} \\
\hline & ${ }^{\mathrm{a}} \mathrm{T}$ & ${ }^{\mathrm{b}} \mathrm{A}$ & $\mathrm{T}$ & $\mathrm{A}$ & $\mathrm{T}$ & $\mathrm{A}$ & $\mathrm{T}$ & $\mathrm{A}$ \\
\hline & $\%$ & $\%$ & $\%$ & $\%$ & $\%$ & $\%$ & $\%$ & $\%$ \\
\hline Positive teaching experience & 1 & 1 & 5 & 6 & 28 & 27 & 64 & 64 \\
\hline $\begin{array}{l}\text { Professional development } \\
\text { opportunities }\end{array}$ & 8 & 7 & 23 & 26 & 42 & 40 & 25 & 26 \\
\hline $\begin{array}{l}\text { Business and community } \\
\text { internship opportunities }\end{array}$ & 32 & 30 & 34 & 29 & 22 & 26 & 9 & 13 \\
\hline Sense of accomplishment* & 0 & 0 & 5 & 4 & 27 & 18 & 66 & 76 \\
\hline $\begin{array}{l}\text { Availability of mentoring } \\
\text { program* }\end{array}$ & 32 & 28 & 31 & 24 & 24 & 29 & 11 & 17 \\
\hline $\begin{array}{l}\text { Availability of support } \\
\text { services for new teachers }\end{array}$ & 21 & 20 & 33 & 29 & 25 & 24 & 19 & 23 \\
\hline $\begin{array}{l}\text { Recognition and support } \\
\text { from supervisor* }\end{array}$ & 6 & 6 & 18 & 11 & 40 & 37 & 34 & 42 \\
\hline $\begin{array}{l}\text { Recognition and support } \\
\text { from peers }\end{array}$ & 5 & 6 & 18 & 21 & 46 & 41 & 28 & 31 \\
\hline $\begin{array}{l}\text { Positive interactions with } \\
\text { students }\end{array}$ & 0 & 0 & 3 & 2 & 25 & 27 & 69 & 70 \\
\hline $\begin{array}{l}\text { Approval of family and/or } \\
\text { friends }\end{array}$ & 14 & 12 & 21 & 25 & 38 & 36 & 26 & 26 \\
\hline Pleasant working conditions & 0 & 2 & 8 & 9 & 39 & 39 & 52 & 49 \\
\hline $\begin{array}{l}\text { Quality and quantity of } \\
\text { resources }\end{array}$ & 4 & 6 & 15 & 13 & 42 & 41 & 36 & 37 \\
\hline Leadership opportunities & 8 & 11 & 27 & 28 & 42 & 39 & 21 & 21 \\
\hline Perception of job security & 6 & 6 & 14 & 16 & 37 & 34 & 41 & 40 \\
\hline Potential for salary increases & 5 & 6 & 13 & 16 & 35 & 33 & 45 & 41 \\
\hline
\end{tabular}

Note. Percentage may not total $100 \%$ due to rounding. $(N=608)$. Group comparison between traditionally and alternatively certified teachers based upon total question responses. The Mann-Whitney $U$ test was used to compare the responses of traditionally and alternatively certified teachers.

${ }^{\mathrm{a}} \mathrm{T}=$ Traditional certification program. ${ }^{\mathrm{b}} \mathrm{A}=$ Alternative certification program. $* p<.05$

to policies and procedures within the school district. Paid curriculum development, on-site certification courses, and tuition assistance were reported by over $50 \%$ of the traditionally and alternatively certified teachers as not available. Alternatively certified teachers reported as available and used to a significant degree a mentor 
(30\%) and curriculum and instructional resources (39\%), whereas traditionally certified teachers reported available and used to a significant degree a mentor $(21 \%)$ and curriculum and instructional resources (32\%). Significant differences were reported in ratings of two support services: (a) on-site certification courses ( $p=$ $.0398)$, and (b) tuition assistance for certification courses $(p=.0001)$.

Table 4

Career and Technical Education Teachers' Support Services Used During First Six Months of Teaching.

\begin{tabular}{|c|c|c|c|c|c|c|c|c|}
\hline \multirow[b]{3}{*}{ Support services used } & \multicolumn{2}{|c|}{$\begin{array}{c}\text { Not } \\
\text { Available }\end{array}$} & \multicolumn{2}{|c|}{$\begin{array}{l}\text { Available } \\
\text { Did Not } \\
\text { Use }\end{array}$} & \multicolumn{2}{|c|}{$\begin{array}{c}\text { Available } \\
\text { Used } \\
\text { Some } \\
\text { Degree }\end{array}$} & \multicolumn{2}{|c|}{$\begin{array}{l}\text { Available } \\
\text { Used } \\
\text { Significant } \\
\text { Degree }\end{array}$} \\
\hline & ${ }^{\mathrm{a}} \mathrm{T}$ & ${ }^{\mathrm{b}} \mathrm{A}$ & $\mathrm{T}$ & $\mathrm{A}$ & $\mathrm{T}$ & $\mathrm{A}$ & $\mathrm{T}$ & $\mathrm{A}$ \\
\hline & $\%$ & $\%$ & $\%$ & $\%$ & $\%$ & $\%$ & $\%$ & $\%$ \\
\hline Teacher handbook & 16 & 20 & 20 & 16 & 43 & 38 & 18 & 23 \\
\hline Curriculum and instructional & & & & & & & & \\
\hline $\begin{array}{l}\text { resources } \\
\text { Mentor }\end{array}$ & 11 & 15 & 11 & $\begin{array}{l}14 \\
17\end{array}$ & 43 & 29 & $\begin{array}{l}32 \\
21\end{array}$ & 39 \\
\hline $\begin{array}{l}\text { Mentor } \\
\text { Peer cunnort oroun }\end{array}$ & 32 & 26 & 14 & 17 & 29 & 26 & 21 & 30 \\
\hline Peer support group & 40 & 32 & 15 & 20 & 29 & 26 & 13 & 19 \\
\hline $\begin{array}{l}\text { Orientation to policies and } \\
\text { procedures within the } \\
\text { school district }\end{array}$ & 16 & 15 & 20 & 24 & 44 & 39 & 17 & 19 \\
\hline $\begin{array}{l}\text { Paid curriculum } \\
\text { development time prior to } \\
\text { teaching }\end{array}$ & 70 & 67 & 8 & 9 & 11 & 11 & 6 & 8 \\
\hline On-site certification courses* & 74 & 67 & 10 & 13 & 7 & 10 & 4 & 6 \\
\hline $\begin{array}{l}\text { Tuition assistance for } \\
\text { certification } \\
\text { courses* }\end{array}$ & 72 & 56 & 8 & 10 & 8 & 10 & 7 & 20 \\
\hline
\end{tabular}

Note. Percentage may not total $100 \%$ due to rounding. $N=608$. Group comparison between traditionally and alternatively certified teachers based upon total question responses. The Mann-Whitney $U$ test was used to compare the responses of traditionally and alternatively certified teachers.

${ }^{\mathrm{a}} \mathrm{T}=$ Traditional certification program. ${ }^{\mathrm{b}} \mathrm{A}=$ Alternative certification program. $* p<.05$

The fourth research question was, "Are there differences in the likelihood to continue in the teaching profession based upon type of certification program completed?" To answer this question, respondents were divided and compared based upon type of teacher certification program (traditional or alternative certification) 
Table 5

Career and Technical Education Teachers' Comparison of Teaching Certification Program and Intentions to Continue or Leave the Teaching Profession

\begin{tabular}{|c|c|c|}
\hline Teaching intentions & $\frac{\text { Traditional }}{\%}$ & $\frac{\text { Alternative }}{\%}$ \\
\hline Plan to continue ( 8 or more years) & 51 & 56 \\
\hline Probably continue teaching ( 3 to 7 years) & 30 & 29 \\
\hline Actively considering non-teaching job & 7 & 3 \\
\hline Retiring & 3 & 4 \\
\hline
\end{tabular}

Note. Percentage may not total $100 \%$ due to rounding. $N=608$.

(Table 5). Over $50 \%$ of the respondents, regardless of type of teacher certification program indicated they plan to continue teaching for eight or more years. Only $10 \%$ of the traditionally certified teachers and $5 \%$ of the alternatively certified teachers reported they were actively considering a non-teaching job or otherwise planning to leave the teaching profession. There were no differences reported in likelihood to continue in the teaching profession.

\section{Conclusions}

Several findings emerged from this study regarding CTE teachers' perceptions of their first year teaching experience based upon type of teacher certification program. The present study asked CTE teachers, at the time they began teaching, if their requirements for teacher certification had been completed. Of the CTE respondents, $79 \%$ of the traditionally certified teachers had completed all the requirements when they began teaching, and $23 \%$ of the alternatively certified teachers had completed all the requirements when they began teaching. These results are consistent with previous research (Lynch, 1996), which reported many CTE teachers are not fully certified when they begin teaching.

CTE teachers completing a traditional certification program (baccalaureate degree in education; or fifth-year or post-baccalaureate program) versus an alternative certification program reported differences in the pre-service preparation areas of pedagogy and knowledge of subject matter. This concurs with the findings of Darling-Hammond et al. (2002). A contrasting finding is that in pedagogy, traditionally certified teachers reported being more prepared than alternatively certified teachers. In contrast, in knowledge of subject matter, alternatively certified teachers felt more prepared than traditionally certified teachers.

Regardless of certification program completed teachers in this study reported a need for additional ongoing support in two key areas: classroom management and working with special needs students. Accepted classroom management practices vary from school to school, but teachers can be better prepared for the challenge of classroom management by having a thorough knowledge of the many factors that 
affect student behavior, such as the arrangement of the classroom, establishment of class rules, choice of instructional activities, managing conflict and compromise, and improving students' social skills. New teachers also need a thorough understanding of how to work with students with disabilities. In addition to more pre-service preparation in these areas, teachers should have ongoing professional development opportunities available to them and should be encouraged to develop collaborative relationships with special education teachers.

Teachers completing a traditional or alternative certification program responded similarly concerning factors important to them in deciding whether to continue or not continue in the teaching profession. In both groups, respondents did not highly rate the importance of a mentoring program. Thirty-two percent of the traditionally certified teachers rated a mentor program as not important, as did $28 \%$ of the alternatively certified teachers. This finding stands in contrast to the conclusions reached by Kirby and LeBude (1998) and Odell and Ferraro (1992), who emphasized, based on their research findings, the retention-enhancing value of providing a mentor teacher during the first years of a new teacher's career. The present study did not probe the reasons for respondents' lack of enthusiasm for mentors, but it may be that those responding "not important" found a previous mentoring experience not helpful, or, because they had prior non-CTE teaching experience, may have viewed a mentor as not important or not critical to remaining in the profession. It is also possible that those who had a good relationship with their mentor found the relationship more helpful than did those who did not have a good relationship with their mentor.

Positive teaching experience, sense of accomplishment, and positive interaction with students were rated as very important by both traditionally and alternatively certified teachers in deciding whether to continue in the teaching profession. However, differences were found between alternatively and traditionally certified teachers on three factors important to deciding to continue in the teaching profession. The three factors were sense of accomplishment, availability of a mentoring program, and recognition and support from supervisor. These differences may be due to a lack of self-confidence on the part of alternatively certified teachers as they enter the teaching profession. These findings may be an indication that these teachers will need additional support in order to remain in the teaching profession. Providing such support may increase the likelihood of both traditional and alternatively certified teachers continuing teaching as a lifelong career (Shen, 1997; Ingersoll, 1999).

Teachers who reported a more positive rating of their teaching experience also reported a greater likelihood of staying in the teaching profession. An equal percentage $(64 \%)$ of traditionally certified teachers and alternatively certified teachers rated their teaching experience as very positive or extremely positive. The reported likelihood of remaining in the teaching profession did not vary based upon type of teacher certification program. Whether a CTE teacher participated in a baccalaureate degree in education, fifth-year or post-baccalaureate program, or 
alternative certification program, $51 \%$ of the traditionally certified teachers and $56 \%$ of the alternatively certified teachers reported they plan to continue teaching eight or more years.

The finding that traditionally and alternatively certified CTE teachers felt equally likely to remain in the profession suggests concerns about the long-term commitment of alternatively certified CTE teachers may not be well-founded. At the same time, these findings do not support Kwiatkowski's (1999) contention that alternatively certified teachers were more committed to teaching in challenging settings. An emphasis on adequate preparation so the first year of teaching is a positive experience should help improve retention of all teachers, whatever their certification route.

\section{Summary and Implications for Further Research}

Policymakers, state departments of education, and schools and colleges of education providing teacher preparation programs must help assure that teachers who are alternatively certified will be prepared to enter the teaching profession. Findings from this study indicate a need for more collaborative efforts among those preparing teachers and those hiring them. These findings will assist those responsible for state certification policy in reviewing existing procedures and modifying pre-service and in-service programs. It is anticipated that state departments of education will continue to confront new challenges as the availability of alternative certification routes increases.

This study has yielded information that may benefit state departments of education as they focus on teacher quality in response to the NCLBA. Federal criteria for a highly qualified public elementary school or secondary school teacher requires that each teacher has "obtained full state certification as a teacher (including alternative certification). . . and has not had certification or licensure requirements waived or emergency, temporary, or provisional basis" (United States General Accounting Office, 2003, p. 7). In this study, 67\% of the respondents reported participating in a traditional teacher certification program. However, at the time these respondents began teaching, $21 \%$ had not completed all the requirements for full state certification.

This study further indicates the challenge states have with their teacher certification data systems. In this study, only 28 states were able to provide a list of CTE teachers hired between 1996 and 2000. Data collection practices need to be improved at the state level so as to accurately identify those teachers who have obtained full state certification. States will need to develop up-to-date data systems to track teacher certification.

The role and value of a teacher mentor needs to be better understood. The NCLBA has revised criteria for alternative certification programs that would require this type of program to have "teacher mentors in order for those teachers to be considered high qualified" (United States General Accounting Office, 2003, p. 10). 
The apparent discrepancy between the findings of this study and that of other researchers suggests the need for further research on the benefits of teacher mentors and on what factors tend to enhance the value of teacher mentoring experiences.

Researchers should continue to study the relationship between types of teacher certification and teachers' intentions to remain in the field. Equally important would be research on which components of teacher preparation influence retention. Within this area of study, it would be helpful to better understand the factors influencing retention of teachers in urban and rural settings, where many alternatively certified teachers find their first jobs.

A longitudinal study should be conducted to compare the likelihood of retention of traditionally and alternatively certified CTE teachers with varying levels of preparation. The findings of this study suggest that better preparation in classroom management and in working with students with disabilities would be helpful to beginning teachers. The impact of improved preparation in these areas may be demonstrated in retention data. A study of this type would reveal concerns of traditionally and alternatively certified CTE teachers and provide guidance for potential teacher candidates.

Alternative teacher certification programs can help to alleviate critical teacher shortages. However, these programs must offer high quality preparation so that newly certified teachers can be effective in the classroom and will want to stay in the field. The NCLBA legislation should help to spur initiatives to assure that alternatively certified teachers are fully qualified and feel ready for the challenges of classroom teaching.

\section{References}

Caffarella, R. S. (1992). Psychosocial development of women: Linkages of teaching and leadership in adult education (Information Series No. 350). Columbus, OH: ERIC Clearinghouse on Adult, Career, and Vocational Education, Center on Education and Training for Employment. (ERIC Document Reproduction Service No. ED354386).

Darling-Hammond, L., Chung, R., \& Frelow, F. (2002). Variation in teacher preparation: How well do different pathways prepare teachers to teach? Journal of Teacher Education, 53(4), 286-302.

Feistritzer, C. E., \& Chester, D. T. (2000). Alternative teacher certification: A stateby-state analysis 2000. Washington, DC: National Center for Education Information.

Feistritzer, C. E., \& Chester, D. T. (2001). Alternative teacher certification: A stateby-state analysis 2001. Washington, DC: National Center for Education Information. 
Fraser, J. W. (2001, January 31). Time to cut the link between teacher preparation and certification? Education Week on the Web. Retrieved April 21, 2003, from http://www.edweek.org/ew/ewstory.cfm?slug=20fraser.h20

Goldhaber, D. D., \& Brewer, D. J. (2001). Evaluating the evidence on teacher certification: A rejoinder. Educational Evaluation and Policy Analysis, 23(1), 79-86.

Ingersoll, R. M. (1999). Teacher turnover, teacher shortages, and the organization of schools. Seattle, WA: Center for the Study of Teaching and Policy.

Kirby, B. M., \& LeBude, A. V. (1998). Induction strategies that work: Keeping agricultural, health, and biotechnology career development beginning teachers in the classroom. Journal of Vocational and Technical Education, 15(1), 1727.

Kwiatkowski, M. (1999). Debating alternative teacher certification: A trial by achievement. In M. Kanstoroom \& C. E. Finn, Jr. (Eds.), Better teachers, better schools, (pp. 215-238). Washington, DC: Thomas B. Fordham Foundation.

Laczko-Kerr, I., \& Berliner, D. C. (2002). The effectiveness of "Teach for America" and other under-certified teachers on student academic achievement: A case of harmful public policy. Education Policy Analysis Archives, 10(37). Retrieved January 9, 2003, from http://epaa.asu.edu/epaa/v10n37/.

Lynch, R. L. (1996). Vocational teacher education: At a crossroads. Vocational Education Journal, 71(1), 22-24.

Marlow, L., Inman, D., \& Betancourt-Smith, M. (1997). Beginning teachers: Are they still leaving the profession? Clearing House, 70(4), 211-214.

Odell, S. J., \& Ferraro, D. P. (1992). Teacher mentoring and teacher retention. Journal of Teacher Education, 43(3), 200-204.

Ruhland, S. K. (2001). Teacher shortage: An analysis of factors impacting the turnover and retention of secondary career and technical education teachers. Journal of Career and Technical Education, 17(2), 36-47.

Ruhland, S. K., \& Bremer C. D. (2002). Alternative teacher certification procedures and professional development opportunities for career and technical education teachers. St. Paul, MN: The National Research Center for Career and Technical Education.

Shen, J. (1997). Has the alternative certification policy materialized its promise? A comparison between traditionally and alternatively certified teachers in public schools. Educational Evaluation and Policy Analysis, 19(3), 276-283.

United States General Accounting Office. (2003). No Child Left Behind Act. More information would help states determine which teachers are highly qualified. (GAO, Publication No. 03-631). Washington, DC: Author. 
Walter, R. A., \& Gray, K. C. (2002). Teacher preparation/licensure in career and technical education: A public policy analysis. Journal of Vocational Education Research, 27(1), 127-149.

\section{Author Notes}

This research project was part of the program of work of the National Research Center for Career and Technical Education at the University of Minnesota funded by the U.S. Department of Education, Office of Vocational and Adult Education entitled "Alternative Teacher Certification Procedures and Professional Development Opportunities for Career and Technical Education Teachers." The authors acknowledge Dr. Ray Narveson for his assistance with the data analysis.

Sheila K. Ruhland is Assistant Professor in the Department of Work, Community, and Family Education, University of Minnesota, 420 Vocational Technical Education Building, 1954 Buford Avenue, St. Paul, MN 55108. E-mail: ruhla006@umn.edu.

Christine D. Bremer is Program Coordinator in the National Center on Secondary Education and Transition, Institute on Community Integration, University of Minnesota, 6 Pattee Hall, 150 Pillsbury Drive SE, Minneapolis, MN 55455. E-mail: breme006@umn.edu. 
Journal of Vocational Education Research, Vol. 28, No. 3, pp. 303-304.

(C) 2003

Journal of Vocational Education Research Field Reviewers for Volume 28

The following individuals have graciously contributed their time and expertise to the constructive review of manuscripts submitted to the Journal of Vocational Education Research during the calendar year 2003.

\begin{tabular}{ll}
\hline \multicolumn{1}{c}{ Reviewer } & \multicolumn{1}{c}{ Institution } \\
\hline Elaine Adams & The University of Georgia \\
Oscar Aliega & University of Minnesota \\
Marcia A. Anderson & Southern Illinois University, Carbondale \\
James E. Bartlett II & University of South Carolina \\
Greg Belcher & Pittsburg State University \\
Debra Bragg & University of Illinois Urbana-Champagne \\
Michael F. Burnett & Louisiana State University \\
William Camp & Cornell University \\
Marissa Castellanos & Johns Hopkins University \\
Carol A. Conroy & SRI International \\
Rodney L. Custer & Illinois State University \\
Laura Eisenman & University of Delaware \\
Cheryl Evanciew & Clemson University \\
Curtis Finch & Virginia Tech University \\
Jim Flowers & North Carolina State University. \\
Susan Fritz & University of Nebraska \\
Howard R. D. Gordon & Marshall University \\
Kenneth Gray & The Pennsylvania State University \\
James A. Gregson & University of Idaho \\
Brad Greiman & Louisiana State University \\
Helen C. Hall & The University of Georgia \\
Betty Heath-Camp & Virginia Tech University \\
Victor Hernandez & Wheeling Jesuit University \\
&
\end{tabular}

(table con'd) 


\begin{tabular}{ll}
\hline \multicolumn{1}{c}{ Reviewer } & \multicolumn{1}{c}{ Institution } \\
\hline Roger Hill & The University of Georgia \\
Barbara E. Hinton & University of Arkansas \\
Francine Hultgren & University of Maryland \\
Diane H. Jackman & Northern Illinois University \\
Richard M. Joerger & The University of Minnesota \\
Adam J. Kantrovich & Morehead State University \\
Neil Knobloch & University of Illinois Urbana-Champagne \\
K. Peter Kuchinke & University of Illinois Urbana-Champagne \\
Ted Lewis & The University of Minnesota \\
Joyce P. Logan & University of Kentucky \\
Krisanna Machtmes & Louisiana State University \\
Robert Martin & Iowa State University \\
Larry Miller & The Ohio State University \\
Jay Rojewski & The University of Georgia \\
Sheila Ruhland & University of Minnesota \\
John W. Schell & The University of Georgia \\
Clifton L. Smith & The University of Georgia \\
Bettye P. Smith & The University of Georgia \\
Daisy Stewart & Virginia Tech University \\
James R. Stone III & The University of Minnesota \\
William J. Stull & Temple University \\
Michael K. Swan & Washington State University \\
Kirk Swortzel & Mississippi State University \\
Hollie Thomas & FSU College of Education \\
Allen Truell & Ball State University \\
Rose Mary Wentling & University of Illinois Urbana-Champagne \\
Jill T. White & University of West Florida \\
Heather Williams & University of Southern Mississippi \\
Myra Womble & The University of Georgia \\
Chris Zirkle & The Ohio State University \\
\hline
\end{tabular}

